Ronny Mikyo Mitsuoka

\title{
Aplicação de métodos de imagem molecular no estudo dos efeitos terapêuticos da galectina-3 em glioblastoma
}

Dissertação apresentada à Faculdade de Medicina da

Universidade de São Paulo para obtenção do título de Mestre em Ciências

Faculdade de Medicina da Universidade de São Paulo

Programa de Oncologia

Orientador: Dr Emerson Soares Bernardes

São Paulo 
Dados Internacionais de Catalogação na Publicação (CIP)

Preparada pela Biblioteca da

Faculdade de Medicina da Universidade de São Paulo

Creprodução autorizada pelo autor

Mitsuoka, Ronny Mikyo

Aplicação de métodos de imagem molecular no estudo dos efeitos terapêuticos da galectina-3 em glioblastoma / Ronny Mikyo Mitsuoka. -- São Paulo, 2015.

Dissertação(mestrado)--Faculdade de Medicina da Universidade de São Paulo.

Programa de Oncologia.

Orientador: Emerson Soares Bernardes.

Descritores: 1.Galectina 3 2.Glioblastoma 3.Imagem molecular 4.Tomografia computadorizada de emissão de fóton único 5.Tecnécio 6.Neoplasias 7.Camundongos

USP/FM/DBD-207/15 


\section{DEDICATÓRIA}

Dedico esta dissertação à meu falecido pai Masayoshi Mitsuoka, meu eterno amigo e essência da minha força interior para superar as adversidades. À meu grande mestre Prof. Silvano Raia que me ensinou o diferencial, e à minha amada Miriam Salvelina pelo seu grande amor. 


\section{AGRADECIMENTOS}

Inicialmente, eu gostaria de agradecer a todos que contribuíram para conclusão desta dissertação de mestrado, uma caminhada de muito aprendizado, amizade, dedicação e muitas expectativa quanto a próxima etapa.

Nesta trajetória, agradeço ao orientador Dr Emerson Bernardes pelas orientações e ensinamentos, pela oportunidade de aquisição de novos conhecimentos e habilidades, dedicação e apoio incondicional para realização deste projeto.

Ao meu eterno mestre e mentor Prof. Silvano Raia pelo incentivo, credibilidade e inestimável apoio durante longos anos de convivência. Fui abençoado, particularmente, pela oportunidade de aprender valores e condutas indispensáveis para formação do profissional que desejo me tornar, ao lado deste ícone da medicina brasileira. Minha admiração e grande amor serão eternos.

Ao Prof. Giovanni Cerri pela orientação, conselho e apoio inicial fundamentais para decisão do caminho a seguir.

Ao Prof. Carlos Buchpiguel pelo afável diálogo, direcionamento inicial e amabilidade pela minha pessoa, bem como pelas palavras de encorajamento e perspectivas futuras.

A aluna de doutorado Sofia, pela paciência e dedicação para ensinar varias técnicas importantes para realização deste projeto. Agradeço a sua amizade e conversas ao longo destes anos de trabalho.

A todos os pós-graduandos e funcionários do ICESP/CTO e FMUSP que me ajudaram durante o mestrado.

A CAPES pela concessão da bolsa de mestrado durante o período de projeto.

A minha amada Miriam Salvelina pelo amor, dedicação e apoio durante estes anos que estamos juntos, incentivando e renovando minhas esperança para continuar neste caminho que escolhi seguir.

E a todos meus amigos que torcem pelo meu sucesso profissional e pessoal. Muito obrigado. 
"A mente que se abre a uma nova ideia jamais voltará ao seu tamanho original" Albert Einstein 
Esta dissertação ou tese está de acordo com as seguintes normas, em vigor no momento desta publicação:

Referências: adaptado de International Committee of Medical Journals Editors (Vancouver).

Universidade de São Paulo. Faculdade de Medicina. Divisão de Biblioteca e Documentação. Guia de apresentação de dissertações, teses e monografias. Elaborado por Anneliese Carneiro da Cunha, Maria Julia de A. L. Freddi, Maria F. Crestana, Marinalva de Souza Aragão, Suely Campos Cardoso, Valéria Vilhena. 3a ed. São Paulo: Divisão de Biblioteca e Documentação; 2011.

Abreviaturas dos títulos dos periódicos de acordo com List of Journals Indexed in Index Medicus. 


\section{SUMÁRIO}

Lista de abreviaturas

Lista de figuras

Lista de tabelas

Resumo

Abstract

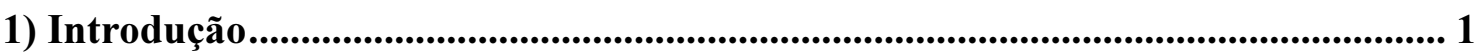

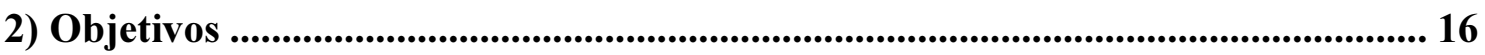

3) Material e Métodos......................................................................................................... 17

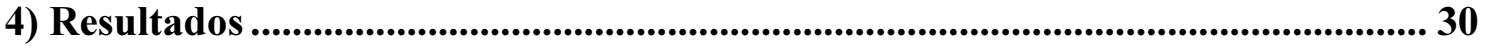

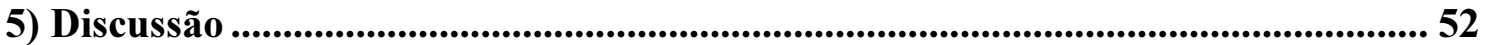

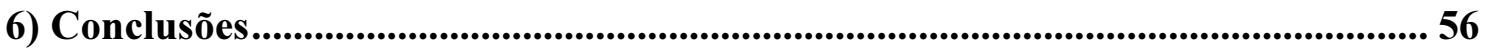

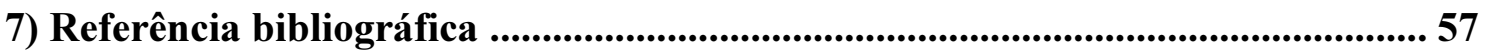




\section{LISTA DE ABREVIATURAS}

AMP - Ampicilina

ATP - Adenosina trifosfato

BSA - Soro fetal bovino (Bovine serum albumin)

$\mathrm{CO}_{2}$ - Dióxido de carbono

$\mathrm{CaCl}_{2}$ - Cloreto de cálcio

CCD - Dispositivo de carga acoplada (charge-coupled device)

DMEM - Dulbecco's Modified Eagle Medium

ENP - Proliferação neoplásica precoce (Early neoplastic proliferation)

ER - Retículo endoplasmático (Endoplasmic reticulum)

E.Coli - Escherichia Coli

Ds Red - Proteína vermelho fluorescente (Discosoma sp. red fluorescent protein)

Gal-3 - Galectina-3

Gal-3c - Galectina 3 truncada

GFAP - Proteína acídica fibrilar glial (Glial fibrillary acidic protein)

GFP - Proteína fluorescente verde

GST - Glutationa transferase (Glutathione S-transferase)

$\mathrm{HCl}$ - Ácido clorídrico

HPLC - Cromatografia Liquida de Alta eficiência (High Pressure Liquid Cromatography)

HYNIC - Ácido hidrazinonicotínico (hydrazinonicotinamide acid)

$\mathrm{IC}_{50}$ - Concentração máxima inibitória (half maximal inhibitory concentration)

lba-1 - Ionized calcium-binding adapter molecule

IHC - Imuno-histoquimica

IL-17 - Interleucina 17

IFN- $\gamma$ - Interferon gamma

IPTG - Isopropiltiogalactosídeo (isopropylthio- $\beta$-galactoside)

LB - Lysogeny Broth

MUC-1 - Mucina-1

$\mathrm{NaCl}$ - Cloreto de sódio

$\mathrm{N}_{2}$ - Nitrogênio

NK - Células exterminadoras naturais (Natural Killer Cell)

Opti-MEM - Opti-Minimal Essential Medium

PBS - Tampão fosfato-salino (Phosphate buffered saline)

PCR - Reação em cadeia da polimerase (Polymerase chain reaction)

Luc - Luciferase

RPM - Rotações por minuto

SDS-PAGE - sodium dodecyl sulphate-polyacrylamide gel electrophoresis

${ }^{99 \mathrm{~m}} \mathrm{Tc}$ - Tecnécio

TCA - Ácido tricloroacético

TMZ - Temozolamida

Tris - Hidroximetil Aminometano (Hydroxymethyl aminomethane) 


\section{LISTA DE FIGURAS}

Figura 1. Representação esquemática do principio de decaimento e Pag. 3 formação do pósitron.

Figura 2. Representação esquemática do processo de aniquilação.

Figura 3. Representação esquemática do principio físico do SPECT e PET. Pag. 4

$\begin{array}{lll}\text { Figura 4. Princípios gerais de imagem por fluorescência. } & \text { Pag. } 6\end{array}$

$\begin{array}{lll}\text { Figura 5. Princípio geral da imagem por bioluminescência. } & \text { Pag. } 7\end{array}$

Figura 6. Galectinas, progressão tumoral e metástase. Pag. 9

Figura 7. Representação esquemática da galectina-3 endógena presente na Pag. 23 superfície da célula.

Figura 8. Representação esquemática da quantidade de sítios de ligação Pag. 23 disponíveis para galectina-3 recombinante humana produzida no estudo.

Figura 9. Perfil eletroforético de Galectina-3 e galectina-3 truncada obtida Pag. 30 por digestão enzimática.

Figura 10. Perfil eletroforético de Galectina-3 e galectina-3 truncada obtida Pag. 31 diretamente pelos plasmídeos pET11 ou pGEX-4T-2.

Figura 11. Análise da expressão de galectina-3 e sítios de ligação de Pag. 33 galectina-3 na superfície de células de glioblastoma U87.

Figura 12. Citotoxicidade de Temozolamida e galectina-3 em células U87. Pag. 34

Figura 13. Transfecção de células de Glioblastoma U87 por três diferentes Pag. 35 agentes de transfecção.

Figura 14. Cálculo da relação fótons/célula em células U87. Pag. 36

Figura 15. Padronização da injeção de corante e implantação das células Pag. 37 U87 Luc 2 no cérebro de camundongos.

Figura 16. Sequência de eventos do modelo piloto do tratamento in vivo por Pag. 38 galectina-3 associada ou não a TMZ.

Figura 17. Efeito da temozolamida in vivo.

Figura 18. Efeito terapêutico da galectina-3 nativa (monoterapia) in vivo. Pag. 41

Figura 19. Efeito terapêutico da galectina-3 nativa em associação com Pag. 42 temozolamida in vivo.

Figura 20. Purificação de galectina-3 por HPLC 
Figura 21. Estudo de estabilidade da ${ }^{99 m}$ Tc-HYNIC-Galectina-3 em Pag. 45 diferentes soluções.

Figura 22. Estudo de estabilidade da ${ }^{99 \mathrm{~m}}$ Tc-HYNIC-Galectina-3. Pag. 46

Figura 23. Análise da biodistribuição da Galectina-3 nativa administrada Pag. 47 I.V.

Figura 24. Imagem SPECT/CT da galectina-3 nativa administrada I.V. Pag. 48

Figura 25. Imagem por fluorescência da galectina-3 nativa administrada IV Pag. 50 em linhagem de glioblastoma U87.

Figura 26. Imagem por fluorescência da galectina-3 nativa administrada IV Pag. 51 em linhagem gástrica MKN45. 


\section{LISTA DE TABELAS}

Tabela 1. Comparativo entre as modalidades de imagem molecular PET e Pag. 7 SPECT.

Tabela 2. Comparativo entre as modalidades de imagem molecular ótica Pag. 8 Bioluminescência e Fluorescência.

Tabela 3. Valores absolutos da relação fóton/célula da linhagem Pag. 36 transfectada U87 Luc2.

Tabela 4. Valores absolutos de fótons/célula da linhagem U87Luc2 Pag. 40 tratados por TMZ.

Tabela 5. Valores absolutos de fótons/célula da linhagem U87Luc2 Pag. 41 tratados por Gal-3.

Tabela 6. Valores absolutos de fótons/célula da linhagem U87Luc2 Pag. 43 tratados por $\mathrm{TMZ}+\mathrm{Gal}-3$. 


\section{RESUMO}

Mitsuoka RM. Aplicação de métodos de imagem molecular no estudo dos efeitos terapêuticos da galectina-3 em glioblastoma [dissertação]. São Paulo: Faculdade de Medicina, Universidade de São Paulo; 2015.

O glioma de grau IV (geralmente chamado de Glioblastoma Multiforme - GBM) é o tumor mais agressivo e maligno do sistema nervoso central. A elevada mortalidade e baixa expectativa de vida proporcionado por esta doença, tem direcionado os esforços de muitos pesquisadores no desenvolvimento de novas formas de diagnóstico precoce, assim como a busca por terapias inovadoras.

A galectina-3, uma proteína ligante de glicanas, é expressa diferencialmente em tecido normal vs. neoplásico e possui um papel importante na adesão, diferenciação, imunomodulação, apoptose, ciclo celular, assim como processos de transformação e progressão neoplásica. Diversos estudos têm demonstrado que a interferência nas funções exercidas pela galectina-3 pode representar uma estratégia promissora no tratamento de vários tipos de tumores, incluindo o glioblastoma. De fato, tem se verificado que a administração da forma truncada de galectina-3 em modelos experimentais murinos, possui um efeito antitumoral significativo quando administrada em conjunto com quimioterápicos. No entanto, ainda não se encontra esclarecido se a interferência com as funções da galectina-3 endógena são exercidas diretamente no microambiente tumoral ou de maneira sistêmica. Dessa forma, neste trabalho buscou-se um entendimento mais profundo e completo sobre o papel anti-tumoral de galectina-3 nativa e truncada em associação com o quimioterápico temozolamida num modelo de glioblastoma humano. Adicionalmente, as ferramentas de PET-SPECT, assim como imagem molecular ótica por fluorescência ou bioluminescênca foram utilizadas para se avaliar a biodistribuição da galectinas-3 em camundongos Balb/c nude inoculados com tumor.

Inicialmente demonstrou-se que, nas células U87 de glioblastoma humano, a galectina-3 nativa e não a galectina-3 truncada apresenta efeito antitumoral in vitro quando associada com temozolamida com valores de IC50 de $0.008 \mathrm{mM}$ e $1.893 \mathrm{mM}$ respectivamente. Os testes in vivo foram dessa forma prosseguidos com a galectina-3 nativa. Através da técnica de imagem ótica por bioluminescência, observou-se que o 
tratamento simultâneo de galectina-3 com temozolamida levou a uma redução do crescimento do tumor gerado pelas células U87-Luc2 (U87 transfectadas com o gene reporter da luciferase) em camundongos Balb/c nude. Esta redução foi observada mesmo após a parada do tratamento (período de acompanhamento). Curiosamente, no tratamento com apenas galectina-3 observou-se uma redução do crescimento tumoral das células U87-luc2 cujo efeito foi anulado após a suspensão do tratamento.

Através de análises por PET-SPECT avaliou-se a biodistribuição da galectina-3 marcada com ${ }^{99 \mathrm{~m}} \mathrm{Tc}\left({ }^{99 \mathrm{~m}} \mathrm{Tc}-\mathrm{HYNIC} / \mathrm{Gal}-3\right)$ em camundongos Balb/c nude previamente inoculados com a linhagem U87. Demonstrou-se que esta proteína migra principalmente para os rins e, em menores quantidades para o baço, não ligando todavia no tumor. Devido à meia-vida do ${ }^{99 \mathrm{~m}} \mathrm{Tc}-\mathrm{HYNIC} / \mathrm{Gal}-3$ não permitir estudos prolongados, a galectina-3 conjugada com VivoTag 680XL foi utilizada para se avaliar a biodistribuição por 48h, 96h e 14 dias em camundongos Balb/c nude inoculados com a linhagem de glioblastoma U87. Além de se confirmar o padrão de distribuição acima descrito, observou-se que a galectina-3 não liga no tumor independentemente do modelo tumoral utilizado.

Os resultados obtidos neste estudo demonstram que galectina-3 possui um efeito antiproliferativo quando administrada em conjunto com temozolamida num modelo de glioblastoma humano (células U87). Surpreendentemente, foi possivel observar pela primeira vez que o efeito antiproliferativo de galectina-3 não se deve à sua atuação direta no tumor. Nossos dados sugerem que, quando administrada in vivo, a galectina-3 atua em locais distintos do microambiente tumoral como os rins e baço, afetando portanto de maneira indireta o crescimento tumoral.

Descritores: galectina 3; glioblastoma; imagem molecular; tomografia computadorizada de emissão de fóton único; tecnécio; neoplasias; camundongos. 


\begin{abstract}
Mitsuoka RM. Application of molecular imaging methods in the study of the therapeutic effects of galectin-3 in glioblastoma [dissertation]. São Paulo: "Faculdade de Medicina, Universidade de São Paulo"; 2015.
\end{abstract}

Grade IV glioma or glioblastoma multiforme (GBM) is the most aggressive and malignant tumor of the central nervous system. The high mortality and low life expectancy provided by this disease have directed the efforts of many researchers to develop innovative therapeutic strategies and early diagnosis tools.

Galectin-3 is a glycan-binding protein differentially expressed in normal and neoplastic tissue and has an important role in adhesion, differentiation, immune modulation, apoptosis, cell cycle, tumor transformation and neoplastic progression. Several studies have shown that interference with the functions performed by galectin-3 could represent a promising strategy in the treatment of several kinds of tumors, including glioblastoma. Indeed, it has been found that galectin-3 truncated form has a significant antitumor effect when associated with chemotherapy in murine experimental models. However, it's not clear yet whether the interference with galectin-3 endogenous functions is performed directly in the tumor microenvironment or systemically. Thus, this study aimed to understand the anti-tumor effect of truncated and native galectin-3 in combination with temozolomide chemotherapy in a human glioblastoma model. Additionally, PET, SPECT and bioluminescence tools were used to evaluate the biodistribution of galectin-3 in Balb / c nude mice inoculated with the U87 glioblastoma cell line.

Here it was shown that in U87 cells, native galectin-3 and not the truncated form has anti-tumor effect in vitro when associated with temozolomide with IC50 values of $0.008 \mathrm{mM}$ and $1.893 \mathrm{mM}$, respectively.

Therefore the in vivo studies were pursued with native galectin-3. Using the optical bioluminescence technique, it was observed that the simultaneous treatment of galectin-3 with temozolomide led to a reduction of tumor growth generated by U87Luc2 cells (U87 cells transfected with the luciferase reporter gene) in Balb / c nude. This reduction was observed even after stopping treatment (follow-up period). Interestingly, treatment of U87-Luc2 derived-tumor with only galectin-3 led to a 
reduction of tumor growth whose effect was abolished after discontinuation of treatment.

The biodistribution of 99mTc labeled-galectin-3 (99mTc-HYNIC / Gal-3) was performed by molecular image tools (PET-SPECT scan) in mice BALB/c nude previously inoculated with the U87 line. It was shown that this protein migrates primarily to the kidneys and, in a smaller amount to the spleen, but doesn't bind the tumor. Because the half-life of 99m Tc-HYNIC / 3-Gal doesn't allow prolonged studies, galectin-3 conjugated with VivoTag 680XL was used to assess in vivo biodistribution at 48h, 96h and 14 days in Balb / c nude mice inoculated with the human glioblastoma cell line U87. Besides confirming the distribution pattern described above, it was found that galectin-3 doesn't bind to the tumor, regardless the tumor model.

This study shows that galectin-3 has an antiproliferative effect when associated with temozolomide in the human glioblastoma model U87. Surprisingly, it was observed, that the in vivo antiproliferative effect of galectin-3 is not due to its direct binding to tumor cells. Our data suggest that when administered in vivo, galectin-3 acts in distinct locations of the tumor microenvironment such as the kidneys and spleen, thus indirectly affecting tumor growth.

Descriptors: galectin 3; glioblastoma; molecular Imaging; tomography, emission-computed, single-photon; technetium; neoplasms; mice. 


\section{1) INTRODUÇÃO}

\section{1) Imagem molecular}

Atualmente, a identificação, diagnóstico e tratamento da grande maioria dos cânceres dependem de técnicas que geram imagens anatômicas dos tumores, como ultrassom, tomografia computadorizada ou ressonância magnética. Essas técnicas clássicas de imagem detectam as patologias baseando-se na identificação de distorções anatômicas de estruturas e comparando-as com as estruturas normais. Tais mudanças morfológicas, entretanto, são consideradas como produtos finais de uma série de complexas modificações moleculares, que derivam da oncogênese. Consequentemente, uma vez que aberrações bioquímicas precedem as alterações anatômicas, o desenvolvimento de técnicas que sejam capazes de detectar os tumores em estágios iniciais da doença tem sido alvo de grande interesse pela comunidade científica. Essa mudança de paradigma tem sido estimulada pelos avanços das áreas de Genômica e Proteômica, que por sua vez abriram caminho para o surgimento de uma nova disciplina chamada "Imagem Molecular".

No geral, imagem molecular é uma terminologia relativamente recente que engloba procedimentos diagnósticos por imagem que envolvam reações entre agentes de imagem e moléculas-alvo específicas, como enzimas e receptores celulares ${ }^{[1]}$. Essencialmente, um agente de imagem se constitui de uma porção que interage com um alvo específico, enzima ou receptor celular; e uma porção que permite a sua detecção, como, por exemplo, um elemento radioativo, uma partícula magnética ou uma molécula fluorescente. A imagem molecular permite abordar processos biológicos nos níveis celular e subcelular, em organismos vivos intactos.

Basicamente, as técnicas de imagem podem ser classificadas em três grandes grupos, de acordo com os seguintes parâmetros: (1) quanto à energia utilizada para se obter imagem visual (raios-X, emissão de pósitron, micro ondas etc); (2) quanto à resolução espacial (macro ou microscópica) e (3) o tipo de informação obtida (anatômica, fisiológica ou celular/molecular) ${ }^{[2]}$. Na medicina clínica utilizam-se rotineiramente sistemas de imagem macroscópica, como a tomografia computadorizada (CT), ressonância magnética (MRI) e Ultrassom (US). Recentemente, a clínica passou a se beneficiar da imagem molecular através da tomografia por emissão de pósitron (PET) 
e da tomografia computadorizada por emissão de fóton único (SPECT-CT), sendo estas duas últimas comumente empregadas na pesquisa experimental.

Além do PET e SPECT, a pesquisa científica tem à sua disposição uma variedade de tecnologias de imagem como a fluorescência, bioluminescência, microscopia confocal e outras. No caso do câncer, por exemplo, tais tecnologias permitem ao pesquisador e/ou médico não apenas simploriamente observar a localização de um tumor, mas também avaliar e observar a expressão e atividade de moléculas específicas (proteínas, receptores, etc) e células (células tronco, macrófagos, etc), bem como processos biológicos (metástases, angiogênese, apoptose, etc), e assim compreender o comportamento tumoral ou mesmo observar uma resposta terapêutica ${ }^{[3]}$.

Como já comentado, as técnicas de imagem molecular permitem visualizar e mensurar quantitativamente processos biológicos e celulares in vivo ${ }^{[4]}$. Enquanto a imagem da modalidade anatômica desempenha função essencialmente cirúrgica, diagnóstica e de monitoramento terapêutico ${ }^{[5]}$, a imagem molecular tem evoluído rapidamente para permitir a obtenção de diagnósticos precoces mais precisos e estabelecer tratamentos individualizados. Além disso, o uso de técnicas de imagem molecular permite uma melhoria na qualidade de vida do paciente, uma vez que é possível caracterizar as patologias do tecido doente sem a necessidade de coletar biópsias por procedimentos cirúrgicos invasivos, o que por sua vez permite um planejamento racional e específico da conduta terapêutica a ser utilizada.

A seguir, destacaremos os métodos de Imagem Molecular utilizados nesse trabalho.

\section{2) Imagem Molecular (PET/SPECT)}

A Medicina Nuclear é uma especialidade médica que utiliza pequenas quantidades de substâncias radioativas durante a realização de exames por imagem e/ou tratamentos, permitindo a visualização de componentes biológicos em condições normais e/ou patológicas em indivíduos vivos. Dependendo das propriedades do radiofármaco selecionado, aspectos importantes de processos bioquímicos ou da biologia celular podem ser visualizados tanto por SPECT ou PET ${ }^{[6]}$.

O PET pode ser descrito como um mapa da distribuição de um radiofármaco emissor de pósitrons em determinado local do organismo vivo (animais ou ser humano). O processo, ilustrado na figura 1 , pode ser descrito basicamente como um composto $\mathrm{X}$ 
decaindo para um composto $\mathrm{Y}$, consequentemente emitindo um pósitron $\left(\beta^{+}\right)$e um neutrino (v).

$$
{ }_{Z}^{A} X \rightarrow \underset{Z-1}{A} Y+{ }_{+1}^{0} e+v
$$

Figura 1. Representação esquemática do principio de decaimento e formação do pósitron. De um composto $\mathrm{X}$ decaindo para um $\mathrm{Y}$, e assim, originando um pósitron e neutrino. A letra "A" significa o número de massa (soma do número de prótons + número de neutros no núcleo) e "Z" significa o número atômico (número total de prótons do núcleo). Figura de Rev Panam Salud Publica v.20, 2006.

O fundamento físico que permite a detecção e a localização dinâmica tridimensional de PET é baseado em um processo chamado de aniquilação.

Como exemplo, a figura 2 ilustra esquematicamente todo o processo, desde o decaimento do carbono ao boro até a aniquilação do pósitron com um elétron do meio e a consequente formação do par de fótons de $511 \mathrm{keV}$ cada, em direções opostas. Esses fótons são detectados externamente, e a informação é usada para a reconstrução das imagens ${ }^{[7,8,9]}$.

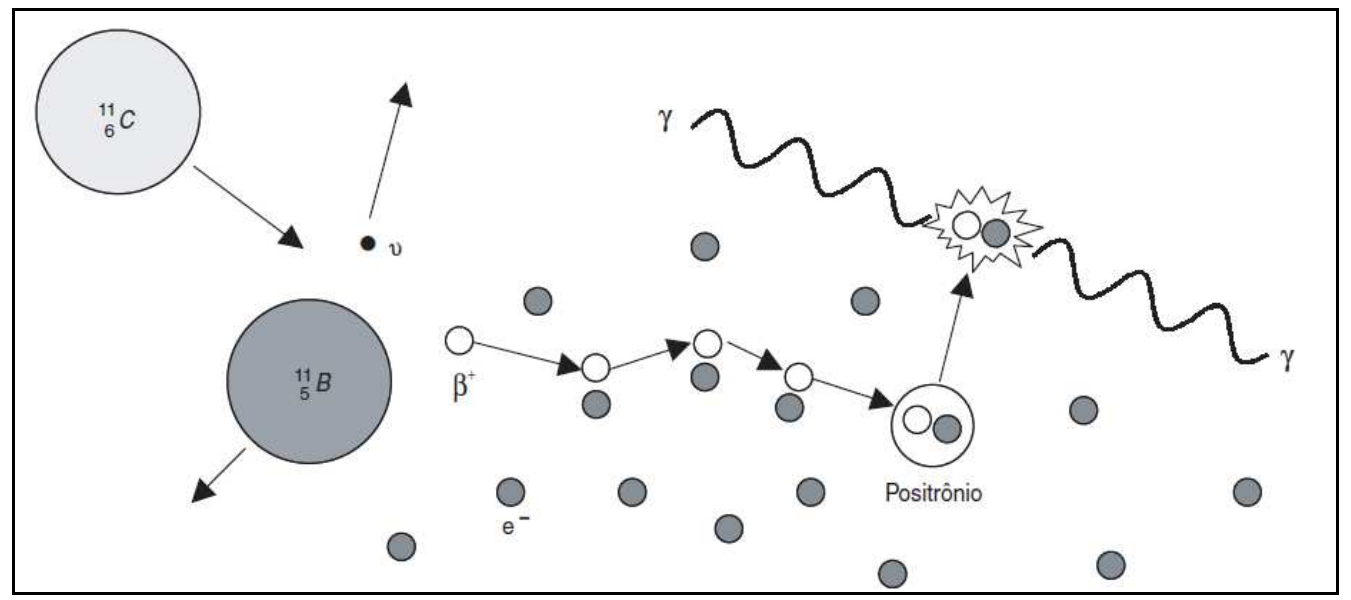

Figura 2. Representação esquemática do processo de aniquilação.

$\mathrm{O}$ elemento radioativo carbono $\left({ }^{11} \mathrm{C}\right)$ de número atômico $\mathrm{Z}=6(\mathrm{Z}$ representa o número total de prótons no núcleo) decai para o elemento boro $\left({ }^{11} \mathrm{~B}\right)$ de número atômico $Z=5$, consequentemente, emitindo um pósitron e um neutrino. $\mathrm{O}$ pósitron $\left(\beta^{+}\right)$se combina com elétron (e $\mathrm{e}^{-}$próximo, originando o par de fótons de energia $511 \mathrm{keV}$ em direções opostas (aniquilação). Figurada adaptada de Rev Panam Salud Publica v.20, 2006

O SPECT, de maneira simplificada, fundamenta-se na detecção de fótons de um radioisótopo. O isótopo radioativo sofre decaimento, emitindo raios $\gamma$ de energias bem definidas $(<511 \mathrm{keV})$ detectados por cristais de cintilação em uma $\gamma$-câmara ${ }^{[10,11,12]}$. A 
representação esquemática do princípio de funcionamento do SPECT e PET pode ser observado na figura 3.
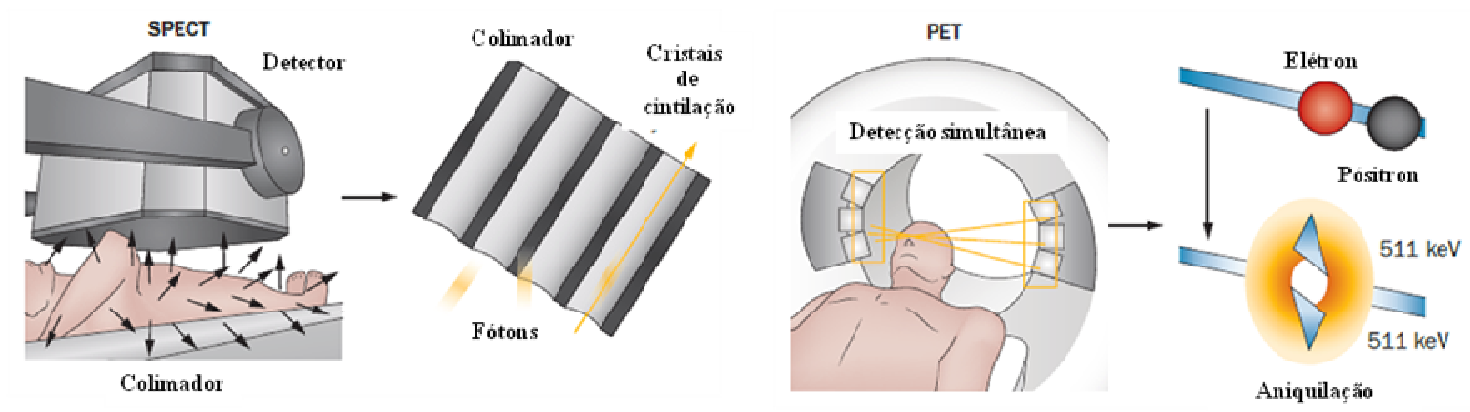

Figura 3. Representação esquemática do principio físico do SPECT e PET.

O SPECT fundamenta-se na detecção de fótons de um radioisótopo, por cristais de cintilação em uma $\gamma$-câmara. Como os fótons são emitidos em varias direções é necessário o uso de um colimador, a qual permite que apenas fótons perpendiculares a superfície do detector seja mensurado. A formação da imagem é uma reconstrução de um conjunto de sobreposições de varias imagens planas capturadas pela rotação da $\gamma$ câmara ao redor do paciente. O PET fundamenta-se na detecção de dois fótons ao mesmo tempo, com energias iguais de $511-\mathrm{keV}$ que são emitidos em direções opostas simultaneamente em um ângulo de $180^{\circ}$, este processo é chamado de coincidência. Ao unir e calcular múltiplas linhas de "coincidência" a imagem é obtida, desse modo no PET não há a necessidade de colimadores. Figurada adaptada de Nat. Rev. Clin. Oncol. v...9, 2012

As principais vantagens dessas técnicas são sua alta sensibilidade e profundidade de penetração ilimitada. A versatilidade das técnicas de imagem molecular também advém de sua habilidade em atingir potencialmente qualquer evento molecular ou bioquímico, através da incorporação de isótopos radioativos em agentes bioquímicos que ocorrem naturalmente.

As maiores limitações das técnicas de imagem molecular residem principalmente no risco de exposição à radiação em pacientes e profissionais da saúde, e no fato de que a preparação da maioria dos radioisótopos requer o uso de um acelerador de partículas carregadas (Cíclotron), cujo custo é elevado e não está facilmente disponível em todas as Instituições.

\section{3) Imagem Molecular Óptica (fluorescência/bioluminescência)}

Recentemente, o surgimento de novas tecnologias não invasivas ou minimamente invasivas para detecção de processos biológicos em modelos pré-clínicos tem crescido progressivamente. Uma técnica de imagem denominada como imagem 
molecular ótica tem proporcionando aos pesquisadores oportunidades singulares no estudo de doenças humanas, e em futuro próximo, espera-se que tal técnica seja empregada em aspectos ainda mais importantes, como o diagnóstico e tratamento destas doenças. Toda essa perspectiva ocorre em virtude do aprimoramento contínuo da instrumentação, identificação de novos alvos moleculares com base no genoma e desenvolvimento de novos marcadores específicos.

Esta tecnologia tem sido utilizada para monitorar o crescimento de tumores e metástase, avaliar os efeitos biológicos de novos medicamentos e monitorar processos biológicos no microambiente tumoral em modelos animais.

A imagem molecular óptica apresenta algumas vantagens em relação as ferramentas de imagem PET e SPECT/CT, como por exemplo o baixo custo na aquisição das imagens, rapidez na leitura e aquisição da imagem ( $<5$ minutos), fácil manuseio pelo operador, aquisição de várias imagens dos animais simultaneamente, fornecimento de informações relacionadas aos níveis de expressão e estado funcional de marcadores moleculares, entre outros ${ }^{[13,14]}$. Além disso, essa tecnologia dispensa o uso de radiação ionizante.

A imagem molecular óptica pode ser dividida basicamente em dois grupos: fluorescência e bioluminescência.

\section{a) Fluorescência}

A técnica de fluorescência explora as propriedades de emissão de luz induzida pela excitação de fluorocromos que são incorporados em proteínas (por exemplo, GFP ou DsRed), corantes fluorescentes ou nanomateriais fluorescentes, e assim, possibilitam a visualização e quantificação destes marcadores fluorescentes distribuídos em um tecido.

O uso de novas tecnologias no desenvolvimento de compostos fluorescentes utilizados na observação de processos celulares e subcelulares in vivo tem evoluído continuamente. Deste modo, o uso da técnica de fluorescência em futuro próximo é bastante promissor, e espera-se que isso contribua de forma significativa para a pesquisa biológica, para a descobertas de novos medicamentos e em sua utilização na medicina clínica ${ }^{[14]}$.

A imagem ótica por fluorescência está ilustrada esquematicamente na figura 4, e de maneira resumida, fundamenta-se da seguinte maneira: uma fonte de luz externa emite um feixe de luz com um comprimento de onda especifico capaz de excitar um 
fluoróforo localizado, em geral, sob a superfície de um tecido. O ganho de energia do fluoróforo, resultado da absorção de fóton, passa de um estado fundamental (S0) para o estado excitado (S1) permanecendo assim por cerca de $10^{-8}$ segundos (este período é definido como tempo de vida do fluoróforo). Após o período de excitação do fluoróforo, o sistema retorna ao estado fundamental (S0) e, em consequência, é acompanhado pela libertação de energia em excesso através da emissão de fótons (com comprimento de onda diferente ao inicial) que posteriormente é capturado por câmera específica ${ }^{[15]}$.
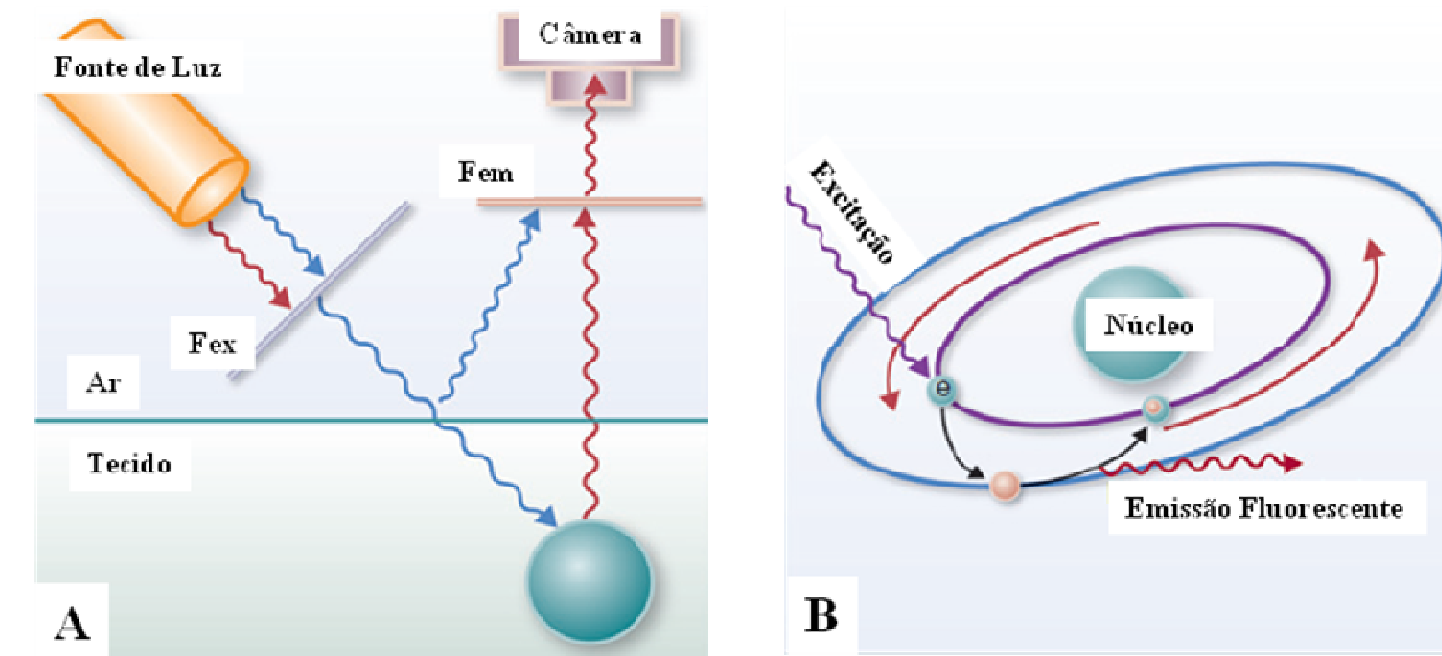

B

Figura 4. Princípios gerais de imagem por fluorescência. Uma luz de comprimento de onda de excitação apropriado é selecionado com um filtro (Fex), localizado entre a fonte de luz e o tecido. A luz de excitação viaja através do tecido e é absorvida por um fluoróforo, que subsequentemente, emite luz em comprimento de onda diferente. Parte desta luz emitida sai do tecido, é selecionado por um segundo filtro (Fem) e assim pode ser detectado por uma câmera (A). A luz absorvida pelo fluoróforo, induz a conversão de um elétron (e) no estado fundamental para um estado eletronicamente excitado. Durante o retorno do elétron para o estado fundamental, ocorre a liberação de energia em excesso através da emissão de radiação (B). Figura adaptada de Clin Cancer Res v.19, 2013

\section{b)Bioluminescência}

O termo bioluminescência refere-se basicamente a um processo no qual energia química converte-se em energia luminosa (550 - $650 \mathrm{~nm}$ de comprimento de onda), devido a um processo enzimático que requer um substrato químico. A pesquisa científica sobre o assunto levou à descoberta do sistema enzima-substrato luciferaseluciferina (do latim Lúcifer, " Luz portadora ").

O princípio desta técnica baseia-se em uma reação química enzima/substrato (Luciferase/luciferina) cujo produto é emissão de luz. Portanto, não há necessidade de uma fonte externa de luz como na técnica de fluorescência. Basicamente, uma reação 
enzima/substrato (luciferase/luciferina) ocorre na presença de ATP, magnésio e oxigênio, produzindo oxiluciferina. Tal reação química resulta em emissão de luz visível em espectro de comprimentos de ondas entre 400 a $620 \mathrm{~nm}$, facilmente capturado por câmera específica $(\mathrm{CCD})^{[16]}$. O princípio geral da bioluminescência está ilustrado na figura 5. Ao contrário da técnica de fluorescência, a bioluminescência não apresenta ruído de fundo, o que torna a técnica altamente sensível.

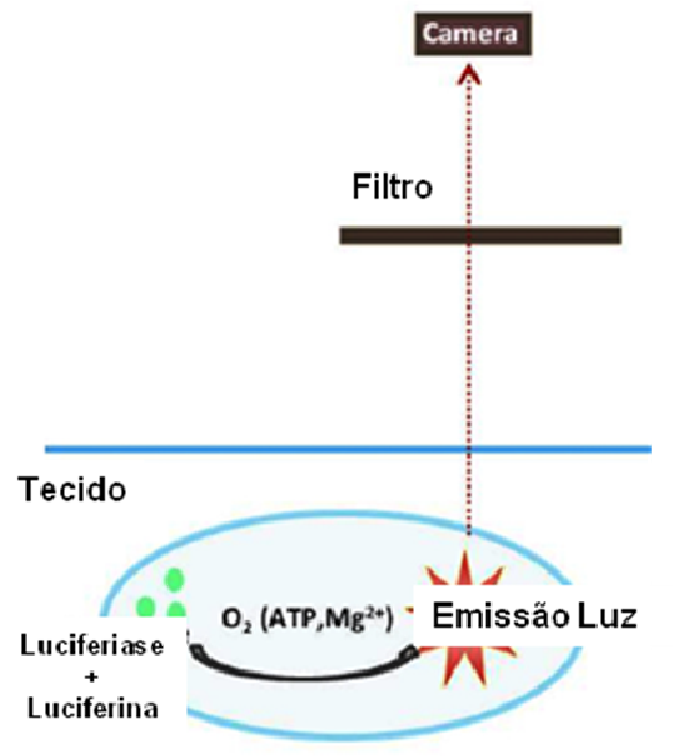

Figura 5. Princípio geral da imagem por bioluminescência. A reação química entre Luciferase (Enzima) e Luciferina (Substrato), na presença de oxigênio, ATP e magnésio, resulta na emissão de luz visível (emissão de espectros de $400 \mathrm{~nm}$ a $620 \mathrm{~nm}$ ), que é captada por uma câmera CCD. Figura adaptada de Current Pharmaceutical Biotechnology, v.14, 2013.

Um resumo sobre as técnicas de imagem mencionado neste estudo quanto as vantagens e desvantagens de cada técnica pode ser observado nas tabelas 1 e 2 .

Tabela 1. Comparativo entre as modalidades de imagem molecular PET e SPECT

\begin{tabular}{cccc}
\hline Técnica de imagem & Vantagens & Desvantagens & Exemplos \\
\hline SPECT & Alta profundidade de & Exposição a radiação & ${ }^{99 m} \mathrm{Tc}$ \\
& imagem & Tempo de aquisição & ${ }^{131} \mathrm{I}$ \\
& Possibilidade de & de imagem muito & ${ }^{111} \mathrm{In}$ \\
& imagem de corpo & longo & \\
& inteiro & & \\
& Imagem Molecular & & \\
& quantitativa & & \\
& Permite combinar & & \\
& imagem e terapia &
\end{tabular}




\begin{tabular}{|c|c|c|}
\hline PET & $\begin{array}{l}\text { Alta profundidade de } \\
\text { imagem } \\
\text { Possibilidade de } \\
\text { imagem de corpo } \\
\text { inteiro } \\
\text { Imagem Molecular } \\
\text { quantitativa }\end{array}$ & $\begin{array}{c}\text { Exposição a radiação } \\
\text { Tempo de aquisição } \\
\text { de imagem muito } \\
\text { longo } \\
\text { Custo elevado }\end{array}$ \\
\hline
\end{tabular}

Tabela 2. Comparativo entre as modalidades de imagem molecular ótica Bioluminescência e Fluorescência

\begin{tabular}{cccc}
\hline Técnica de imagem & Vantagens & Desvantagens & Exemplos \\
\hline Fluorescência & Não utiliza de & Profundidade de imagem & GFP \\
& irradiação & Limitada $(\leq 1 \mathrm{~cm})$ & DsRed \\
& ionizante & Impossibilidade de & \\
Tempo de & imagem de corpo inteiro & \\
& aquisição de & Necessidade de fonte de & \\
& imagem rápido & luz externa & \\
& Baixo custo & & \\
& & & \\
Bioluminescência & & & \\
& Não utiliza de & Profundidade de imagem & Luciferina/Luciferase \\
& irradiação & Limitada $(\leq 1 \mathrm{~cm})$ & Renilla/Luciferase \\
& ionizante & Impossibilidade de & \\
Tempo de & imagem de corpo inteiro & \\
& aquisição de & & \\
& imagem rápido & & \\
& Baixo custo & & \\
& & &
\end{tabular}

\section{4) Galectinas}

As galectinas são uma família de lectinas animais, com elevado grau de conservação, definidas por possuírem duas características em comum: (i) afinidade por glicanas contendo $\beta$-galactosídeos terminais e (ii) sequência de aminoácidos conservada no domínio de reconhecimento de carboidratos (CRD). Com relação à estrutura, algumas contêm um único CRD por cadeia proteica, apresentando-se na forma dimérica (galectina 1,2). Outras têm 2 CRDs numa só cadeia polipeptídica (galectina 4, 8 e 9) ${ }^{[17]}$. Vale ressaltar a estrutura particular da galectina-3, objeto desse estudo, a qual apresenta dois domínios proteicos: um correspondente a um CRD (C-terminal); e o outro a um domínio regulatório (N-terminal) que possui repetições de uma sequência rica em prolina, glicina e tirosina ${ }^{[17]}$. 
Apesar das galectinas apresentarem características típicas de proteínas citosólicas, podem ser transportadas para o núcleo ou outros locais sub-celulares, assim como secretadas por vias não clássicas (não-ER-Golgi). São encontradas tanto na matriz extracelular quanto ligadas na superfície das células ${ }^{[18,19]}$. Na superfície das células, a interação entre essas galectinas e os seus ligantes regula diversos processos biológicos como a adesão, diferenciação, imunomodulação, apoptose, ciclo celular, assim como processos de transformação e progressão neoplásica ${ }^{[20,21]}$.

A progressão tumoral desde o sítio primário até invasão tecidual (sítio secundário) é um processo de muitas fases, implicando adesão, migração, invasão e angiogênese. As diferentes galectinas participam de várias etapas desta cascata (esquematizado na figura 6 adaptada). Alguns membros podem perturbar a interação intercelular, colaborando para desagregação de células tumorais no sítio primário, e consequentemente disseminando-as pela circulação ${ }^{[20]}$. Outras podem funcionar regulando a expressão de integrinas, bem como participar na adesão interagindo junto a elas. Tais funções podem favorecer a adesão célula/célula ou célula/matriz extracelular em processos de agrupamento homotípico ${ }^{[19,20]}$.

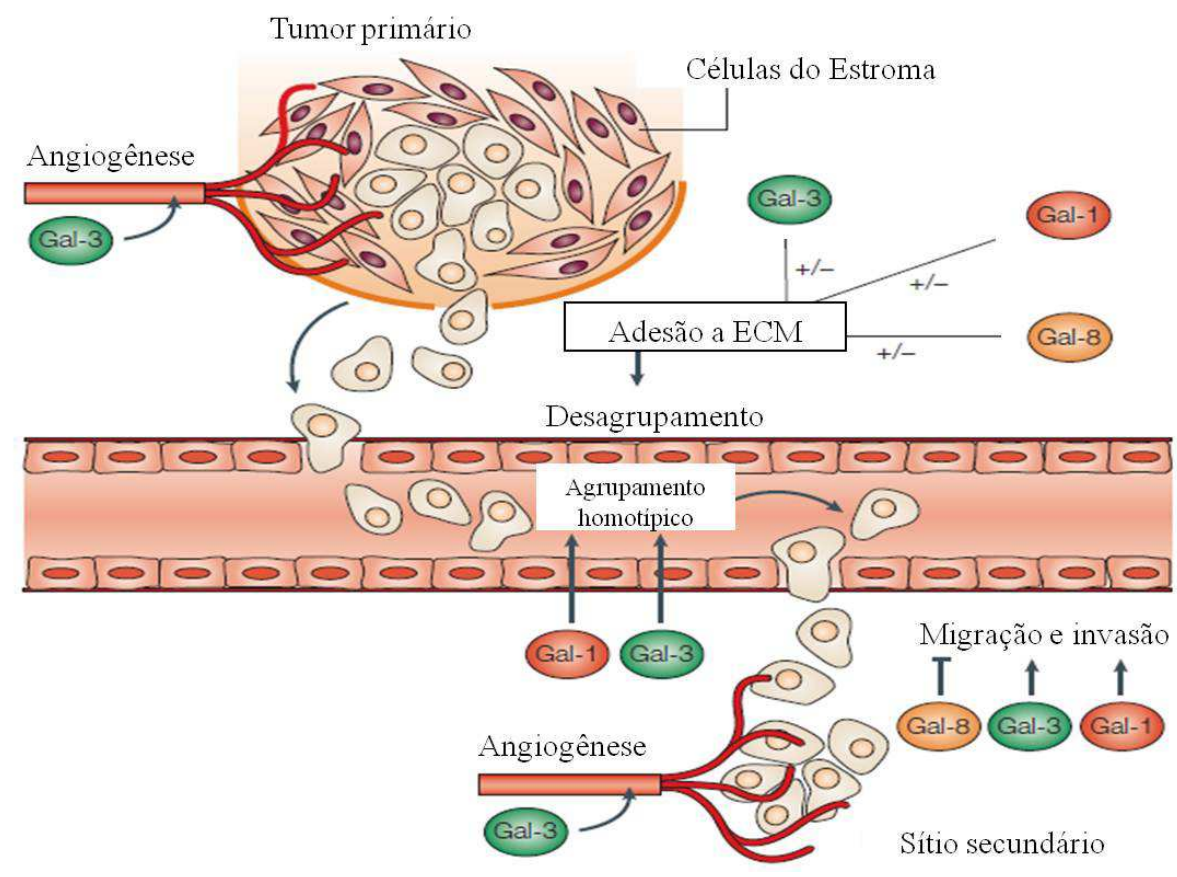

Figura 6. Galectinas, progressão tumoral e metástase. A progressão tumoral, a partir do sítio primário até a invasão tecidual e formação do sítio secundário, é um processo que envolve muitas etapas. Diferentes galectinas exercem papéis importantes ao longo deste processo. Inicialmente, no tumor primário, alguns membros podem inibir a adesão celular, favorecendo assim o desprendimento das células tumorais e disseminando-as pela circulação. Em seguida, outras galectinas auxiliam a adesão homotípica e formação 
de êmbolos, garantindo a sobrevivência e migração das células tumorais. Ao fim, estas proteínas podem influenciar a invasão tecidual, favorecendo a adesão ao endotélio, a formação do sítio secundário e a promoção de angiogênese. Figura adaptada de Nature Reviews Cancer, 5(1):34, 2005.

\section{5) Galectina-3 e câncer}

A galectina-3, um dos membros mais estudado desta família, possui um Domínio de Reconhecimento de Carboidratos (CRD) e um domínio amino terminal que contém uma sequência de múltiplas repetições de 3 aminoácidos (Gly-Pro-Tyr). A presença deste domínio N-terminal diferencia a galectina-3 dos outros membros da família, pois confere aos monômeros a particularidade de auto organizar-se através deste domínio, permitindo a capacidade para oligomerização e, consequentemente, possibilitando sua participação no processo de adesão célula/célula e célula/matriz extracelular ${ }^{[20]}$. Tal efeito de galectina-3 é atribuída, em parte, pela sua interação com uma variedade de glicoproteínas da matriz extracelular tais como fibronectinas, colágeno IV, elastina, e laminina ${ }^{[17]}$.

Pesquisas recentes tem evidenciado a participação da galectina-3 na regulação de diversas atividades de células do câncer, contribuindo para tumorigênese, progressão do câncer e metástase ${ }^{[22]}$. Como exemplo, Barrow et al. (2011) demonstraram que a galectina-3 circulante interage com o antígeno oncofetal TF (Thomsen-Friedenreich) presente na proteína transmembranar MUC-1 expressa em células tumorais, expondo sítios de ancoragem anteriormente ocultos, e promovendo a adesão das células tumorais ao endotélio vascular ${ }^{[23,24]}$. Este fenômeno desencadeia o agrupamento das células tumorais, favorecendo o aprisionamento destes aglomerados na micro circulação e prolongando a sobrevida e difusão metastática para sítios remotos.

Além disso, alterações em sua expressão são frequentes em câncer e em situações pré cancerígenas ${ }^{[25]}$. Inohara e colaboradores, por exemplo, investigaram a diferença de expressão de galectina-3 entre neoplasias benignas e malignas de tireoide. De um total de 172 amostras analisadas por imuno-histoquímica todas as neoplasias malignas de tireoide apresentaram alta expressão para galectina-3, em contraste com tumores benignos e tecidos normais, os quais não apresentaram expressão de galectina$3^{[26]}$

Sob nova ótica, Schoeppner e colegas avaliaram se a expressão de galectina-3 correlacionava-se negativamente com a sobrevida de pacientes com câncer de cólon. A 
análise de 66 pacientes com adenocarcinoma de cólon (reconhecidamente classificados pela escala de Dukes) quanto à sobrevida e expressão de galectina-3 revelou que uma maior expressão de galectina-3 está relacionada à piora na sobrevida ${ }^{[27]}$.

\section{6) Galectina-3 e Glioblastoma}

Células da glia constituem os tipos celulares do sistema nervoso central que mais comumente originam neoplasias, genericamente denominados gliomas. A organização Mundial da Saúde (WHO) classifica os gliomas em quatro escalas ou graus de malignidade (I a IV) determinados por critérios clínicos e histopatológicos. O grau I corresponde a tumores menos agressivos e com maior tempo de sobrevida e o grau IV a tumores mais agressivos e com menor tempo de sobrevida ${ }^{[28]}$.

Glioma de grau IV (geralmente chamado de Glioblastoma Multiforme - GBM) é o tipo de tumor cerebral mais maligno com incidência cerca de $23 \%$ de todos os tumores cerebrais primários ${ }^{[29]}$. Este tipo de tumor é caracterizado por atipia nuclear, pleiomorfismo celular, elevada atividade mitótica, proliferação microvascular e necrose ${ }^{[28]}$. O GBM constitui uma preocupação singular pois as células tumorais podem migrar e infiltrar extensas regiões do cérebro, tornando alvos ineficazes para o tratamento cirúrgico. Além disso, após ressecção cirúrgica, células tumorais residuais periféricas podem desenvolver novos tumores em mais de $90 \%$ dos $\operatorname{casos}^{[30,31,32]}$ considerado atualmente como uma das neoplasias mais desafiadoras da clinica moderna.

Em virtude da elevada mortalidade e baixa expectativa de vida proporcionada por esta doença (em média 15 meses) ${ }^{[33,34]}$, muitos pesquisadores tem direcionado esforços a fim de desenvolver novas formas de diagnóstico precoce e, principalmente, buscar inovadoras formas terapêuticas.

Há poucos estudos que relacionam a expressão de galectina-3 e a ocorrência de tumores cerebrais. Apesar de escassos, eles contribuem com dados suficientes para a percepção de que esta associação não é casual e possa trazer novos conhecimentos sobre a patogênese tumoral ${ }^{[35]}$.

Neder e colaboradores, por exemplo, investigaram a galectina-3 como uma possível ferramenta de diferenciação para os tumores do SNC, particularmente quanto a diferenciação de astrocitomas (pilocíticos e difuso) e oligodendrogliomas ou oligodendrogliomas anaplásico (alto grau) de glioblastomas (GBMs). A falta de marcadores adequados ainda representa um sério problema clinico, pois não há nenhum 
marcador imuno-histoquímico (IHC) útil para diferenciar estes gliomas, prejudicando assim a correta conduta terapêutica a ser utilizada e consequentemente reduzindo a sobrevida do paciente. Os pesquisadores quantificaram a expressão do gene da Gal-3 por PCR em 45 amostras cirúrgicas e observaram um aumento significativo em GBMs e astrocitomas pilocíticos em relação a oligodendrogliomas, oligodendrogliomas anaplásico (alto grau) e astrocitomas difusos. Desse modo, inferiram que Gal-3 é expressa diferencialmente em tumores do sistema nervoso central, tornando a detecção IHC da Gal-3 uma ferramenta útil na distinção destes gliomas ${ }^{[36]}$.

Mas apesar da galectina-3 mostrar-se como um possível marcador e a sua expressão ter sido relatado correlacionado com o grau de malignidade em gliomas humanos classificada pela Organização Mundial da Saúde (WHO), a expressão de galectina-3 no início de lesões neoplásicas tais como a proliferação neoplásica precoce (ENP) e em microtumor ainda está longe de ser totalmente compreendida. Seguindo por esta linha de pesquisa, Binh e colaboradores estudaram a expressão de galectina-3 em gliomas de ratos induzidos por agente químico em lesões pré-neoplásicas e neoplásicas, examinando por imunohistoquímica a galectina-3, lba-1 (marcador especifico de microglia) e GFAP (marcador especifico de astrócitos).

Os resultados mostraram que a galectina-3 foi detectada por imuno-histoquimica e claramente associada com a localização exata do ENP, enquanto que negativa para os tecidos cerebrais normais. Em ENP e microtumor, a galectina-3 foi expressa em células neoplásicas astrocitárias mas raramente em microglia. Já em glioma maligno, no entanto, a galectina- 3 foi expressa em ambas as células neoplásicas astrocíticas e da microglia. Esses resultados indicaram que a expressão de galectina-3 na microglia e macrófagos aumenta de acordo com a progressão do glioma. Baseados nos resultados obtidos os autores acreditam que a galectina-3 é um bom marcador específico que indica o estágio inicial da tumorigênese em gliomas ${ }^{[37]}$.

Mas, embora os resultados sejam animadores e indiquem uma relação direta entre a expressão de galectina-3 e malignidade tumoral, ainda é necessária a realização de estudos mais aprofundados para uma melhor compreensão do papel da galectina-3 na progressão de tumores do SNC, a fim de que novas estratégias anti-tumorais com foco nesta lectina possam ser desenvolvidas. 


\section{7) Glicosilação e resistência a quimioterápico}

Apesar de vários trabalhos na literatura relacionarem a expressão de determinados antígenos carboidratos com um pior prognóstico, pouquíssimos trabalhos têm investigado o papel da glicosilação na resistência aos quimioterápicos utilizados na prática clínica. Recentemente, em 2013, foi publicado o primeiro trabalho que demonstrou a relação entre expressão de uma sialiltransferase (ST6Gal I) com a maior resistência ao quimioterápico cisplatina ${ }^{[38]}$. Nesse trabalho, os autores demonstraram que a sialilação (adição de ácido siálico terminal) em glicoproteínas de superfície promovida pela expressão da ST6Gal I leva à uma redução na ativação de caspase induzida pelo tratamento com cisplatina e, consequentemente, maior resistência à morte celular. Entretanto, as vias envolvidas ou os receptores-chave nessa resposta diferencial não foram investigados em profundidade. Acredita-se que estudos que venham a demonstrar quais vias de sinalização estão diretamente alteradas em consequência da glicosilação "aberrante" dos receptores de superfície celular poderão revelar novas estratégias de intervenção terapêutica. Dentre essas estratégias podemos citar o uso de inibidores de glicosilação e, a utilização de inibidores específicos para vias de sinalização identificadas em conjunto com quimioterápicos já utilizados no combate ao câncer.

Vários estudos têm sugerido que a ligação das galectinas a $\beta$-galactosídeos é sensível à adição de resíduos de ácido siálico terminal. Recentemente foi demonstrado que a adição de ácido siálico $\alpha$-2-6 (através da indução de alta expressão da ST6Gal I) no receptor da $\beta-1$ integrina protegeu as células tumorais da apoptose induzida pela galectina- $3^{[39]}$. Sugere-se que a produção de estruturas sialiladas inibe a ligação das galectinas a $\beta$-galactosídeos, impedindo a auto-agressão por elas induzida, e ao mesmo tempo permitindo que elas sejam secretadas e induzam morte das células do sistema imunitário, facilitando a progressão das neoplasias.

Cientes da importância que as interações proteína-carboidratos podem assumir no contexto da resistência à quimioterápicos, é que nos propusemos a avaliar o efeito da associação entre galectina-3 e temozolamida para tratamento de glioblastoma. 


\section{8) Galectina-3 um papel terapêutico}

A literatura tem demonstrado que o uso de inibidores solúveis da galectina-3 apresentam efeito anti- tumoral ${ }^{[40]}$. Outros grupos de investigadores revelaram sucesso quando utilizaram a galectina-3 truncada (Gal-3c) no tratamento de alguns tumores, quando administrada sozinha ${ }^{[41]}$ ou em combinação com outras drogas antitumorais ${ }^{[42]}$. A galectina-3 truncada mantém a capacidade de ligar a carboidrato, mas devido à perda da porção N-terminal, perde a capacidade de dimerizar ou oligomerizar e de promover interação célula-célula e célula-matriz extracelular e, assim, funcionaria como um inibidor dessas funções.

John e colaboradores avaliaram a potencialidade da galectina-3 como um possível agente terapêutico em câncer de mama ${ }^{[41]}$. Para testar esta hipótese terapêutica, os pesquisadores implantaram ortotopicamente células da linhagem de câncer de mama MDA-MB 435 em camundongos balb/c nude e em seguida administraram galectina-3 truncada, monitorando a evolução do tratamento durante 90 dias. Neste estudo demonstrou-se que o volume do tumor foi significativamente menor no animal tratado com galectina-3 truncada quando comparado ao grupo controle (sem tratamento). Além disso, no grupo tratado com galectina-3 truncada poucos animais apresentaram metástases nos linfonodos em comparação ao grupo controle.

Seguindo a mesma hipótese, Mirandola e colaboradores avaliaram o papel terapêutico da galectina-3 truncada em Mieloma Multiplo (MM), sozinha ou em associação com o quimioterápico Bortezomida ${ }^{[42]}$. Para isso a linhagem U266 de MM humano foi inoculada subcutaneamente em modelo murino e o efeito terapêutico foi avaliado em três grupos: (1) apenas galectina-3 truncada, (2) apenas Bortezomida e (3) combinação de galectina-3 truncada com Bortezomida. Os resultados demonstraram que o tratamento com galectina-3 truncada ou Bortezomida (individualmente) apresentou redução da massa tumoral de 13,5\% e 19,6\% respectivamente, mas em associação (galectina-3 truncada + Bortezomida) o tratamento promoveu uma redução de $94 \%$ do tumor.

Diferente dos estudos anteriores que utilizaram a galectina-3 truncada para competir com a galectina-3 endógena ${ }^{[41,42]}$, Newton-Northup e colaboradores identificaram um peptídeo de alta afinidade pelo domínio CRD da galectina-3, capaz de inibir sua ligação ao antígeno tumoral TF (Thomsen-Freidenreich). Os autores relataram que em linhagens de câncer de mama, o tratamento pelo peptídeo em questão foi capaz 
de reduzir a adesão celular em cerca de $59 \%$ em testes in vitro. Já em teste in vivo em modelo nude, inoculada com linhagem transfectada MDA-MB 231 Luc que expressa gene repórter da luciferase para imagens por bioluminescência, o tratamento com peptídeo G3-C12 foi capaz de reduzir em 72\% a colonização das células tumorais ao pulmão dos animais ${ }^{[43]}$.

Diante dos resultados promissores apresentados anteriormente, no presente estudo buscou-se investigar o papel anti-tumoral da galectina-3 truncada e galectina-3 recombinante humana (nativa) em associação com quimioterápico de referência (TMZ) utilizando uma linhagem de glioblastoma humano (U87) in vitro $e$ in vivo. Adicionalmente, buscou-se avaliar a biodistribuição da galectinas-3 nativa por imagem molecular SPECT. Esta abordagem poderá contribuir para o aprofundamento do estudo desta proteína e seus efeitos na biologia tumoral e, principalmente, continuar em direção para a inovação terapêutica contra as células tumorais. 


\section{2) OBJETIVOS}

Compreender e avaliar o papel terapêutico da galectina-3 in vitro e in vivo em modelo xenográfico de Glioblastoma humano por técnicas de imagem molecular ótica. Além disso pretende-se analisar a biodistribuição da galectina-3 na presença e ausência de tumor por técnica de imagem molecular SPECT (Tomografia Computadorizada por Emissão de Fóton Único)

\section{1) Objetivos específicos}

$\checkmark$ Avaliar in vitro o efeito da galectina-3 nativa e truncada (sozinha ou em associação com Temozolamida) na proliferação e morte celular da linhagem de glioblastoma humano (U87).

$\checkmark$ Avaliar in vivo o efeito terapêutico da galectina-3 nativa (sozinha ou em associação com Temozolamida) no crescimento tumoral de células U87, em camundongos balb/c nude, através de técnicas de imagem ótica por bioluminescência.

$\checkmark$ Avaliar in vivo a biodistribuição de galectina-3 nativa por técnicas de imagem molecular (SPECT/CT) em camundongos balb/c nude na ausência e presença de tumor.

$\checkmark$ Avaliar in vivo a biodistribuição de galectina-3 nativa por técnica de imagem ótica por fluorescência em camundongos balb/c nude com tumor. 


\section{3) MATERIAL E MÉTODOS}

\section{1) Linhagem de glioblastoma U87}

A linhagem celular de Glioblastoma Humano U87 utilizada nesse estudo foi obtida da American Type Culture Collection (ATCC, HTB-14). Esta linhagem celular foi mantida em cultura em meio DMEM low glucose (Invitrogen - Brasil) suplementado com soro fetal bovino (GIBCO - Brasil) a 10\% e antibióticos: $100 \mathrm{IU} / \mathrm{ml}$ ampicilina, $100 \mu \mathrm{g} / \mathrm{mL}$ estreptomicina e $25 \mu \mathrm{g} / \mathrm{mL}$ anfotericina B (Sigma - Brasil).

\section{2) Transfecção da linhagem de glioblastoma U87 com o gene repórter da luciferase}

Células da linhagem de glioblastoma U87 $\left(1 \times 10^{4}\right)$ foram plaqueadas em placa de 6 poços e incubadas a $37^{\circ} \mathrm{C}$ com $5 \%$ de $\mathrm{CO}_{2}$ durante $24 \mathrm{hs}$. No dia seguinte, três agentes de transfecção (Lipofectamina 2000 (Invitrogen - Brasil), PEI (Polysciences) e X-Fect (Clontech -EUA) foram utilizados para testar a melhor eficácia de transfecção do plasmídeo pGL4.51[CMV/luc2/Neo] (Promega - Brasil). Todas as transfecções foram realizadas de acordo com as instruções dos respectivos fabricantes, Invitrogen, Sigma e Clontech). Ao fim da incubação de 24 hs pós transfecção, foi adicionado o substrato $(150 \mu \mathrm{g} / \mathrm{mL})$ D-luciferina (Promega - Brasil) às células de glioblastoma U87 transfectadas pelos agentes de transfecção mencionados anteriormente. Utilizando-se o equipamento de imagem IVIS Spectrum (Perkin Elmer - USA) foi avaliado o resultado da transfecção, para então, selecionar o agente mais adequado a ser utilizado.

\subsection{1) Lipofectamina 2000}

A transfecção em placa de 6 poços foi realizada com o preparo de duas soluções. Solução A: $5 \mu \mathrm{g}$ do plasmídeo pGL 4.51[CMV/Luc2/Neo] (Promega - Brasil) que contém o gene repórter de luciferase, em $250 \mu \mathrm{L}$ de meio Opti-MEM (Gibco - Brasil) incubados por 5 minutos à temperatura ambiente. Solução B: $5 \mu \mathrm{L}$ do agente de transfecção Lipofectamina 2000 em $245 \mu \mathrm{L}$ de meio Opti-MEM, incubados por 5 minutos à temperatura ambiente.

Cuidadosamente a solução A foi adicionada à solução $\mathrm{B}$, e após suave agitação, a mistura resultante foi incubada por 20 minutos à temperatura ambiente. Em seguida a mistura foi adicionada (gota a gota) ao poço contendo as células de glioblastoma U87 e 
incubado a $37^{\circ} \mathrm{C}$ e $5 \%$ de $\mathrm{CO}_{2}$ durante 4 hs. Ao fim do período de $4 \mathrm{hs}$, todo sobrenadante foi descartado e substituído por 2,0 mL de meio DMEM (Sigma-Brasil) com $10 \%$ soro fetal bovino (Gibco-Brasil) e a placa incubada a $37^{\circ} \mathrm{C}$ durante $24 \mathrm{hs}$.

\subsection{2) Polietilenoimina (PEI)}

De modo análogo ao item 3.2.1, porém com as seguintes alterações: Solução A contendo $1 \mu \mathrm{g}$ do plasmídeo pGL 4.51[CMV/Luc2/Neo] e na Solução B contendo $3 \mu \mathrm{L}$ de Polietilenoimina .

\subsection{3) X-fect}

De modo análogo ao item 3.2.1, porém com as seguintes alterações: Solução A contendo $5 \mu \mathrm{g}$ do plasmídeo pGL 4.51[CMV/Luc2/Neo] em $100 \mu \mathrm{L}$ de tampão de reação de Xfect (Clontech - EUA) e na solução B 1,5 $\mu \mathrm{L}$ do polímero de Xfect em $98,5 \mu \mathrm{L}$ de tampão de reação de Xfect. As soluções A e B foram agitados a uma velocidade média em vórtex para garantir solução homogênea e, incubados por 10 minutos antes de adicionar às células.

\section{3) Seleção Clonal das células de glioblastoma U87 transfectada}

As células de glioblastoma U87 transfectadas por lipofectamina 2000 (agente de transfecção que apresentou melhor desempenho), foram tripsinizadas e cultivadas em garrafa de cultura em meio de cultura DMEM low glucose (Invitrogen - Brasil) suplementado com soro fetal bovino (GIBCO - Brasil) a 10\% e antibióticos: $100 \mathrm{IU} / \mathrm{mL}$ ampicilina, $100 \mu \mathrm{g} / \mathrm{mL}$ estreptomicina e $25 \mu \mathrm{g} / \mathrm{mL}$ anfotericina B (Sigma - Brasil) e $500 \mu \mathrm{g} / \mathrm{mL}$ de antibiótico Geneticina (Sigma - Brasil) durante 10 dias para seleção de células resistentes ao antibiótico (positivas). Então, as células foram submetidas ao método de diluição limitante para obtenção de clones. O procedimento consiste em tripsinizar as células resistentes e após contagem, cerca de 300 células foram adicionadas a $48 \mathrm{~mL}$ de meio DMEM (Gibco - Brasil) e $500 \mu \mathrm{g} / \mathrm{mL}$ de Geneticina em tubo Falcon, em seguida, distribuídas em cinco placas de 96 poços (100 $\mu \mathrm{L}$ por poço).

No dia seguinte, foram anotados os poços com apenas 1 célula (1 clone) e apenas esse poços foram seguidos e avaliados. As cinco placas foram mantidas durante 7 dias, e no fim o sinal bioluminescente foi verificado com auxilio de sistema de 
imagem IVIS Spectrum. Após identificação dos poços que apresentavam sinal bioluminescente, o clone com a maior expressão do gene da luciferase foi selecionado.

O clone selecionado foi tripsinizado e transferido para placa de 24 poços para expansão, posteriormente para placa de 6 poços e por fim em garrafa de cultura $25 \mathrm{~cm}^{2}$, cultivados em meio DMEM suplementado com soro fetal bovino a $10 \%$ e Geneticina (200 $\mu \mathrm{g} / \mathrm{mL})$ para manutenção do clone. Por motivo sistemático, o clone em questão será denominado como U87Luc2.

\section{4) Cálculo do número de fóton por células da linhagem de glioblastoma U87Luc2 pós seleção clonal}

Em placa de 96 poços, 50.000 células U87Luc2 foram plaqueadas em quintuplicatas e mantidas a $37^{0} \mathrm{C}$ com $5 \%$ de $\mathrm{CO} 2$ durante 24 hs para permitir a adesão celular. Após este período, $150 \mu \mathrm{g} / \mathrm{mL}$ de D-luciferina (Promega - Brasil) foi adicionada em cada poço e o sinal bioluminescente foi adquirido utilizando equipamento de imagem IVIS Spectrum seguindo os parâmetros: tempo de exposição automático, f/stop 1, Binning 8 e FOV D. Uma série consecutiva de imagens foram realizadas até à obtenção da maior intensidade de sinal (mensuração em counts). A quantificação foi realizada definindo a região de interesse (ROI) correspondente a área total do poço utilizando o software Living Image 4.3.1 (Caliper Life Sciences).

Para o cálculo de fótons/segundo/célula foi utilizado a seguinte fórmula:

$$
\frac{\text { Fluxo Total }[\mathrm{p} / \mathrm{s}]}{\text { número de células }}
$$

\section{5) Produção de galectina-3 recombinante humana}

Para produção de galectina-3 humana foi utilizada a bactéria E. coli M15 transformada com vetor contendo a sequência da galectina-3 humana, segundo protocolo descrito por Fermino e colaboradores $(2011)^{[44,45]}$. Em resumo, inicialmente foi preparado $200 \mathrm{~mL}$ de meio LB (Invitrogen-Brasil) (10 g/L) estéril, complementado com ampicilina (Sigma-Brasil) a uma concentração final de $50 \mu \mathrm{g} / \mathrm{mL}$. No primeiro dia, uma alíquota de bactéria foi adicionada a este meio e incubado no Shaker, por $24 \mathrm{hs}$, a $37^{\circ} \mathrm{C}$, a 250 RPM. No segundo dia, $25 \mathrm{~mL}$ da primeira cultura foi adicionado a 1 litro de meio LB com AMP $(50 \mu \mathrm{g} / \mathrm{mL})$ a $37^{\circ} \mathrm{C}$, sob agitação (200 a $\left.250 \mathrm{RPM}\right)$. Esta nova cultura foi mantida no shaker até que uma alíquota desta cultura indicasse uma 
absorbância entre $0.45-0.50$ a $600 \mathrm{~nm}$ (em torno de $3 \mathrm{hs}$ no shaker). Ao atingir essa densidade óptica, foi adicionado, para cada litro de cultura, $0.36 \mathrm{~g}$ de IPTG (SigmaBrasil) diluídos em $1 \mathrm{~mL}$ de meio LB. Em seguida, a cultura de bactérias com IPTG foi incubada por adicionais 5 horas a $37^{\circ} \mathrm{C}$, sob agitação de 250 a 300 RPM. Ao fim destas $5 \mathrm{hs}$, a cultura foi centrifugada a $5000 \mathrm{~g}$ por 30 minutos a $4^{\circ} \mathrm{C}$ para a obtenção do pellet de bactérias. $\mathrm{O}$ sobrenadante foi descartado e o pellet guardado a $-80^{\circ} \mathrm{C}$ até o momento da purificação.

\subsection{1) Purificação da galectina-3 por cromatografia de afinidade}

O pellet de bactérias foi descongelado em banho de gelo e em seguida solubilizada em tampão de lise (7 mL de PBS 1X, pH 7.4, 1 tablete de inibidor de protease (Roche - Brasil), $1 \mathrm{~mL}$ de lisozima $1 \mathrm{mg} / \mathrm{mL}$ (Sigma-Brasil), $10 \mu \mathrm{L}$ de RNAse a $10 \mathrm{mg} / \mathrm{mL}$ (Sigma - Brasil), $10 \mu \mathrm{L}$ de DNAse a $10 \mathrm{mg} / \mathrm{mL}$ (Sigma-Brasil).

A solução resultante do passo anterior foi sonicada cerca de 5 vezes $(\mathrm{W}=40 \mathrm{w})$ por cerca de 1 minuto e entre cada procedimento foi necessário deixar a solução em repouso por cerca de 1 minuto, lembrando que todo o procedimento descrito foi acondicionado em banho de gelo. Ao fim dessa etapa o lisado foi centrifugado a $5.000 \mathrm{~g}$ a $4^{0} \mathrm{C}$ durante $1 \mathrm{~h}$ e o sobrenadante (contendo a galectina-3 solúvel) foi coletado, e o pellet descartado.

O sobrenadante coletado foi aplicado à uma coluna de $\alpha$-Lactosil ( $\alpha$-lactose) (Sigma L763R - Brasil) previamente lavada e equilibrada com PBS 1X. A galectina-3 presente no sobrenadante e retida na coluna de $\alpha$-Lactosil foi eluída com solução de lactose $(150 \mathrm{mM})$ em PBS. Recolheu-se 10-15 frações de $500 \mu \mathrm{L}$ e a quantidade de galectina-3 presente em cada fração foi quantificada em Nanodrop a 280nm (Thermo Scientific - EUA). Posteriormente, a galectina-3 purificada foi submetida a um protocolo de gel-filtração em uma coluna PD-10 (G\&E - Brasil) para remoção da lactose. 


\section{6) Produção de galectina-3 truncada}

A galectina-3 truncada utilizada neste projeto foi produzida de duas maneiras:

\section{(a) Tratamento por colagenase}

A galectina-3 nativa purificada anteriormente, após purificação em coluna PD10 (G\&E - Brasil), foi utilizada como matéria prima para produção de galectina-3 truncada.

A galectina-3 truncada por tratamento por colagenase foi produzida segundo protocolo descrito por Massa e colaboradores (1993) ${ }^{[46]}$ mas com as seguintes modificações: não foi utilizado cloreto de sódio, utilizou-se Trisbase $50 \mathrm{mM}$ (Sigma Brasil) e $\mathrm{CaCl}_{2} 25 \mathrm{mM}$ (Sigma -Brasil).

Em resumo, foi utilizada uma proporção de 20:1 (substrato/enzima) $22 \mathrm{mg}$ de galectina-3 nativa foi adicionado a 1,1 mg de colagenase tipo VII (Sigma - Brasil), solubilizados em $22 \mathrm{~mL}$ de tampão Trisbase $50 \mathrm{mM}$ (Sigma - Brasil) $+\mathrm{CaCl}_{2} 25 \mathrm{mM}$ (Sigma Brasil) e incubados a $37^{0} \mathrm{C}$ durante $16 \mathrm{hs}$.

O produto da reação galectina-3/colagenase foi purificada em coluna de $\alpha$ Lactosil ( $\alpha$-lactose), previamente equilibrada em tampão Trisbase $+\mathrm{CaCl}_{2}$, lavada com PBS 1x e posteriormente eluída com tampão de eluição lactose $150 \mathrm{mM}$ (Sigma Brasil). Recolheu-se 10-15 frações de $500 \mu \mathrm{L}$ e a quantidade de galectina-3 truncada presente em cada fração foi quantificada em Nanodrop (Thermo Scientific - EUA). Posteriormente, a galectina-3 truncada foi submetida a um protocolo de gel-filtração em uma coluna PD-10 (G\&E - Brasil) para remoção da lactose.

\section{b) Bactérias transformadas com os plasmídeos pET11a e pGEX-4T-2}

A produção de galectina-3 truncada foi feita de forma análoga ao protocolo descrito para produção de galectina-3 nativa referido no item 3.5 descrito por Fermino e colaboradores $(2011)^{[44]}$, porém utilizando-se das bactéria E. coli M15 transformadas com os seguintes vetores: pET11a e pGEX-4T-2.

Os plasmídeos para expressão da gal3C, pET11a e pGEX-4T-2 foram gentilmente cedidos pelo Dr Nozomu Nishi (Life Science Research Center, Kagawa University, Kagawa, Japão). 


\section{7) Gel de Poliacrilamida (SDS-Page)}

As galectinas recombinantes produzidas anteriormente (item 3.5 e 3.6) foram analisadas em gel SDS-Page. Para isso, $9 \mu \mathrm{g}$ de proteína foram solubilizadas em tampão de amostra 4x (50\% 0,5 M de Tris- $\mathrm{HCl}$ pH 6,8 (Sigma Aldrich-Brasil), 46\% glicerol 87\% (Merck - Brasil), 9,2 \% SDS (National Diagnostics - USA), 0,05\% de azul de bromofenol 0,25\% p/v e 0,05\% de $\beta$-mercaptoetanol (Sigma Aldrich - Brasil)) e água para um volume final de $30 \mu \mathrm{L}$.

As amostras foram fervidas a $95^{\circ} \mathrm{C}$ durante 5 min e aplicadas $(10 \mu \mathrm{L} /$ poço $)$ em gel SDS-PAGE (gel stacking a 4\% e gel resolving a 12\%) em corrida realizada a $100 \mathrm{~V}$ (Bio-Rad - Brasil).

\section{8) Marcação de galectina-3 recombinante humana com o fluorocromo DyLight 647 e VivoTag 680XL}

Um miligrama de galectina-3 preparada em tampão PBS foi transferida para um tubo contendo o flurocromo DyLight 647 NHS Ester (Thermo Scientific - EUA). A solução foi vortexada e incubada à temperatura ambiente por $1 \mathrm{~h}$ protegido da luz. De forma a purificar a galectina-3 e remover o excesso de fluorocromo, a mistura foi adicionada a uma coluna contendo uma resina de purificação e centrifugada a $1000 \mathrm{x} g$ por $1 \mathrm{~min}$, de acordo com protocolo descrito pelo fabricante. A proteína purificada foi armazenada a $-20^{\circ} \mathrm{C}$ até sua utilização.

Para a marcação com VivoTag 680XL, uma miligrama de galectina-3 em tampão PBS foi transferido para um tubo contendo o fluorocromo VivoTag 680XL (Perkin Elmer). A solução foi incubada no escuro à temperatura ambiente durante 2 horas. O excesso de fluorocromo foi removido em uma coluna centricon $(3,000$ NMWL) (Millipore) e centrifugada a 10.000 x g por $15 \mathrm{~min}$, de acordo com protocolo descrito pelo fabricante. A proteína purificada foi armazenada a $4^{\circ} \mathrm{C}$ até sua utilização.

\section{9) Citometria de fluxo}

Inicialmente, foi avaliada a quantidade de galectina-3 endógena presente na superfície das células U87. Para isso, células de glioblastoma U87 $\left(1 \times 10^{6}\right)$ foram primeiramente bloqueadas com Fc Block (anti-CD16/CD32) por $30 \mathrm{~min}$ e posteriormente incubadas com o anticorpo rato-anti-galectina-3 (M3/38, ATCC TIB166). Após 1 hora de incubação a $4^{\circ} \mathrm{C}$, as células foram lavadas com PBS e 
ressuspendidas em BSA $1 \%$ em PBS contendo anticorpo secundário anti-rato marcado com Alexa-488 (Invitrogen - Brasil). Após 1 hora, as células foram lavadas com PBS, fixadas com formaldeído (Sigma - Brasil) a 4\%, e analisadas no citômetro de fluxo (BD FACSCalibur ${ }^{\mathrm{TM}}$ - EUA). A representação esquemática que avalia a quantidade de galectina-3 endógena na superfície das células pode ser observado na figura 7.

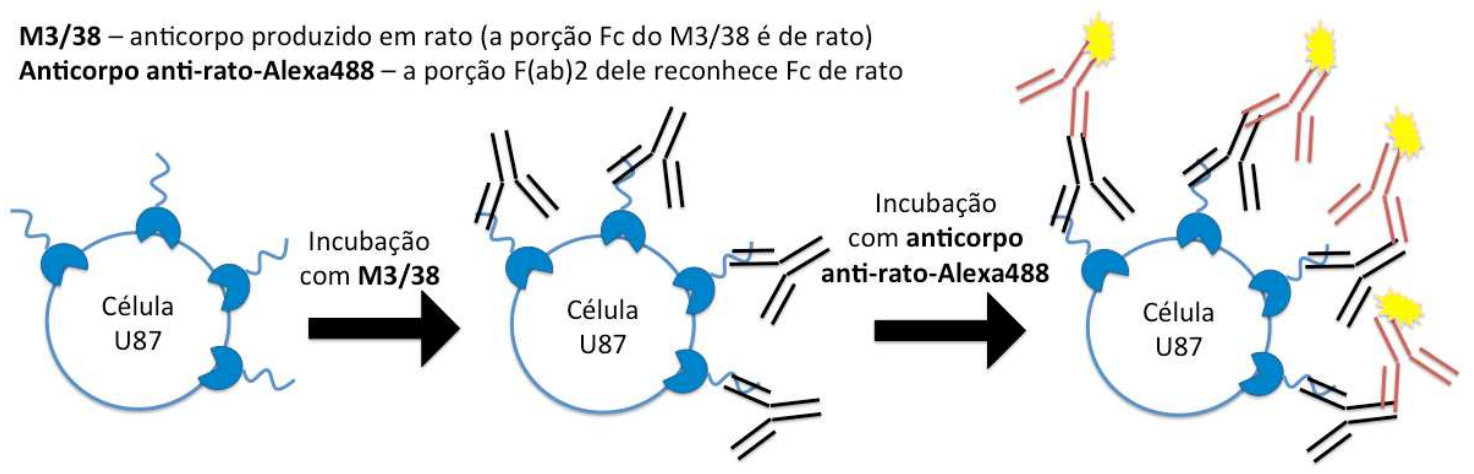

Figura 7. Avaliação da galectina-3 endógena presente na superfície da célula. Representação esquemática do ensaio que visa avaliar a quantidade de galectina-3 endógena presente na superfície das células de glioblastoma U87.

Em uma segunda etapa, foi avaliada a quantidade de sítios de ligação para galectina-3 adicionais, ou seja, outros locais de ligação para galectina-3 recombinante humana exógena, além das já existentes (galectina-3 endógena). Para isso, células foram incubadas com $50 \mu \mathrm{g}$ de galectina-3 recombinante humana previamente marcada com fluorocromo DyLight 647 NHS Ester, (Thermo Scientific - EUA) na presença ou ausência de lactose $(50 \mathrm{mM})$. Após 1 hora de incubação a $4^{\circ} \mathrm{C}$, as células foram lavadas com PBS, fixadas com formaldeído (Sigma - Brasil) a 4\% e analisadas em citômetro de fluxo (BD FACSCalibur ${ }^{\mathrm{TM}}$ ). Os dados obtidos foram analisados com o programa FCS Express (De Novo Software). A representação esquemática que avalia a capacidade da galectina-3 recombinante humana de se ligar na superfície das células de glioblastoma U87, assim inferindo possíveis sítios de ligação para proteína em questão, pode ser observado na figura 8 . 


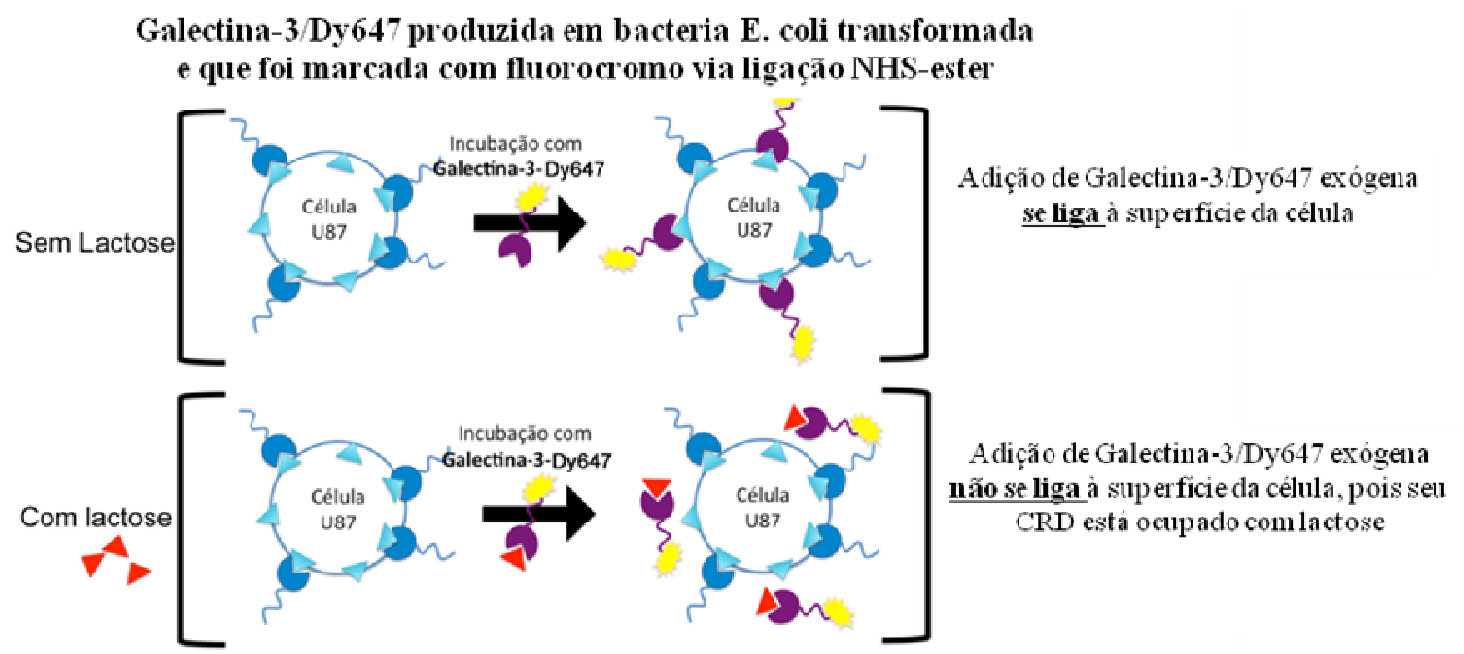

Figura 8. Avaliação da quantidade de sítios de ligação para galectina-3 recombinante humana produzida no estudo. Representação esquemática do ensaio que visa avaliar a quantidade de sítios livres adicionais para ligação da galectina-3 recombinante humana (exógena). Adicionalmente, a lactose foi utilizada para demonstração que a galectina-3 recombinante humana produzida no estudo foi capaz de se ligar a célula U87. Pois ao adicionar o inibidor (Lactose) a galectina-3 não será mensurado no citômetro por estar associado a lactose .

\subsection{0) Avaliação do efeito terapêutico da galectina-3 nativa e truncada in vitro}

Células da linhagem de glioblastoma humano U87 foram semeadas (2000 células por poço) em placa de 96 poços em volume de $150 \mu \mathrm{L}$ e incubadas a $37^{\circ} \mathrm{C}, 5 \%$ $\mathrm{CO}_{2}$ por $24 \mathrm{hs}$.

Após 24hs, uma placa foi fixada pela adição de $30 \mu \mathrm{L}$ de $50 \%$ (w/v) Ac. Tricloroacético (Sigma - Brasil) gelado para uma concentração final de 10\% e incubada por 60 minutos a $4^{\circ} \mathrm{C}$. Esta placa representa a medida da população celular no tempo de adição da droga $(\Delta t=$ zero $)$. Nas restantes placas de 96 poços, as células foram tratadas com uma diluição seriada de concentrações de temozolamida (Schering Plough - Brasil) ( $2 \mathrm{mM}$ a $0,0156 \mathrm{mM}$ ) ou não receberam tratamento (controle de crescimento (C) sem droga). Divididos em 6 grupos: Grupo \#1 controle. Grupo \#2 tratadas com galectina-3 $(50 \mu \mathrm{g} / \mathrm{mL})$. Grupo \#3 tratadas com galectina-3c $(50 \mu \mathrm{g} / \mathrm{mL})$. Grupo \#4 tratadas com galectina-3 $(50 \mu \mathrm{g} / \mathrm{mL})$ e $50 \mathrm{mM}$ lactose. Grupo \#5 tratadas com galectina-3c (50 $\mu \mathrm{g} / \mathrm{mL})$ e $50 \mathrm{mM}$ lactose. Grupo \#6 tratadas com $50 \mathrm{mM}$ lactose.

O ensaio terminou pela adição de $30 \mu \mathrm{L}$ de $50 \%$ (w/v) TCA gelado para uma concentração final de $10 \%$ e incubada por 60 minutos a $4^{\circ} \mathrm{C}$. O sobrenadante foi descartado e a placa lavada 5 vezes com água da torneira e secadas ao ar. Uma solução de $0,4 \%$ de sulforodamina B (Sigma - Brasil) diluída em 0,1\% de ácido acético (100 $\mu \mathrm{L}$ ) 
foi adicionada a cada poço de placa de 96 poços e incubada por 10 min à temperatura ambiente. Após coloração, a coloração inespecífica foi removida pela lavagem das placas com uma solução de $0,1 \%$ de ácido acético (5X) e secadas ao ar. A coloração foi solubilizada pela adição de $100 \mu \mathrm{L} 100 \mathrm{mM}$ trizma base e a absorbância medida num leitor de placa de ELISA (Thermo Scientific - EUA) a $515 \mathrm{~nm}$. O software GraphPad 4.0 foi utilizado para o cálculo do IC50, pelo cálculo estatístico da curva de doseresposta sigmoidal.

\subsection{1) Modelo animal}

Os experimentos foram realizados após aprovação pela Comissão de Ética no uso de animais da Faculdade de Medicina da USP (CEUA-Protocolo número 4379), conforme a determinação do CONCEA.

Foram utilizados 24 camundongos nude fêmeas adultas jovens, com idade entre 7 e 9 semanas, provenientes do Biotério Central da Faculdade de Medicina USP. Os animais foram mantidos em gaiolas coletivas com cinco animais em cada gaiola, com água e ração ad libitum com controle de temperatura $\left(22^{\circ} \mathrm{C} \pm 2{ }^{\circ} \mathrm{C}\right)$, umidade $(45 \% \pm$ $15 \%$ ) e ciclo claro/escuro de $12 \mathrm{hs}$.

\subsection{2) Avaliação do efeito terapêutico da galectina-3 por Bioluminescência in vivo}

Antes da inoculação das células tumorais nos camundongos, as células U87 Luc2 foram lavadas com PBS, contadas e ajustadas para uma densidade adequada com PBS adicional. Em seguida uma suspensão de $100 \mu \mathrm{L}$ contendo $1 \times 10^{6}$ células U87 Luc2 foi inoculada por via subcutânea no dorso dos camundongos nude.

Os camundongos foram aleatoriamente divididos em três grupos ( 5 animais por grupo). O Grupo \#1 foi tratado com TMZ (6,25 mg/kg/camundongo) por gavagem uma vez por dia durante 14 dias. O Grupo \#2 foi tratado com galectina-3 (100 $\mu \mathrm{g}$ ) via intraperitoneal duas vezes por semana durante 14 dias. Os animais do Grupo \#3 foram tratados em associação: TMZ $(6,25 \mathrm{mg} / \mathrm{kg} /$ camundongo) por gavagem uma vez ao dia, e com galectina-3 $(100 \mu \mathrm{g})$ via intraperitoneal duas vezes por semana durante 14 dias.

O inicio dos tratamentos ocorreu somente após confirmação de crescimento celular (U87 Luc2), identificado por bioluminescência em equipamento de imagem IVIS Spectrum (após cerca de 7 dias). Ao termino do tratamento, os animais foram acompanhados por mais 14 dias sem a administração de substâncias terapêuticas. 
Para obtenção de imagens in vivo, os animais foram anestesiados com 3\% de isofluorano seguido da injeção de $150 \mathrm{mg} / \mathrm{Kg}$ de D-luciferina (Promega - Brasil). O sinal bioluminescente foi adquirido utilizando equipamento de imagem IVIS Spectrum seguindo os parâmetros: tempo de exposição automático, f/stop 1, Binning 8 e FOV D. Uma série de imagens foi adquirida até a obtenção da maior intensidade de sinal (mensuração em counts). A quantificação foi realizada definindo a região de interesse ROI utilizando o software Living Image 4.3.1.

\subsection{3) Padronização da implantação de células intracraniano (corante)}

Inicialmente, os animais foram anestesiados com xilazina $(8 \mathrm{mg} / \mathrm{Kg})$ e quetamina $(80 \mathrm{mg} / \mathrm{Kg})$ via intraperitoneal. Após anestesia dos animais, a cabeça dos camundongos foi fixada na posição PRONA para incisão vertical da pele que recobre o crânio, e exposição da sutura coronal e bregma. Um pequeno orifício foi feito no crânio com auxilio de broca cirúrgica (Fine Sciences Tools, Foster City, CA, EUA) em um ponto localizado $2 \mathrm{~mm}$ à direita da sutura sagital mediana e $2 \mathrm{~mm}$ posterior à sutura coronal. Em seguida, $2 \mu \mathrm{L}$ de corante azul de Evans em agulha (26 gauge) foi injetado por meio de sistema de microinjeção esteriotáxico (Automated Multisite Microinjection System with InjectoMate, Neurostar, Sindelfingen, Alemanha) durante 8 minutos, permanecendo o sistema em repouso 10 minutos adicionais.

Ao fim, a agulha foi removida, janela craniana ocluída por cimento odontológico (Fillcanal, Technew - Rio de Janeiro) e incisão da pele suturada. Ao término da cirurgia foi administrado fármaco analgésico Cetoprofeno $(2 \mathrm{mg} / \mathrm{kg}$ ) (Biofen 1\%, Biofarm - São Paulo) via intra muscular.

\subsection{4) Implantação da linhagem de glioblastoma U87 intracraniano}

De modo análogo ao descrito anteriormente no item 3.11, com a diferença de que o corante foi substituído por uma suspensão contendo células de glioblastoma U87Luc2 $\left(2 \times 10^{5}\right)$ em $2 \mu \mathrm{L}$.

Durante e ao fim do procedimento os animais foram cuidadosamente monitorados quanto a sinais de redução de massa corpórea, atividade e instabilidade motora. Observada perda de massa corpórea superior a $20 \%$ os animais seriam sacrificados. 


\subsection{5) Padronização da conjugação de galectina-3 com quelante bifuncional}

O processo de marcação inicia-se conjugando a proteína (Gal-3) com quelante bifuncional HYNIC (Futurechem - Coreia do Sul) para posterior adição do radioisótopo $\left({ }^{99 \mathrm{~m}} \mathrm{Tc}\right)$. Em resumo, preparou-se solução de HYNIC onde 0,6 mg de HYNIC foi dissolvido em $75 \mu \mathrm{L}$ de DMSO (Sigma-Brasil) e armazenado sob proteção à luz. Na próxima etapa adicionou-se $16 \mu \mathrm{L}$ de solução de bicarbonato de sódio 1M (SigmaBrasil) para cada $5 \mathrm{mg}$ de proteína a ser conjugada, a fim de manutenção de $\mathrm{pH}$ levemente básico, em seguida, adicionou-se $5 \mu \mathrm{L}$ da solução de HYNIC em DMSO (previamente preparada). A solução resultante foi homogeneizada, armazenada sob proteção da luz e mantida em temperatura ambiente por 45 minutos.

O conjugado Gal-3/HYNIC formado foi purificado em coluna Sephadex G-25 ((PD-10) (Amersham Biosciences - UK)) com tampão de acetato de sódio 0,15M e pH 6.4, com a finalidade de eliminar o HYNIC livre.

\subsection{6) Marcação da galectina-3 com radionuclídeo}

Em continuidade, após o término do procedimento anterior (item 3.14), $8 \mathrm{mg}$ de tricina (Sigma - Brasil) foi solubilizada em 0,8 mL de água MilliQ, e purgada com $\mathrm{N}_{2}$ gasoso por cerca de 1 minuto, ao fim ajustou-se o $\mathrm{pH}$ desta solução para 4,5 a 5,0 com cerca de $50 \mu \mathrm{L}$ de $\mathrm{HCl} 1 \mathrm{M}$ (Sigma - Brasil). Em seguida, $10 \mathrm{mg}$ de cloreto de estanho foi solubilizado em $500 \mu \mathrm{L}$ de solução de $\mathrm{HCl} 1 \mathrm{M}$. Assim, $50 \mu \mathrm{L}$ dessa solução de cloreto de estanho foi adicionado à solução de tricina inicial, e desta solução resultante, completou-se o volume com solução salina de $\mathrm{NaCl}$ 0,9\% (Sigma - Brasil) para solução final a $10 \mathrm{~mL}$.

Para marcação, 1,25 $\mu \mathrm{L}$ da solução resultante preparada no passo anterior (tricina e cloreto de estanho) foi adicionada em $0,5 \mathrm{mg}$ de proteína conjugada com HYNIC e ${ }^{99 m} \mathrm{Tc}$ (3 - 4,5 mCi), acondicionado em proteção de chumbo e incubado à temperatura ambiente por 30 minutos.

A qualidade da marcação foi analisada em HPLC (Agilent 1260 - Brasil) com fase estacionária coluna Protein-Pak 125 I-125A 10M 7.8x300mm (Waters-USA) em fase móvel tampão fosfato $(0,05 \mathrm{M}$ e $\mathrm{pH} 7)$ em modo isocrático $(1,0 \mathrm{~mL} / \mathrm{min})$ equipado com detector de radiação Gabi (Raytest-Alemanha) e detector de UV a $280 \mathrm{~nm} \mathrm{em}$ corrida de 25 minutos. 


\subsection{7) Ensaios de estabilidade da galectinas-3 radiomarcada com ${ }^{99 m} \mathrm{Tc}$}

\subsection{1) Estabilidade em solução L-cisteína}

Três sistemas de estabilidade foram constituídos:

- \#1, $100 \mu \mathrm{L}^{99 \mathrm{~m}} \mathrm{Tc}-\mathrm{HYNIC/Gal-3}$ foi adicionado a $100 \mu \mathrm{L} \mathrm{NaCl} \mathrm{0,9 \% .}$

- \#2, $100 \mu \mathrm{L}{ }^{99 \mathrm{~m}} \mathrm{Tc}-\mathrm{HYNIC} / \mathrm{Gal}-3$ foi adicionado a $100 \mu \mathrm{L}$ L-cisteína $0,1 \mathrm{mM}$

- \#3, $100 \mu \mathrm{L}^{99 \mathrm{~m}} \mathrm{Tc}-\mathrm{HYNIC} / \mathrm{Gal}-3$ foi adicionado a $100 \mu \mathrm{L}$ L-cisteína 0,01mM.

Para o controle do tempo zero foram separados $20 \mu \mathrm{L}$ das soluções iniciais dos 3 sistemas (\#1, \#2, e \#3). O conteúdo restante (\#1, \#2, e \#3) foi incubado em banho-maria a $37^{\circ} \mathrm{C}$ e coletados alíquotas de $20 \mu \mathrm{L}$ sucessivamente, após 2 e 4 hs de incubação, para análise da galectina-3 marcada por HPLC (High Performance Liquid Chromatography).

\subsection{2) Estabilidade em soro fetal}

Dois sistemas de estabilidade foram constituídos:

- \#1, $100 \mu \mathrm{L}{ }^{99 \mathrm{~m}} \mathrm{Tc}-\mathrm{HYNIC} / \mathrm{Gal}-3$ foram adicionados a $100 \mu \mathrm{L}$ de $\mathrm{NaCl} 0,9 \%$ (proporção de 1:1).

- \#2, $100 \mu \mathrm{L}{ }^{99 m} \mathrm{Tc}-\mathrm{HYNIC} / \mathrm{Gal}-3$ foram adicionados a $100 \mu \mathrm{L}$ de soro fetal bovino (proporção de 1:1).

Para controle no tempo zero foram coletadas alíquotas $(20 \mu \mathrm{L})$ de cada solução. Em seguida, as soluções foram incubadas em banho-maria a $37^{\circ} \mathrm{C}$, e alíquotas de $20 \mu \mathrm{L}$ foram coletadas sucessivamente após 1, 2 e 4 de incubação, para análise do perfil cromatográfico das moléculas de galectina-3 que permaneceram radiomarcadas com ${ }^{99 \mathrm{~m}}$ Tc, utilizando a técnica de HPLC (High Performance Liquid Chromatography).

\subsection{8) Ensaio de Biodistribuição da Galectina-3 nativa}

No ensaio de biodistribuição foram utilizados 3 animais C57/BL6 por intervalo de tempo, 1h e 4 horas pós-administração de Gal-3 marcada com ${ }^{99 \mathrm{~m}} \mathrm{Tc}$ (400 $\left.\mu \mathrm{Ci}\right)$, conforme descrito no item 3.13, injetadas via intravenosa (veia caudal) em cada camundongo. Após a administração, os camundongos foram acondicionadas em gaiolas individuais, forradas com algodão previamente pesado, de forma que a urina produzida no intervalo de tempo fosse estimada e sua radioatividade contada, assim como dos demais órgãos e tecidos em contador gama. 


\subsection{9) Localização da galectina-3 radiomarcada por Imagem SPECT}

As células de carcinoma mamário de camundongo $4 \mathrm{~T} 1$ ( $1 \times 10^{6}$ células $)$ foram previamente inoculadas na mama de camundongos Balb/c. Após 4 semanas de formação do tumor (4T1), os animais foram anestesiados com 3\% de isofluorano seguido da injeção na veia da cauda de $100 \mu \mathrm{L}$ de ${ }^{99 m}$ Tc-HYNIC/Gal-3. 20 minutos após a injeção de galectina-3 radiomarcada, os animais foram anestesiados com isoflurano por inalação (Concentração inicial $0.5 \%$ - anestesia geral 1 a $1.87 \%$ ), colocados na câmara de escaneamento e analisados no microPET (microPET/SPECT/CT- Albira, BRUKER). A anestesia com isoflurano (1-1,87\%) foi mantida durante todo o procedimento de captação de imagem através de um cone para o nariz presente na câmara de escaneamento. A aquisição da imagem foi realizada durante 60 minutos.

\subsection{0) Localização da galectina-3-fluoróforo através de captação de fluorescência in} vivo

As células U87 ( $1 \times 10^{6}$ células) ou MKN45 ( $2 \times 10^{5}$ células) foram inoculadas no dorso de camundongos Balb/C nude. Após 15 dias de formação do tumor, os animais foram anestesiados com 3\% de isofluorano seguido da injeção na veia da cauda de 100 $\mu \mathrm{g}$ galectina-3-VivoTag 680XL. O sinal bioluminescente foi adquirido utilizando equipamento de imagem IVIS Spectrum seguindo os parâmetros: tempo de exposição automático, f/stop 1, Binning 8 e FOV D. Uma série de imagens foi adquirida até a obtenção da maior intensidade de sinal (mensuração em counts). A quantificação foi realizada definindo a região de interesse ROI utilizando o software Living Image 4.3.1. 


\section{4) RESULTADOS}

\section{1) Produção de galectina-3 (nativa e truncada)}

As formas nativa e truncada de galectina-3 utilizadas neste estudo foram produzidas conforme descrito no item 3.5 e 3.6 respectivamente.

A produção de galectina-3 nativa foi realizada segundo protocolo descrito em materiais e métodos obtendo-se um rendimento de cerca de $10 \mathrm{mg}$ de galectina-3 recombinante humana por cada $1 \mathrm{~L}$ de cultura de E. coli transformada com o vetor de expressão de galectina-3.

Especificamente, na produção de galectina -3 truncada foram utilizadas duas metodologias: enzimática e por bactéria transformada. No método enzimático, partiu-se de galectina-3 recombinante humana previamente produzida e posterior incubação com a enzima colagenase VII. No método por bactéria transformada, a galectina-3 truncada foi produzida após cultivo da bactéria $E$ coli transformada com o vetor de expressão da galectina-3 truncada. O perfil da banda de galectina-3 truncada (gel SDS-PAGE) está apresentado na figura 9. Podemos observar na figura 9 que a galectina-3 recombinante humana apresentou uma banda de cerca de $30 \mathrm{kDa}$ enquanto a galectina-3 truncada (sem parte do domínio N-terminal) apresentou uma banda de 17 kDa como esperado.

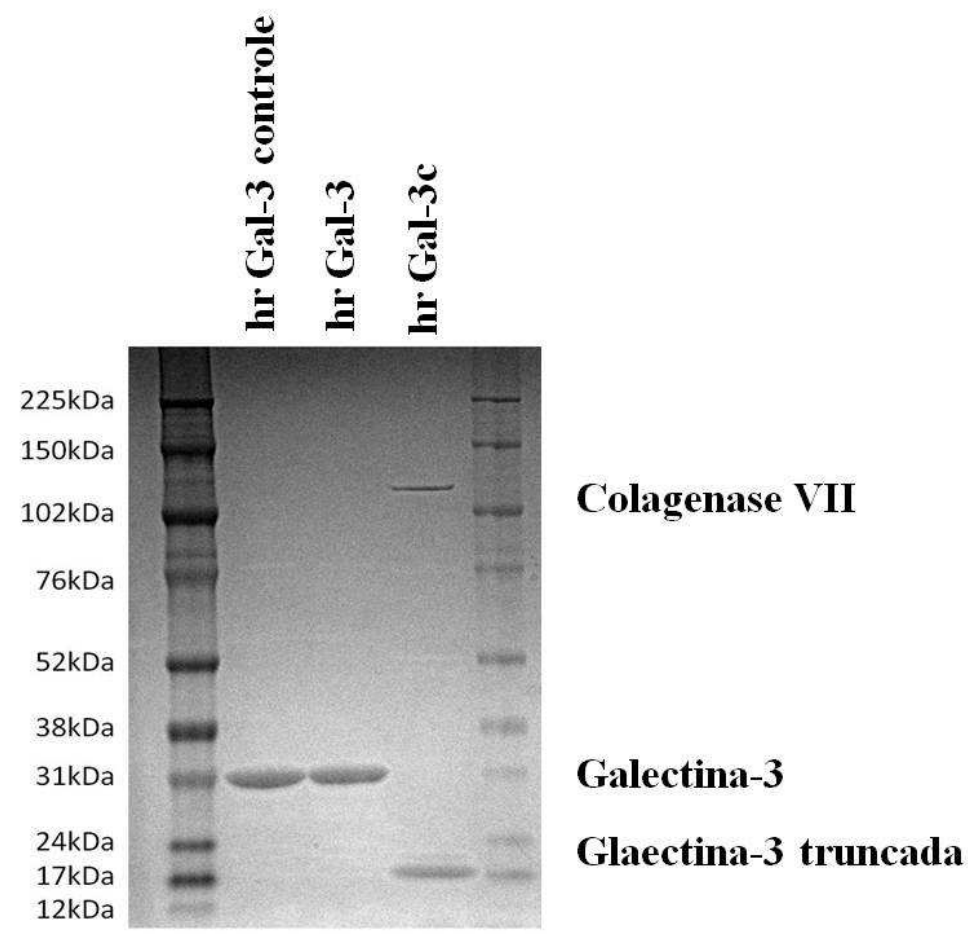

Figura 9. Perfil eletroforético de Galectina-3 e galectina-3 truncada obtida por digestão enzimática. $5 \mu \mathrm{g}$ de galectina-3 recombinante humana (hrGal-3 controle), 
galectina-3 recombinante humana incubada a $37^{\circ} \mathrm{C}$ por $16 \mathrm{~h}(\mathrm{hrGal}-3)$ ou de galectina-3 truncada obtida por incubação com a colagenase VII a $37^{\circ} \mathrm{C}$ por $16 \mathrm{~h}(\mathrm{hrGal}-3 \mathrm{c})$ foram analisadas por SDS-PAGE num gel com $12 \%$ de acrilamida. Após corrida, o gel foi corado com Comassie Blue e fotografado no ImageQuant.

No segundo método (por bactéria transformada) foi utilizada a bactéria (E. coli) transformada por dois plasmídeos diferentes (pET11a e pGEX-4T-2). De modo análogo ao método enzimático a proteína foi analisada quanto ao tamanho e pureza por gel SDS-PAGE (figura 10) e apresentou o resultado como esperado, uma galectina-3 truncada de tamanho $17 \mathrm{kDa}$.

Porém, vale ressaltar que a galectina-3 truncada produzida por E. coli transformada por plasmídeo pET11a produz a galectina-3 truncada diretamente $(17 \mathrm{kDa})$ mas a E. coli transformada por plasmídeo pGEX-4T-2 foi clonada junto com a Tag GST. Dessa forma no gel aparece uma banda de maior peso (43kDa) que é a soma de galectina-3 truncada $(17 \mathrm{kDa})+\mathrm{GST}(26 \mathrm{kDa})$.

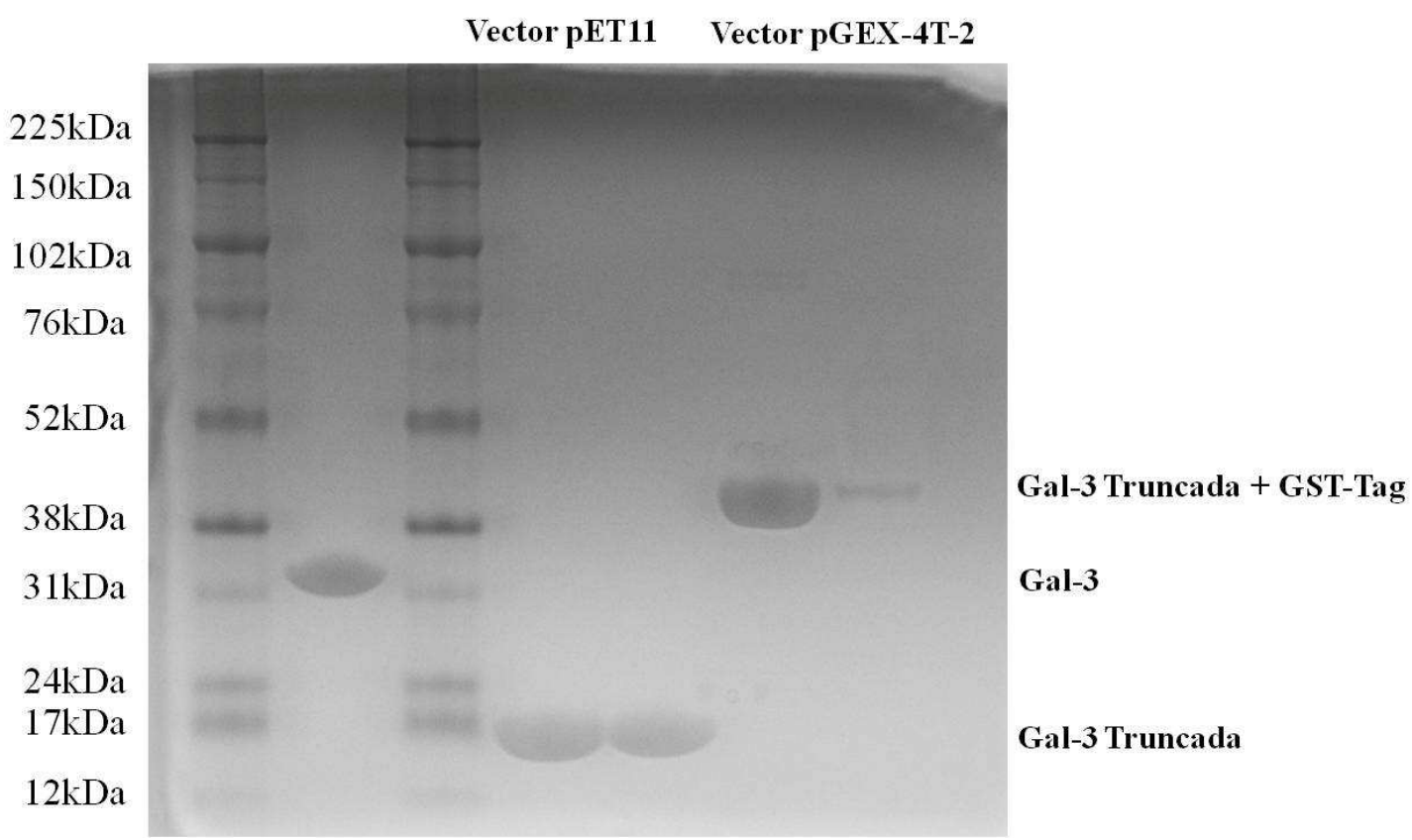

Figura 10. Perfil eletroforético de Galectina-3 e galectina-3 truncada obtida diretamente pelos plasmídeos pET11 ou pGEX-4T-2. $5 \mu \mathrm{g}$ de galectina-3 recombinante humana (controle - $31 \mathrm{kDa}$ ), galectina-3 truncada obtida por meio do plasmideo pET11 (17 kDa) e galectina-3 truncada clonado em adição com Tag GST obtido por meio do plasmídeo pGEX-4T-2 (43 kDa) incubados a $37^{\circ} \mathrm{C}$ por $16 \mathrm{~h}$ foram analisados por SDS-PAGE em gel 12\% de acrilamida. Após corrida, o gel foi corado com Comassie Blue e fotografado no ImageQuant. 


\section{2) Avaliação de sítios de ligação da galectina-3 em células tumorais}

Incialmente, avaliou-se a quantidade de galectina-3 endógena presente na superfície das células de glioblastoma U87 por citometria de fluxo. Usou-se como grupo controle as células da linhagem gástrica MKN45 Mock, previamente descrita como contendo galectina-3 na superfície de suas células. Além do mais, foi utilizada como controle, células MKN45 previamente transfectadas com a enzima ST6GalNAc-I (responsável pela produção do antígeno sialil-Tn) que mascara os ligantes de galectina3 e inibe, dessa forma, sua ligação à superfície das células.

Através da técnica e citometria de fluxo, demonstrou-se que as células U87 expressam galectina-3 em sua superfície (figura $11 \mathrm{~A}$ ). Como podemos observar no grupo controle (figura $11 \mathrm{~B}$ e C), a galectina-3 endógena também está presente na superficie das células Mock e, em menor intensidade, na superficie das células ST6GalNAc-I devido à expressão de sialil-Tn. Este fato se deve a ligação das galectinas a $\beta$-galactosídeos ser sensível à adição de resíduos de ácido siálico terminal. Desse modo a produção de estruturas sialiladas inibe a ligação das galectinas a $\beta$-galactosídeos $[38,39]$

De seguida, avaliou-se a quantidade de sítios de ligação para galectina-3 recombinante humana disponíveis na superficie das células U87 e nos controles MKN45 Mock e MKN45 ST6GalNAc-I. Para tal, a galectina-3 recombinante humana foi inicialmente conjugada com o fluorocromo Dy647 e de seguida incubada com as células U87 ou MKN45 na presença ou ausência de lactose.

Como observado no resultado da figura $11 \mathrm{D}$, a galectina-3 recombinante humana conjugada com Dy647 produzida no estudo é funcionalmente ativa e foi capaz de se ligar na superfície das células U87. Além disso, na presença de lactose (inibidor competitivo do domínio CRD da galectina-3), verificamos uma inibição da ligação da galectina-3 na superfície da célula. Nos grupos controle (figura $11 \mathrm{E}$ e F), verificamos um aumento da ligação de galectina-3 na superfície das células MKN45 Mock em relação às células MKN45 que superexpressam a enzima ST6GalNAc-I. Além do mais, essa ligação foi inibida por lactose $(50 \mathrm{mM})$. Estes resultados demonstram que galectina-3 possui a capacidade de ligar na superfície das células tumorais e que essa ligação é influenciada pelo estado de glicosilação das células tumorais. 

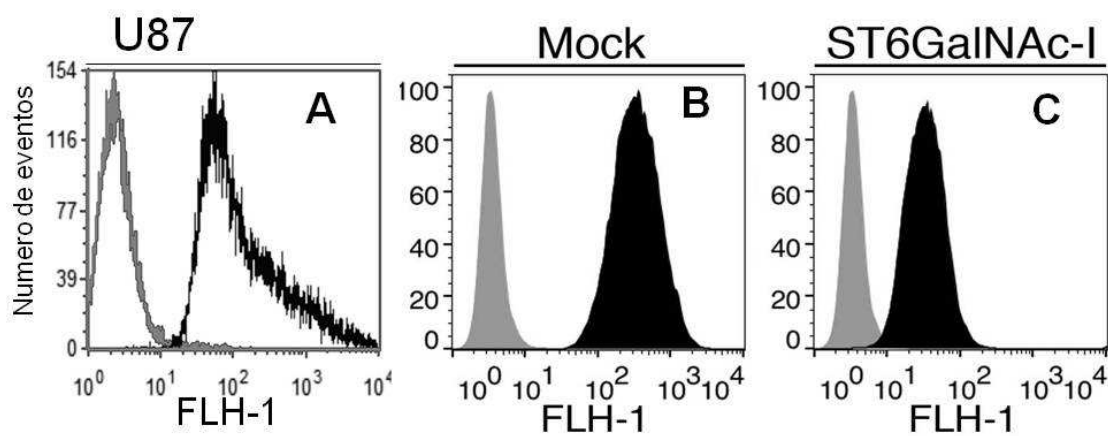

Controle negativo

Galectina-3 presente na superfície da célula
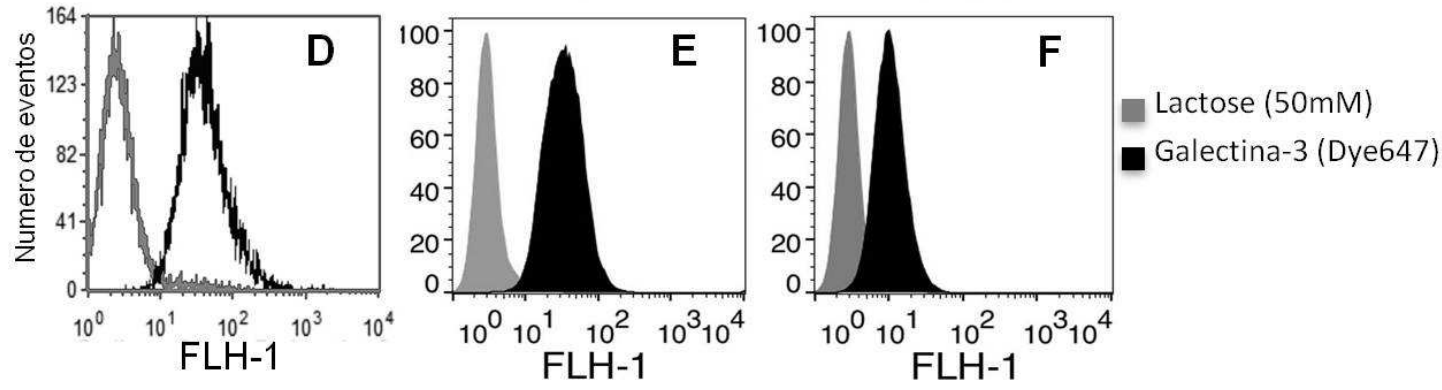

Figura 11. Análise da expressão de galectina-3 e sítios de ligação de galectina-3 na superfície de células de glioblastoma U87. As células U87 (A) e MKN45 Mock (B) ou que superexpressam a enzima ST6GalNAc-I (C) foram incubadas com o anticorpo anti-galectina-3 (M3/38) e posteriormente com o anticorpo secundário anti-ratoAlexa488 de forma a quantificar a expressão de galectina-3 na superfície das células. Alternativamente, $50 \mu \mathrm{g} / \mathrm{mL}$ de galectin-3 marcada com Dye647 foram incubadas com as células U87 (D), Mock (E) ou ST6GalNAc-I (F) na presença ou ausência de lactose $(50 \mathrm{mM})$. A expressão de galectina-3 e os sítios de ligação à galectina-3 foram analisados por citometria de fluxo.

\section{3) Avaliação do efeito terapêutico da galectina-3 (nativa e truncada) in vitro}

Com o objetivo de avaliar o potencial efeito da galectina-3 nativa e truncada no nosso modelo de glioblastoma humano (células U87), utilizamos diversas concentrações de temozolamida (quimioterápico de referência para glioblastoma) em associação à galectina-3 nativa ou truncada.

Inicialmente foi realizado o ensaio de toxicidade com SRB (Sulphorodamine) que consistiu na criação de uma curva de dose resposta com diferentes concentrações de Temozolamida ( $0 \mu \mathrm{M}-2 \mathrm{mM})$. O valor do IC50 (a concentração de uma droga que é necessária para inibir 50\% o crescimento celular in vitro) foi calculado e os resultados encontram-se apresentados na forma de percentagem de viabilidade (em relação a células não tratadas com temozolomida) em função da concentração de temozolamida em escala logarítmica (figura 12). O valor IC50 obtido para as células U87 após $72 \mathrm{~h}$ de tratamento com temozolamida (grupo \#1 controle) foi de $(2,088 \mathrm{mM})$. Na presença de $2 \mu \mathrm{M}$ de galectina-3 (grupo \#2 Galectina-3) observou-se uma redução significativa do 
IC50 para 0,008 mM. No entanto, contrário ao que era esperado, na presença de galectina-3 truncada (grupo \#3 Galectina-3C), o valor de IC50 foi de 1,893 mM, semelhante ao grupo controle. Os valores do IC50 na presença de lactose, grupos \#4 Galectina-3+Lactose, \#5 Galectina-3 truncada+Lactose e \#6 Lactose, foram de 0,876 $\mathrm{mM}, 1,622 \mathrm{mM}$ e $1,578 \mathrm{mM}$ respectivamente. A lactose foi utilizada como inibidor competitivo do domínio de reconhecimento a carboidratos, que quando presente interfere apenas no efeito das galectina-3/galectina-3c e não influencia a ação da TMZ. Dessa forma, observamos que na presença de galectina-3 as células U87 são mais sensíveis à ação da temozolamida, levando a uma redução do IC50. Além do mais, a galectina-3 truncada não influencia a ação da temozolamida.

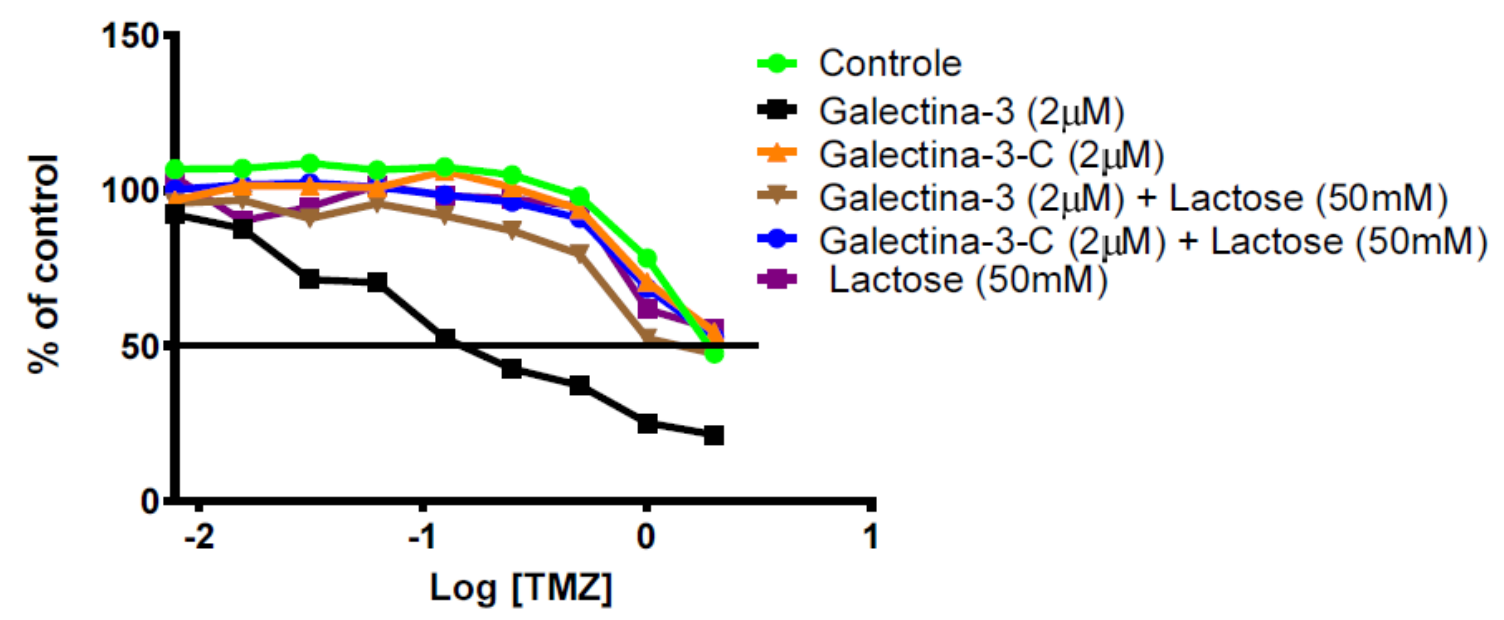

Figura 12. Citotoxicidade de Temozolamida e galectina-3 em células U87. As células de glioblastoma U87 foram plaqueadas em placa de 96 poços e tratadas com várias doses de Temozolamida associado ou não com galectina-3 ou galectina-3c, na ausência ou presença de lactose (inibidor) por $72 \mathrm{~h}$. A viabilidade celular foi medida com SRB (sulforhodamine B) e é apresentada com porcentagem de células viáveis em relação ao controle sem temozolamida. A concentração de temozolamida, apresentada em escala logarítmica, variou de $0,0156 \mu \mathrm{M}$ a $2 \mathrm{mM}$. O valor médio do IC50 (concentração de temozolamida que inibe $50 \%$ o crescimento celular) foi calculada pela análise de regressão não linear utilizando o software GraphPad.

\section{4) Obtenção da linhagem de Glioblastoma U87 transfectada com gene repórter} de luciferase.

Inicialmente foi avaliado o desempenho dos 3 agentes de transfecção utilizados (Lipofectamina 2000, Polietilenoimina (PEI) e X-fect) para transfecção de células de glioblastoma U87. O resultado pode ser observado na figura 13.

A lipofectamina foi o agente que apresentou melhor eficiência no processo de 
transfecção, uma vez que o plasmídeo pGL4.5.1 (CMV/Luc2/Neo) foi inserido nas células de glioblastoma com significativo sucesso. Consequentemente, é possível notar que as células produziram quantidades significativas da enzima luciferase, e ao adicionarmos o substrato da enzima (luciferina), observou-se um sinal bioluminescente intenso $\left(9,12 \times 10^{8}\right.$ fótons/célula). Além disso observa-se na figura 13 que a transfecção ocorreu na grande maioria das células, inferindo assim que o processo de transfecção não prejudicou a viabilidade celular, ou seja, após a transfecção as células transfectadas continuaram vivas, confirmados através de microscopia óptica.

Com o agente X-FECT observa-se um sinal bioluminescente de 4,56 x $10^{6}$ fótons/célula, porém observa-se que o processo de transfecção prejudicou a viabilidade celular, pois quando analisadas por microscopia óptica foram observadas poucas células vivas.

A Polietilenoimina foi ineficaz como agente de transfecção, já que não se observou sinal de bioluminescência, ou seja, a inserção do plasmídeo não ocorreu nas células U87.

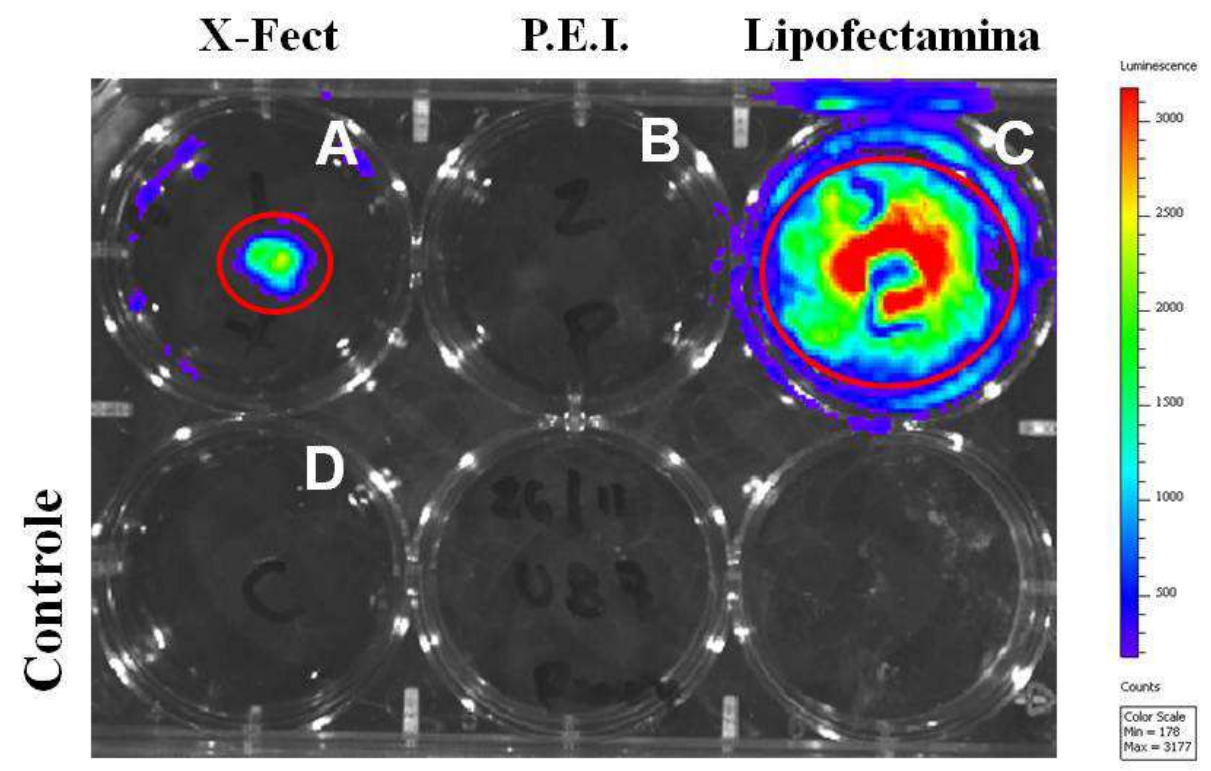

Figura 13. Transfecção de células de Glioblastoma U87 por três diferentes agentes de transfecção. Em placa de seis poços, células da linhagem de glioblastoma U87 $\left(1 \times 10^{4}\right)$ foram incubadas a $37^{0} \mathrm{C}$ durante 24 horas. Em seguida, as células foram transfectadas com um plasmídeo contendo o gene repórter da Luciferase utilizando três diferentes agentes de transfecção: X-Fect (A), PEI (B) e Lipofectamina (C) e o controle (D). Após um período de $24 \mathrm{hs}$ da transfecção, a D-luciferina $(150 \mu \mathrm{g} / \mathrm{mL})$ foi adicionada em cada poço para posterior leitura da emissão de bioluminescência, capturada em equipamento de imagem ótica - IVIS SPECTRUM (Perkin Elmer - USA). 


\section{5) Seleção Clonal e quantificação fóton por célula da linhagem de glioblastoma U87 transfectada}

Após transfecção das células U87 com o vetor contendo o gene repórter da luciferase procedeu-se à seleção clonal dessas células (U87 Luc2). Brevemente, vale lembrar que o clone obtido (U87 Luc2) seguiu os passos descritos desde a escolha do agente de transfecção Lipofectamina 2000 e sua seleção clonal descrita nos itens 3.2 e 3.3 até ao posterior cálculo do número de fótons/células no item 3.4.

O cálculo de fótons/células do clone U87 Luc2 gerado foi calculado após semear as células em 5 poços idênticos como demonstrado na imagem de bioluminescência da figura 14A. Os respectivos valores absolutos de fótons por células podem ser observados na figura 14B e tabela 3. A média calculada foi de 5.800 fóton/célula. Tal relação é cinco vezes maior que o relatado na literatura, a qual clones transfectados adequados para utilização em experimentação em imagem ótica por bioluminescência devem possuir relação de pelo menos 1.000 fóton/células.

A

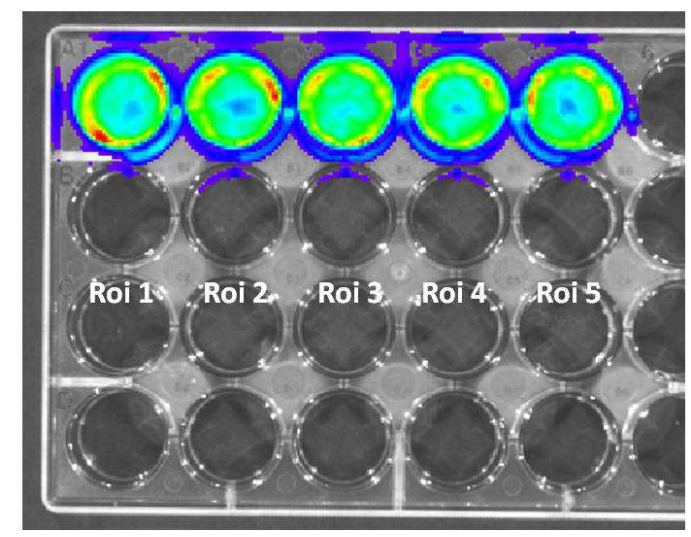

B

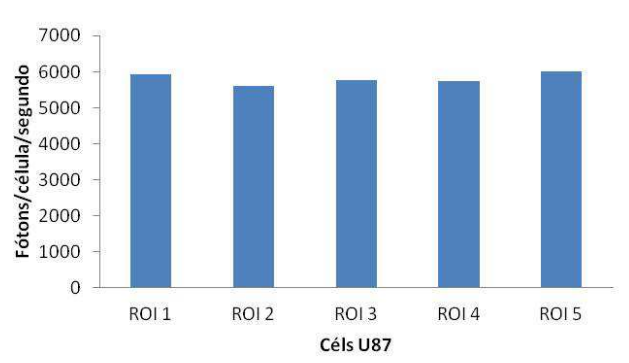

Figura 14. Cálculo da relação fótons/célula em células U87. Imagem por bioluminescência de 50.000 células do clone U87Luc2 semeados em 5 poços idênticos (Roi 1,2,3,4,5) em placa de 96 poços (A). Gráfico em barras da relação fóton por célula de cada poço mostrado anteriormente (B). A divisão fluxo de emissão por 50.000 células fornece a relação fóton por célula do clone U87 Luc2 (fornecendo a media de 5.800 fóton por célula).

Tabela 3. Valores absolutos da relação fóton/célula da linhagem transfectada U87 Luc2

\begin{tabular}{lccc}
\hline Poço & Número de células & Fluxo Total $[\mathbf{p} / \mathbf{s}]$ & Fótons/seg/céls \\
\hline ROI 1 & 50000 & $2,96 \mathrm{E}+08$ & 5920 \\
ROI 2 & 50000 & $2,81 \mathrm{E}+08$ & 5620 \\
ROI 3 & 50000 & $2,88 \mathrm{E}+08$ & 5760 \\
ROI 4 & 50000 & $2,87 \mathrm{E}+08$ & 5740 \\
ROI 5 & 50000 & $3,01 \mathrm{E}+08$ & 6020 \\
\hline
\end{tabular}




\section{6) Padronização e implantação de tumor cerebral em camundongos nude}

O primeiro passo para padronizar a implantação de tumor cerebral em camundongos é definir o local da injeção das células de forma que o crescimento do tumor ocorra sem prejudicar, inicialmente, as funções vitais/motoras do animal. Para isso, essa padronização é feita primeiramente com um corante ao invés das células tumorais propriamente ditas.

A localização do corante no interior do cérebro (observado na figura $15 \mathrm{~A}$ ), permitiu prever onde se localizariam as células tumorais (ao invés do corante) quando injetadas no cérebro.

Concluída com sucesso a etapa anterior, o corante foi substituído pela injeção de uma suspensão contendo células de glioblastoma U87 Luc2 $\left(2 \times 10^{5}\right)$ em $2 \mu \mathrm{L}$. A imagem por bioluminescência das células U87 Luc2 no cérebro do camundongo pode ser observado na figura 15 B e C. Observa-se uma intensa detecção do sinal bioluminescente das células na região cerebral do camundongo (figura 15B) evidenciando a existência de células U87 Luc2. Adicionalmente, o animal foi sacrificado e o cérebro fatiado em cortes, demonstrando assim que a proliferação celular irradiou-se para o interior do cérebro do animal como observado na figura 15C.
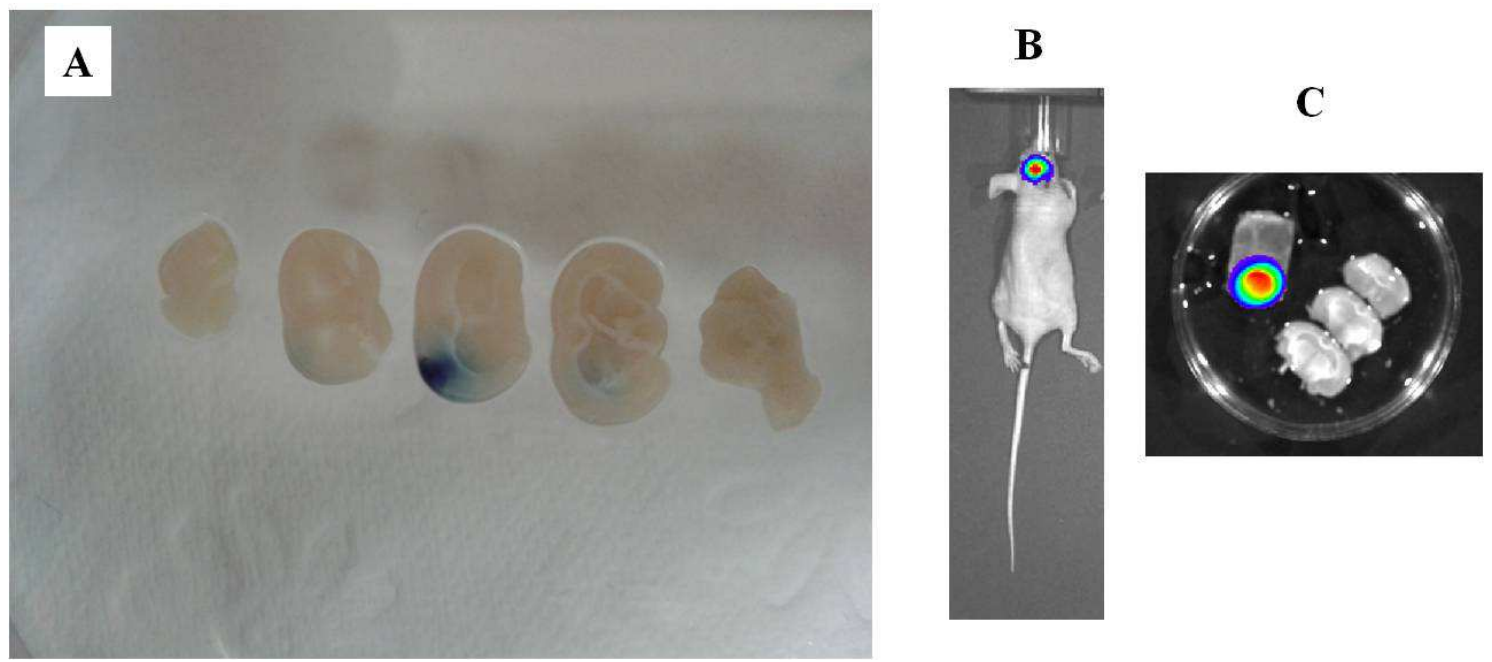

Figura 15. Padronização da injeção de corante e implantação das células U87 Luc 2 no cérebro de camundongos. Corante Azul de Evans $(2 \mu \mathrm{l})$ foi injetado a uma profundidade de $2 \mathrm{~mm}$ da superfície do cérebro, durante um intervalo de 2 minutos, em sistema de microinjeção acoplado a um aparelho esteriotáxico. Os cortes transversais do cerebro revelam como o corante se irradiou internamente (A). Imagem por bioluminescência das células U87 Luc 2 implantadas no cérebro do camundongo (B). Imagem por bioluminescência em cortes do cérebro, evidenciando que as células U87 Luc 2 se proliferaram irradiando-se para o interior do cérebro (C). 


\section{7) Avaliação do efeito terapêutico da galectina-3 (nativa) in vivo}

A avaliação do efeito terapêutico por galectina-3 in vivo foi realizado com as células de glioblastoma U87 previamente transfectadas com o plasmídeo da luciferase. Ao introduzir o substrato (luciferina), ocorre a reação para emissão de bioluminescência e assim pode-se avaliar a viabilidade celular, monitoradas por equipamento específico para captura de emissão de bioluminescência IVIS SPECTRUM.

A sequência dos procedimentos utilizados para estabelecer o modelo de glioblastoma U87 nos camundongos nude e tratamentos com Gal-3, TMZ, e a combinação de Gal-3 e TMZ está esquematizado na figura 16.

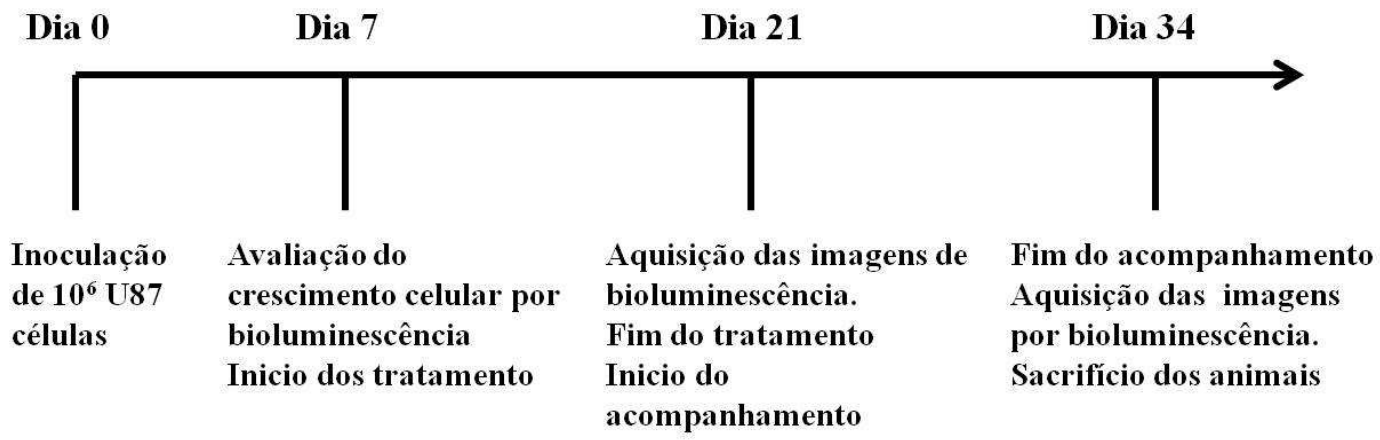

Figura 16. Sequência de eventos do modelo piloto do tratamento in vivo por galectina-3 associada ou não a TMZ.

Vale ressaltar que os tratamentos foram iniciados somente após confirmação de proliferação celular mensurados com auxílio de equipamento específico para captura de emissão de bioluminescência IVIS SPECTRUM.

Inicialmente, as células U87 Luc2 foram injetadas subcutaneamente em camundongos nude. Após 7 dias de crescimento das células U87 Luc2, $\Delta \mathrm{t}=$ zero, as primeiras imagens por bioluminescência foram adquiridas. $\mathrm{O}$ número de fótons iniciais estava na ordem de $10^{8} / 10^{9}$ fótons por célula (o que representa uma quantidade de $10^{5}$ células). Este valor foi obtido após dividir o número total de fótons por 5800 (que representa "uma" célula) conforme descrito no item 4.5.

O grupo \#1, monoterapia de TMZ, foi tratado com $6,25 \mathrm{mg} / \mathrm{kg} /$ camundongo de TMZ, uma vez por dia, durante um período total de 14 dias. O gráfico representativo por dispersão do tratamento por TMZ está demonstrado na figura 17A, e as imagens bioluminescente dos camundongos ao longo do tratamento pode ser visualizados na figura 17 (B, C e D). 
Observa-se que as células U87 Luc2 desde o início até o término do tratamento diminuíram a intensidade do sinal bioluminescente na ordem de $10^{2}$ fótons por célula (ou seja de $10^{8}$ fótons por células iniciais para $10^{6}$ no fim do tratamento), em 4 dos 5 animais avaliados (Tabela 4). Três animais apresentaram número "zero" de fótons por célula ao final do experimento (após tratamento e acompanhamento), sugerindo que todas as células morreram pela ação do quimioterápico como esperado. Apenas um animal foi desconsiderado do estudo pois no período de tratamento não apresentou número de fótons por célula (zero) quando mensurado no equipamento e durante o período de acompanhamento apresentou número de fótons por célula na ordem de $2 \times 10^{6}$ o que nos leva a deduzir que ocorreu algum problema com este animal.
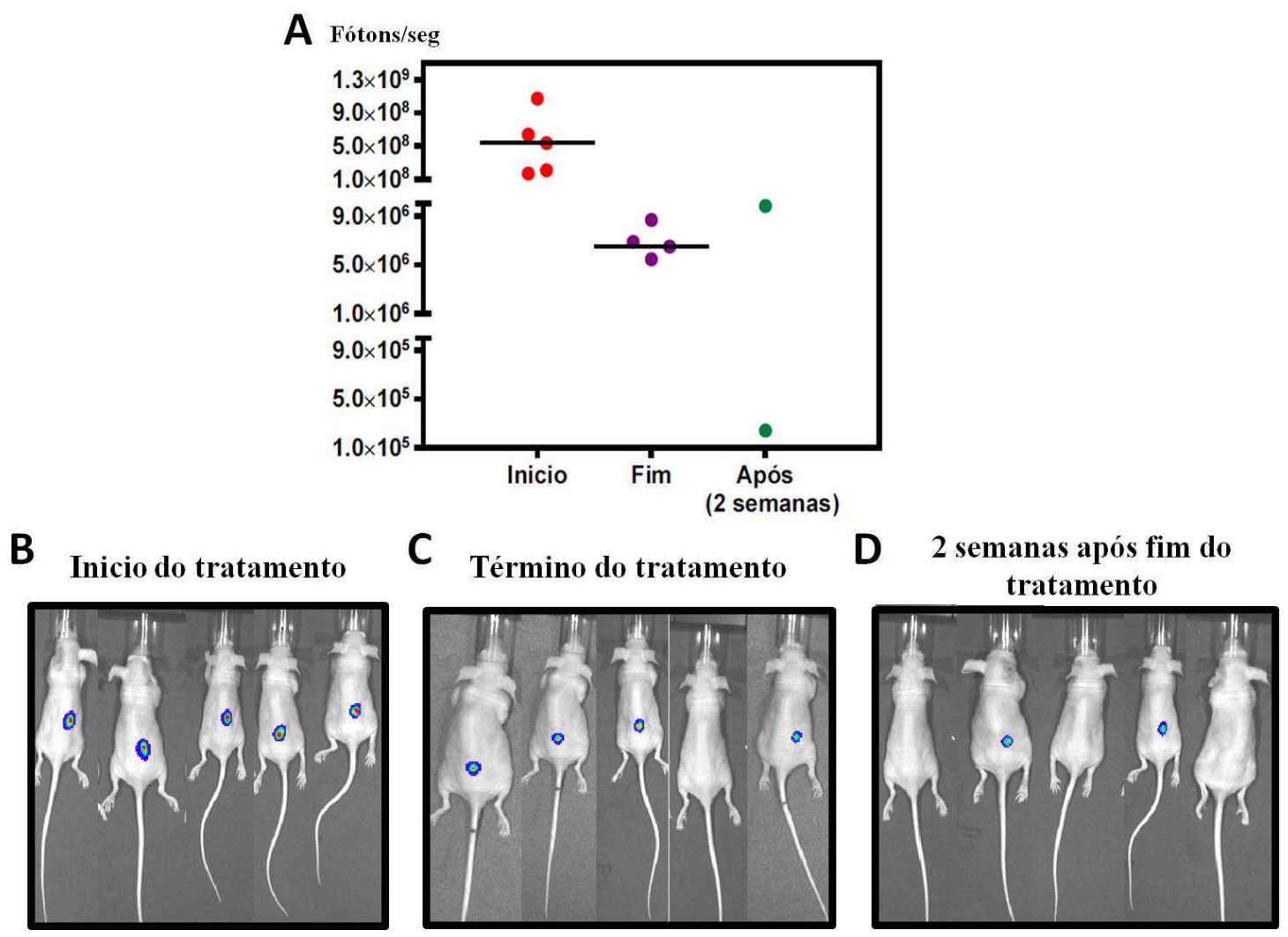

Figura 17. Efeito da temozolamida in vivo. Camundongos Balb/C nude fêmeas foram inoculados com células U87Luc2 $\left(1 \times 10^{6}\right)$ no dorso via subcutânea., tratados por TMZ durante 14 dias, e monitorados por mais duas semanas após fim do tratamento na ausência de terapia mencionada anteriormente. Em (A) gráficos por dispersão do tratamento por TMZ $6,25 \mathrm{mg} / \mathrm{Kg}$ por animal administrado por gavagem diariamente. (B) Imagem por bioluminescência de camundongos no inicio do tratamento por TMZ (C) Imagens de camundongos após 14 dias de tratamento por TMZ (D) Imagens de camundongos após duas semanas de acompanhamento na ausência de tratamento. 
Tabela 4. Valores absolutos de fótons/célula de camundongos tratados por TMZ

\begin{tabular}{cccc}
\hline Animal & Início do tratamento & $\begin{array}{c}\text { Término do } \\
\text { tratamento }\end{array}$ & $\begin{array}{c}\text { Após período de } \\
\text { acompanhamento }\end{array}$ \\
\hline 1 & $6,37 \mathrm{E}+08$ & $6,88 \mathrm{E}+06$ & 0,00 \\
2 & $1,07 \mathrm{E}+09$ & $8,68 \mathrm{E}+06$ & $9,83 \mathrm{E}+06$ \\
3 & $5,34 \mathrm{E}+08$ & $6,49 \mathrm{E}+06$ & 0,00 \\
4 & $1,68 \mathrm{E}+08$ & 0,00 & $2,40 \mathrm{E}+06$ \\
5 & $2,06 \mathrm{E}+08$ & $5,45 \mathrm{E}+06$ & 0,00 \\
\hline
\end{tabular}

O grupo \#2, monoterapia de gal-3, foi administrado intraperitonealmente com $100 \mu \mathrm{g}$ de galetina-3 duas vezes por semana, num período total de 14 dias. $\mathrm{O}$ gráfico representativo por dispersão do tratamento por Gal-3 nativa está demonstrado na figura $18 \mathrm{~A}$, e as imagens bioluminescente dos camundongos ao longo do tratamento pode ser visualizados na figura $18(\mathrm{~B}, \mathrm{C}, \mathrm{D})$.

Observa-se que as células U87 Luc2, de modo análogo ao grupo \#1, desde o início até ao término do tratamento diminuíram a intensidade do sinal bioluminescente na ordem de $10^{2}$ fótons por célula (de $10^{8}$ fótons por células iniciais para $10^{6}$ fótons por células ao fim do tratamento) em todos os 5 animais (Tabela 5). Porém, de modo inesperado, após o período de acompanhamento (sem tratamento) os 5 animais voltaram a apresentaram crescimento celular, identificado devido ao aumento no número de fótons por célula, que passou de $10^{6}$ para $10^{7}$ fótons por célula (crescimento na ordem de $10^{1}$ fótons por célula) em 3 dos 5 animais. Em um animal, o número de fótons por células se manteve constante, e no outro a elevação no número de fótons por célula passou de $10^{6}$ para $10^{8}$ fótons por célula. Estes dados nos levam a pressupor que a gal-3 apresenta um efeito antitumoral quando administrada de forma continua, sem interrupção. 

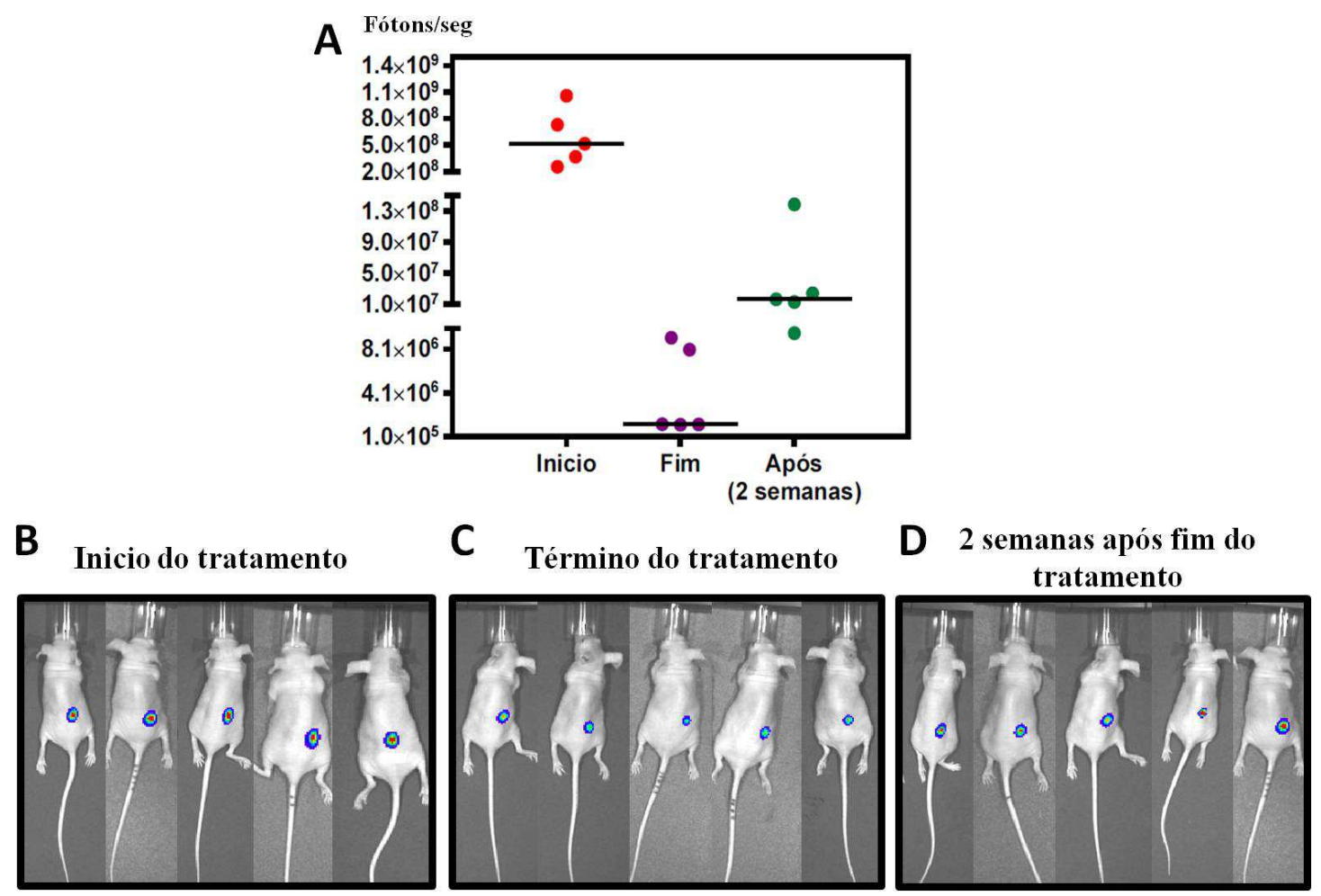

Figura 18. Efeito terapêutico da galectina-3 nativa (monoterapia) in vivo. Camundongos Balb/C nude fêmeas foram inoculados com células U87Luc2 (1 x 10 $\left.{ }^{6}\right)$ no dorso via subcutânea., tratados por Gal-3 durante 14 dias, e monitorados por mais duas semanas após fim do tratamento na ausência de terapia mencionada anteriormente. Em (A) gráficos por dispersão do tratamento por galectina-3 nativa $100 \mu \mathrm{g}$ por animal administrado por via intraperitoneal duas vezes por semana. (B) Imagem por bioluminescência de camundongos no inicio do tratamento por gal-3 nativa, (C) Imagens de camundongos após 14 dias de tratamento por Gal-3 nativa (D) Imagens de camundongos após duas semanas de acompanhamento na ausência de tratamento.

Tabela 5. Valores absolutos de fótons/célula de camundongos tratados por Gal-3

\begin{tabular}{cccc}
\hline Animal & Inicio do tratamento & $\begin{array}{c}\text { Término do } \\
\text { tratamento }\end{array}$ & $\begin{array}{c}\text { Após período de } \\
\text { acompanhamento }\end{array}$ \\
\hline 1 & $2,53 \mathrm{E}+08$ & $8,05 \mathrm{E}+06$ & $1,25 \mathrm{E}+07$ \\
2 & $3,69 \mathrm{E}+08$ & $1,23 \mathrm{E}+06$ & $2,37 \mathrm{E}+07$ \\
3 & $7,30 \mathrm{E}+08$ & $1,21 \mathrm{E}+06$ & $1,63 \mathrm{E}+07$ \\
4 & $1,06 \mathrm{E}+09$ & $9,14 \mathrm{E}+06$ & $9,57 \mathrm{E}+06$ \\
5 & $5,16 \mathrm{E}+08$ & $1,17 \mathrm{E}+06$ & $1,39 \mathrm{E}+08$ \\
\hline
\end{tabular}

O grupo \#3 terapia combinada, foi tratado diariamente com 6,25 $\mathrm{mg} / \mathrm{kg} /$ camundongo de $\mathrm{TMZ}$ e com $100 \mu \mathrm{g}$ de Gal-3 duas vezes por semana administrada intraperitoneal durante um período total de 14 dias. O gráfico representativo por dispersão do tratamento combinado TMZ+Gal-3 nativa está 
demonstrado na figura 19A, e as imagens bioluminescente dos camundongos ao longo do tratamento pode ser visualizados na figura 19 (B, C e D).

Observa-se que as células U87 Luc2 apresentou um resultado melhor que os anteriores. As células U87 Luc2 do inicio ao término do tratamento diminuíram a intensidade do sinal bioluminescente na ordem de $10^{2}$ fótons por célula (de $10^{8}$ fótons por célula iniciais para $10^{6}$ ao fim do tratamento) em todos os 5 animais (Tabela 6). Três animais no final do experimento (após tratamento e acompanhamento), apresentaram número "zero" de fótons por célula deduzindo que todas as células morreram. Dessa forma sugere-se que a combinação entre TMZ e Gal-3 possuiu um efeito antitumoral. Em um dos animais não se observou nenhum efeito resultante do tratamento de TMZ+Gal-3 pois do inicio ao fim do experimento a intensidade do sinal bioluminescente das células permaneceu constante $\left(10^{6}\right.$ fótons por célula). Presume-se que as células ficaram de certa forma "dormentes". Em um outro animal observamos um efeito antitumoral parcial, pois verificou-se uma redução do número de fótons por célula (de $10^{8}$ no inicio para $10^{6}$ fótons por célula ao fim do experimento) mas não uma total remissão do tumor.
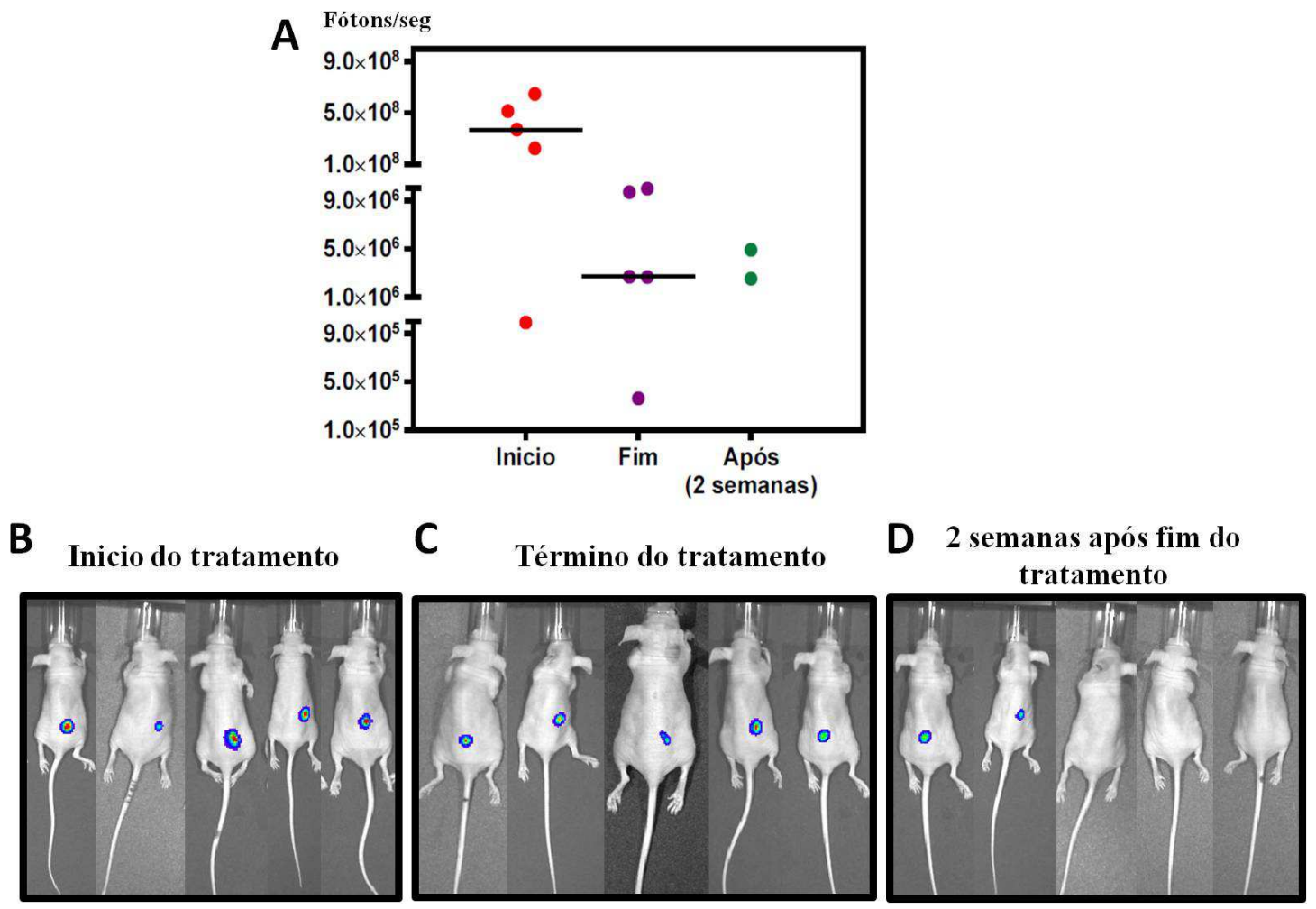

Figura 19. Efeito terapêutico da galectina-3 nativa em associação com temozolamida in vivo. Camundongos Balb/C nude fêmeas foram inoculados com células U87Luc2 $\left(1 \times 10^{6}\right)$ no dorso via subcutânea., tratados em combinação TMZ + 
Gal-3 durante 14 dias, e monitorados por mais duas semanas após fim do tratamento na ausência de terapia mencionada anteriormente. Em (A) gráficos por dispersão do tratamento combinado, TMZ $6,25 \mathrm{mg} / \mathrm{Kg}$ por animal diariamente e galectina-3 nativa $100 \mu \mathrm{g}$ por animal administrado por via intraperitoneal duas vezes por semana . (B) Imagem por bioluminescência de camundongos no inicio do tratamento por combianação (C) Imagens de camundongos após 14 dias de tratamento por combinação (D) Imagens de camundongos após duas semanas de acompanhamento na ausência de tratamento.

Tabela 6. Valores absolutos de fótons/célula de camundongos tratados por TMZ/Gal-3

\begin{tabular}{cccc}
\hline Animal & Inicio do tratamento & $\begin{array}{c}\text { Término do } \\
\text { tratamento }\end{array}$ & $\begin{array}{c}\text { Após período de } \\
\text { acompanhamento }\end{array}$ \\
\hline 1 & $5,13 \mathrm{E}+08$ & $2,66 \mathrm{E}+06$ & $2,53 \mathrm{E}+06$ \\
2 & $9,91 \mathrm{E}+05$ & $9,69 \mathrm{E}+06$ & $4,92 \mathrm{E}+06$ \\
3 & $6,47 \mathrm{E}+08$ & $3,63 \mathrm{E}+05$ & 0,00 \\
4 & $2,23 \mathrm{E}+08$ & $1,59 \mathrm{E}+07$ & 0,00 \\
5 & $3,70 \mathrm{E}+08$ & $2,68 \mathrm{E}+06$ & 0,00 \\
\hline
\end{tabular}

O resultado foi promissor, de modo análogo ao resultado in vitro, os tratamentos com monoterapia por galectina-3 e em combinação com TMZ, inferem resultados promissores, ou seja, é perceptível uma redução celular ao longo do tratamento. Porém um fato inesperado nos intriga, não era esperado que as células tumorais voltassem a crescer após suspensão do tratamento apenas por galectina-3, e em nosso conhecimento, não há dados na literatura que relatem observações semelhantes, o que nos instiga ainda mais a pesquisar sobre o mecanismo de ação da galectina-3 nesse modelo experimental, ainda desconhecido pela comunidade científica.

\section{8) Marcação de galectina-3 $\operatorname{com}^{99} \mathrm{~m}$ Te}

A qualidade da marcação da galectina-3 é um passo importante para experimentação de imagens SPECT. Visto que, influencia na qualidade da imagem adquirida e principalmente nos resultados obtidos.

O processo de marcação iniciou-se conjugando a proteína galectina-3 com o quelante bifuncional HYNIC e seguidamente realizou-se a adição do radioisótopo $\left({ }^{99 \mathrm{~m}} \mathrm{Tc}\right)$. O perfil cromatográfico por HPLC da galectina-3 radiomarcada $\left({ }^{99 \mathrm{~m}} \mathrm{Tc}-\right.$ HYNIC-Gal3) está demonstrado na figura 20. Pela análise do resultado, podemos observar que o tempo de retenção da ${ }^{99 \mathrm{~m}}$ Tc-HYNIC-Gal3 analisada com o detector DAD (280nm) foi entre 7,5-12,5 minutos, com um pico aos 9,5 minutos (figura $20 \mathrm{~A}$ ). 
Com o detector DAD a 240nm (figura 20 B), o tempo de retenção da ${ }^{99 m}$ Tc-Gal-3 foi semelhante ao anterior (entre 7,5-12,5 minutos). $\mathrm{Na}$ figura $20 \mathrm{C}$ podemos observar a detecção de ${ }^{99 m}$ Tc-HYNIC-Gal3 com o detector GABI, que detecta apenas radiação. Nessa figura podemos observar que a radiação foi detectada entre os 7,5-12,5 minutos, indicando que galectin-3 se encontra de fato marcado com ${ }^{99 \mathrm{~m}} \mathrm{Tc}$.
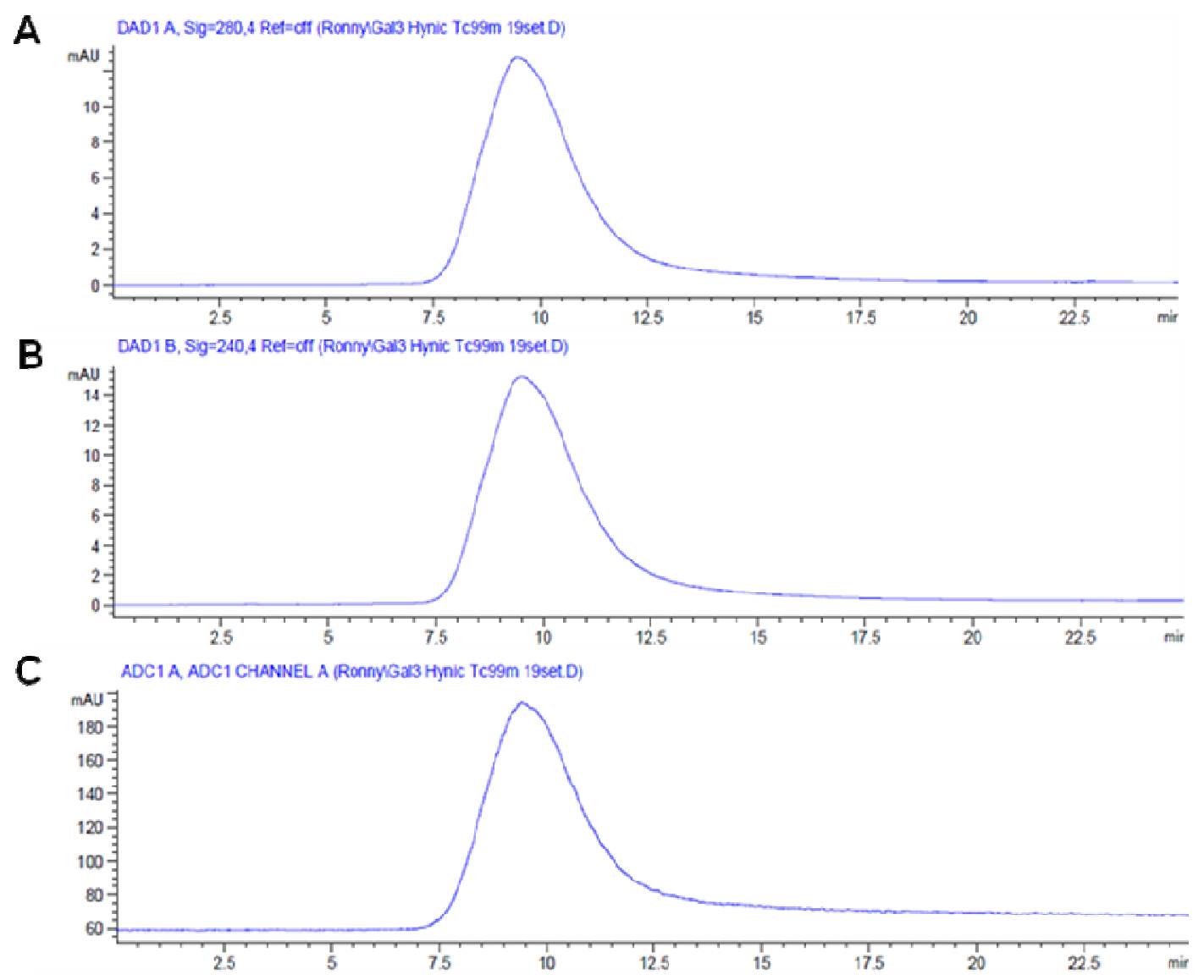

Figura 20. Purificação de galectina-3 por HPLC. O cromatograma representa ${ }^{99 \mathrm{~m}} \mathrm{Tc}$ HYNIC-Gal3 detectada por DAD a (A) $280 \mathrm{~nm}$. ou (B) $240 \mathrm{~nm}$. (C) Cromatograma da ${ }^{99 \mathrm{~m}}$ Tc-HYNIC-Gal3 detectado por GABI (detector de radiação).

\section{9) Estabilidade da galectina-3 marcada com ${ }^{99 m} \mathrm{Tc}$}

\subsection{1) Estabilidade em solução salina e L-cisteína}

A L-cisteína compete com a tricina na formação do complexo ${ }^{99 m} \mathrm{Tc}-\mathrm{HYNIC}$ Gal-3, desestabilizando-o, além de formar complexos estáveis com ${ }^{99 \mathrm{~m}} \mathrm{Tc}$. Dessa forma, o estudo de estabilidade em soluções com diferentes concentrações de L-cisteína é um importante parâmetro na avaliação da estabilidade in vitro das proteínas radiomarcadas. As concentrações de L-cisteína testadas foram de 0,1 e 0,01 mM. Ambas concentrações representam um grande excesso de L-cisteína livre em relação ao que é encontrado num 
ambiente in vivo e, portanto, caso a proteína marcada permaneça estável nessas condições, este se torna um grande indicativo de que sua marcação permaneça estável em estudos de biodistribuição.

Quanto menor a quantidade de ${ }^{99} \mathrm{~m}$ Tc livre, mais estável as moléculas radiomarcadas permanecem nestas soluções. Na figura 21 é possível notar que a quantidade de ${ }^{99 \mathrm{~m}}$ Tc livre em solução quando o complexo ${ }^{99 \mathrm{~m}} \mathrm{Tc}-\mathrm{HYNIC}-G a l-3$ é incubadas em $\mathrm{NaCl} 0,9 \%$ é relativamente baixo mesmo após 2 e 4 horas de incubação $\left(<1 \%\right.$ de ${ }^{99 \mathrm{~m}}$ Tc livre em relação ao complexo $\left.{ }^{99 \mathrm{~m}} \mathrm{Tc}-\mathrm{HYNIC}-\mathrm{Gal}-3\right)$. Isto indica que a molécula radiomarcada permaneceu estável, por pelo menos esses períodos de tempo, quando em solução salina.

Com relação à incubação do complexo do ${ }^{99 m}$ Tc-HYNIC-Gal-3 com L-cisteína a uma concentração de $0,01 \mathrm{mM}$, o complexo permaneceu estável após 2 e 4 horas de incubação e foi encontrado apenas cerca de $3 \%$ de ${ }^{99 \mathrm{~m}}$ Tc livre em solução. Por sua vez, a incubação do complexo do ${ }^{99 \mathrm{~m}}$ Tc-HYNIC-Gal-3 com a concentração maior de Lcisteína $(0,1 \mathrm{mM})$, verificamos que após 4 horas de incubação houve um ligeiro aumento na quantidade de ${ }^{99 \mathrm{~m}} \mathrm{Tc}$ livre em solução (cerca 5\%). Apesar deste discreto aumento, a porcentagem de ${ }^{99 \mathrm{~m}} \mathrm{Tc}$ livre é considerada ainda relativamente baixa e sugere que a galectina-3 radiomarcada permaneça estável por tempo suficiente para procedermos a análise de biodistribuição (figura 21).

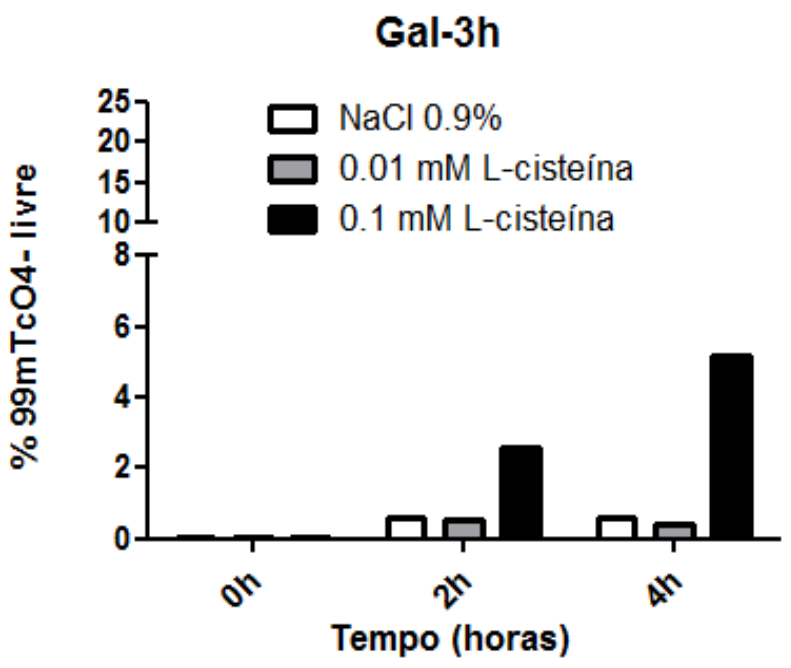

Figura 21. Estudo de estabilidade da ${ }^{99} \mathrm{~m}$ Tc-HYNIC-Galectina-3 em diferentes soluções. ${ }^{99 \mathrm{~m}} \mathrm{Tc}-\mathrm{HYNIC}-G a l e c t i n a-3$ foi mantida em soluções de $\mathrm{NaCl} 0,9 \%$ e de Lcisteína $(0,01 \mathrm{mM}$ e $0,1 \mathrm{mM})$ durante diferentes intervalos de tempo. Após os períodos indicados, a quantidade de ${ }^{99 \mathrm{~m}} \mathrm{TcO} 4$ livre em solução foi mensurada por HPLC. Quanto mais estável a molécula, menor é a quantidade de ${ }^{99 \mathrm{~m}} \mathrm{TcO} 4$ livre em solução. 


\subsection{2) Estabilidade em soro fetal bovino}

O estudo de estabilidade da proteína galectina-3 radiomarcada com $99 \mathrm{mTc}$ foi de seguida analisado na presença de soro bovino fetal. Este estudo foi feito de forma análoga ao estudo de estabilidade em solução salina e L-cisteína. No entanto, , o método de análise utilizado foi diferente: ao invés de avaliar a porcentagem de ${ }^{99 \mathrm{~m}} \mathrm{Tc}$-livre em solução, foram quantificados os níveis totais de galectina-3 radiomarcadas com tecnécio, utilizando HPLC.

Pela observação da figura 22 podemos verificar que a galectina-3 radiomarcada $\left({ }^{99 m}\right.$ Tc-HYNIC-Gal-3) incubada na presença da solução salina $(\mathrm{NaCl} 0,9 \%)$ permaneceu estável por 24 horas, ou seja, 99\% das moléculas radiomarcadas permaneceram marcadas nesse intervalo de tempo.

Diferentemente do obtido para os ensaios de estabilidade em solução salina, a galectina-3 radiomarcada $\left({ }^{99 \mathrm{~m}} \mathrm{Tc}-\mathrm{HYNIC}-\mathrm{Gal}-3\right)$ incubada em soro fetal bovino apresentou uma estabilidade irregular ao longo das 24 horas de incubação. Podemos observar uma redução da ${ }^{99}{ }^{9}$ Tc-HYNIC-Gal-3 ao longo do tempo em relação ao controle $0 \mathrm{~h}$.

Gal-3

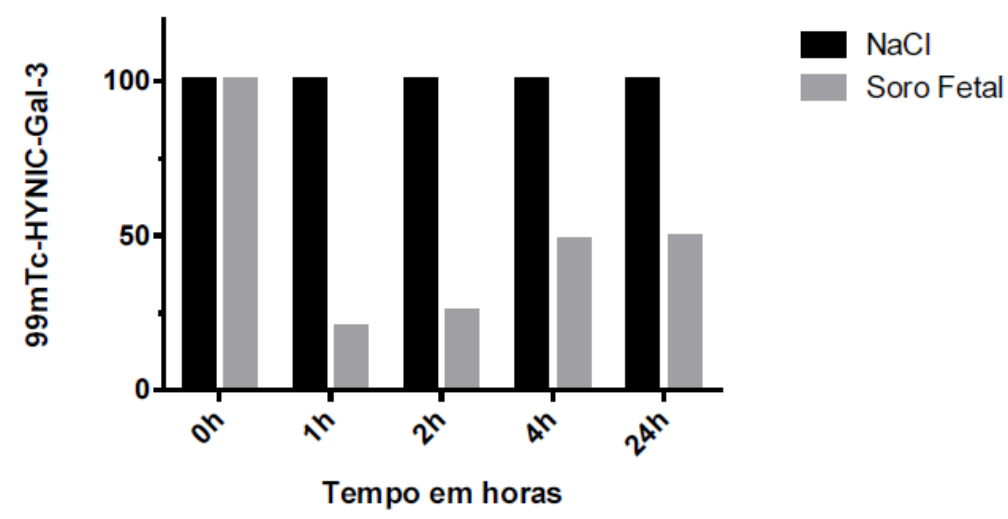

Figura 22. Estudo de estabilidade da ${ }^{99 m}$ Tc-HYNIC-Galectina-3 $.{ }^{99 m} \mathrm{Tc}-H Y N I C-$ Galectina-3 Foi mantida em soluções de $\mathrm{NaCl}$ 0,9\% e Soro fetal bovino durante diferentes intervalos de tempo. Após os períodos indicados foram quantificados os níveis totais de galectina-3 radiomarcadas com tecnécio por HPLC. 


\subsection{0) Biodistribuição ${ }^{99 \mathrm{~m}}$ Tc-HYNIC-Gal-3 em camundongos}

No ensaio de biodistribuição in vivo foram utilizados 3 animais para cada intervalo de tempo (1h e 4 horas após a administração de ${ }^{99 m}$ Tc-HYNIC-Gal-3). Através da figura 23 podemos observar o padrão de biodistribuição da galectina-3 radiomarcada após 1 e 4 horas da sua injeção na veia da cauda do camundongo. A análise da biodistribuição demonstrou que a galectina-3 estava presente principalmente nos rins, e em menores quantidades no baço e bexiga (urina) dos animais, inferindo que tal evidência pode estar relacionada ao observado na clínica, ou seja, em cintilografia com ${ }^{99 \mathrm{~m}}$ Tc-sestaMIB, o radiofarmaco é eliminado via renal (urina).

No caso do baço pode-se sugerir que este órgão serviu como reservatório para eventual liberação sistêmica, ou simplesmente retirou a galectina-3 da circulação. Com esse resultado podemos deduzir que a galectina-3 não apresenta uma ligação específica, mas sim, liga-se inespecificamente a todos os órgãos que apresentarem glicoconjugados. Adicionalmente, podemos verificar que a proteína radiomarcada ${ }^{99 \mathrm{~m}} \mathrm{Tc}-\mathrm{HYNIC}-\mathrm{Gal}-3$ não ultrapassa a barreira hemato-encefálica, visto que não observamos sinal no cérebro.

\section{Biodistrbuição 99m Tc-Hynic/Gal-3}

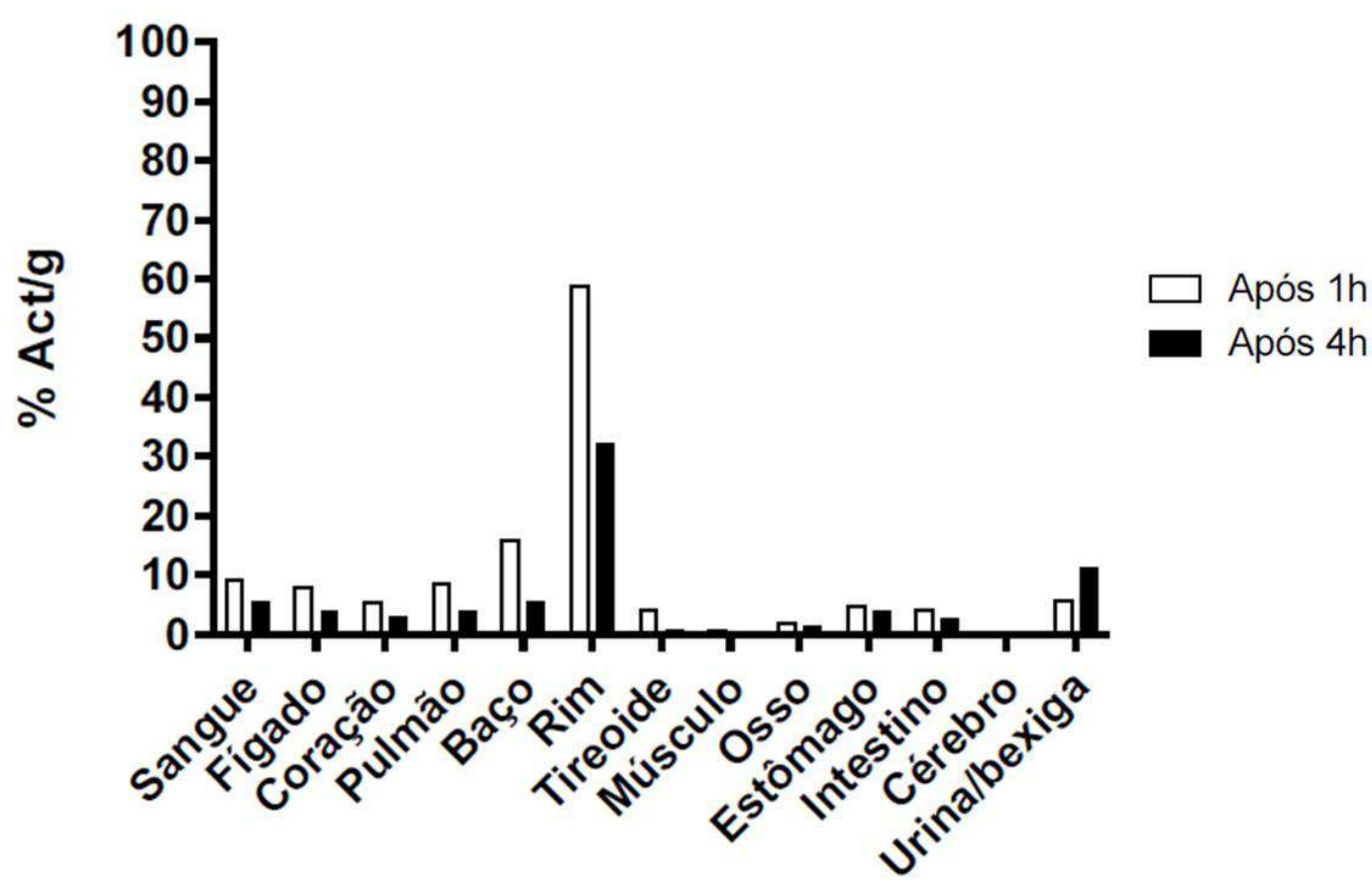

Figura 23. Análise da biodistribuição da Galectina-3 nativa administrada I.V. Galectina-3 humana radiomarcada com ${ }^{99 \mathrm{~m}} \mathrm{Tc}$ (99 Tc-Hynic/Gal-3) foi injetada intravenosamente na veia da cauda de camundongos Balb/C saudáveis. Após 1 e 4 horas, os animais foram sacrificados, e a radioatividade foi medida em cada órgão coletado. $\mathrm{O}$ gráfico mostra a \% média de radioatividade injetada/grama de tecido/3 animais em cada intervalo de tempo. 


\subsection{1) Localização da galectina-3 radiomarcada por Imagem SPECT/CT}

De seguida, procedeu-se à análise, por imagem SPECT, da biodistribuição de ${ }^{99 \mathrm{~m}}$ Tc-HYNIC-Gal-3 em animais Balb/C previamente inoculados com as células de mama murina 4T1. Após formação de tumor pelas células 4T1, a galectina-3 marcada com ${ }^{99 m}$ Tc foi injetada na veia da cauda do camundongo de forma a se avaliar o reconhecimento do tumor pela galectina-3. Pela figura $24 \mathrm{~A}$ podemos observar que o complexo ${ }^{99 \mathrm{~m}}$ Tc-HYNIC-Gal-3 é encontrado principalmente nos rins (R) e na bexiga (B), porém não apresenta marcação no tumor (T). Adicionalmente, na figura 24B, observa-se o complexo ${ }^{99 \mathrm{~m}}$ Tc-HYNIC-Gal-3 nos rins, e na figura $24 \mathrm{C}$ na bexiga (B) porém em ambas não apresenta marcação no tumor $(\mathrm{T})$.

SPECT

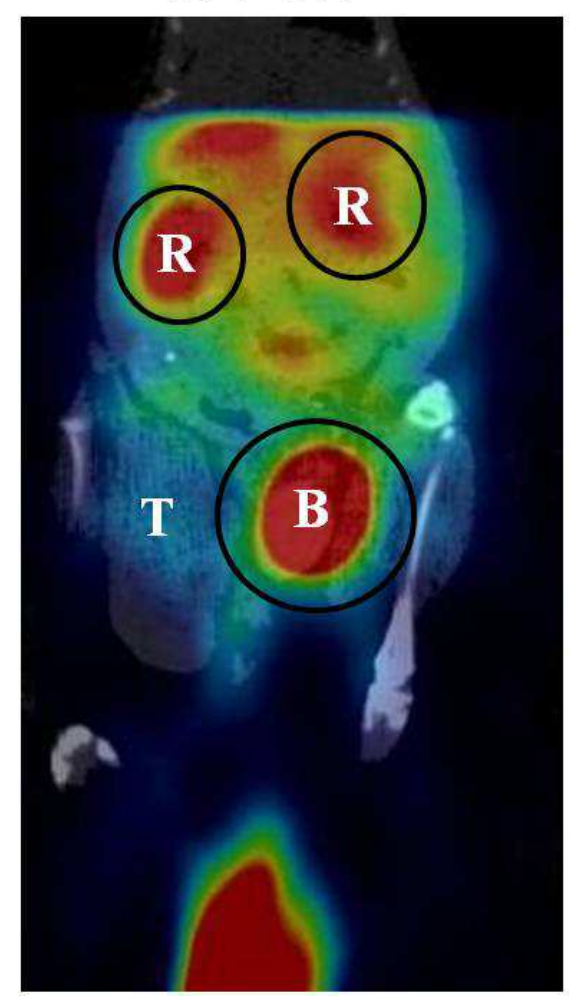

\section{CT}

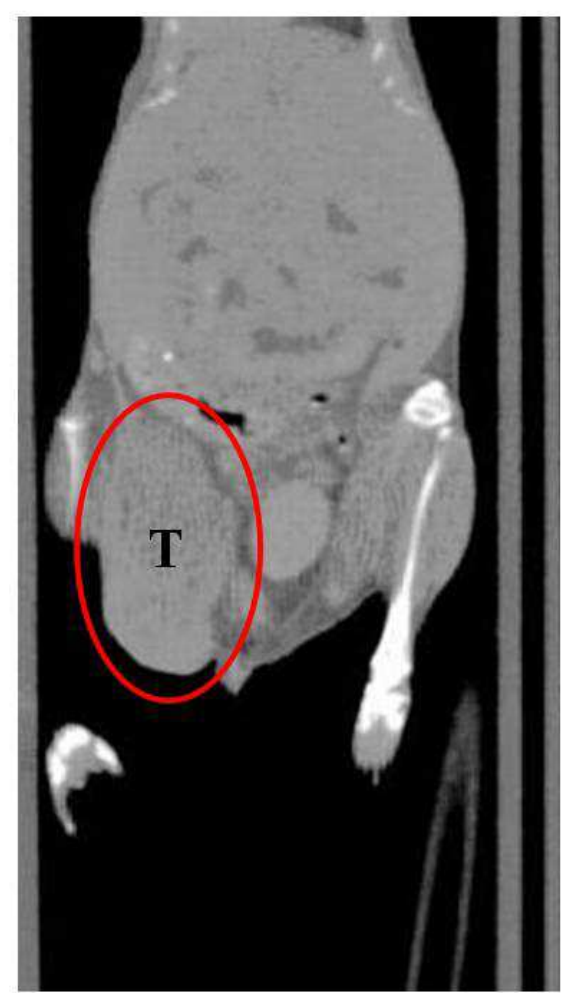

Figura 24A. Imagem SPECT-CT da Galectina-3 nativa administrada I.V. Galectina-3 humana radiomarcada com ${ }^{99 \mathrm{~m}} \mathrm{Tc} \quad\left({ }^{99 \mathrm{~m}} \mathrm{Tc}-H y n i c-G a l-3\right)$ foi injetada intravenosamente na veia da caudal de camundongos Balb/C previamente inoculados com as células 4T-1 de mama murina. $\mathrm{R}$ - rim, $\mathrm{B}$ - bexiga e $\mathrm{T}$ - tumor. 


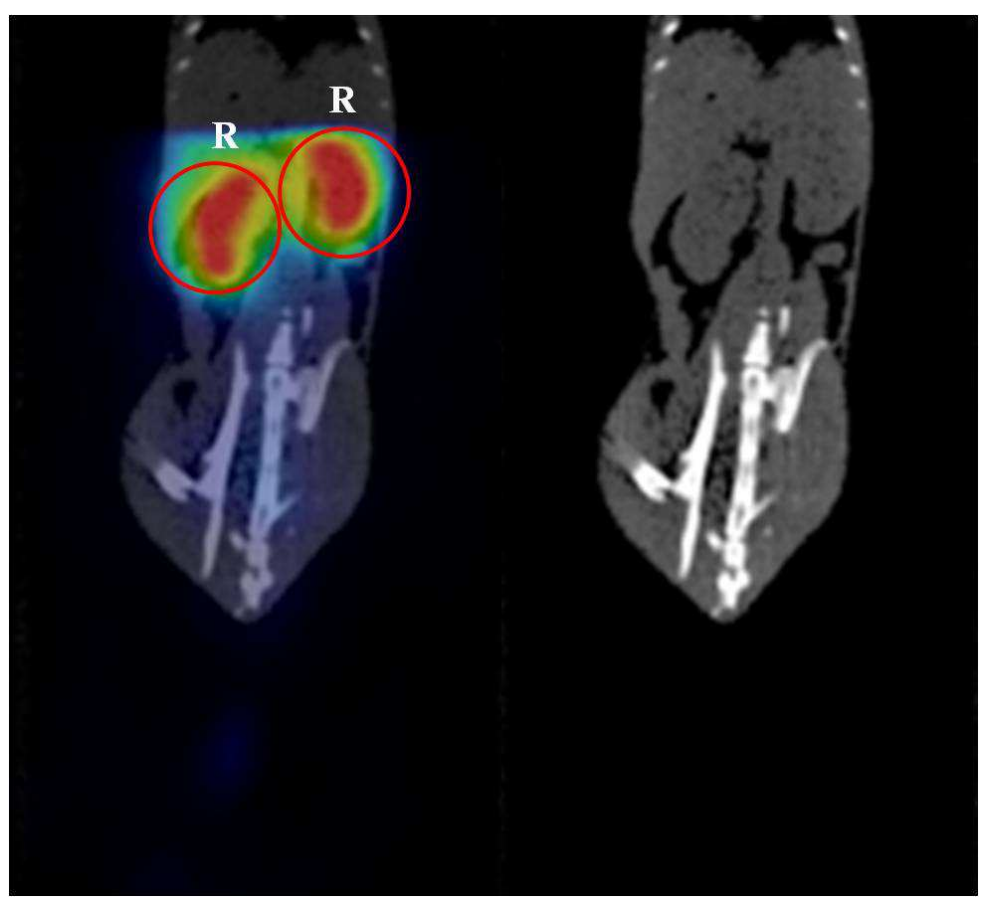

Figura 24B. Imagem SPECT-CT da Galectina-3 nativa administrada I.V. Galectina-3 humana radiomarcada com ${ }^{99 \mathrm{~m}} \mathrm{Tc}$ ( $\left.{ }^{99 \mathrm{~m}} \mathrm{Tc}-H y n i c-G a l-3\right)$ foi injetada intravenosamente na veia da caudal de camundongos Balb/C previamente inoculados com as células $4 \mathrm{~T}-1$ de mama murina. $\mathrm{R}$ - rim.

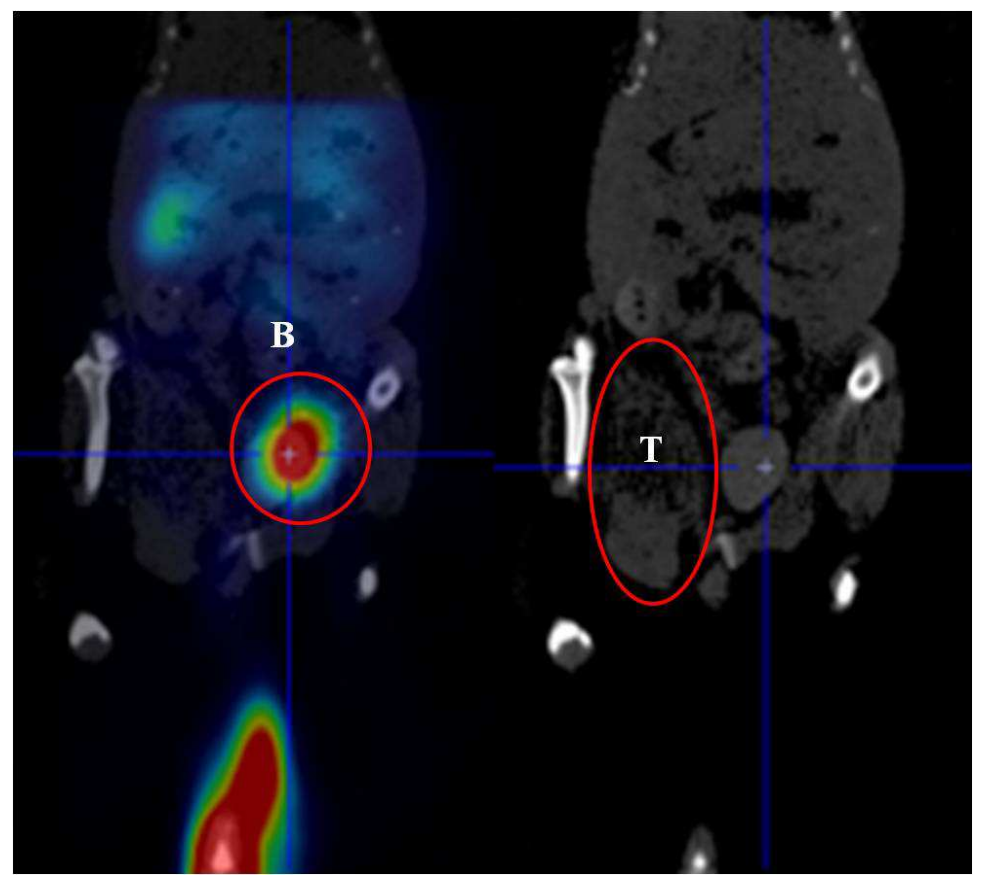

Figura 24C. Imagem SPECT-CT da Galectina-3 nativa administrada I.V. Galectina-3 humana radiomarcada com ${ }^{99 \mathrm{~m}} \mathrm{Tc}$ ( $\left.{ }^{99 \mathrm{~m}} \mathrm{Tc}-\mathrm{Hynic}-\mathrm{Gal}-3\right)$ foi injetada intravenosamente na veia da caudal de camundongos Balb/C previamente inoculados com as células 4T-1 de mama murina. $\mathrm{B}$ - bexiga e $\mathrm{T}$ - tumor 


\subsection{2) Localização da galectina-3-fluoróforo através de captação de fluorescência in}

vivo

Por fim, precedemos à análise da biodistribuição de galectina-3 em camundongos Balb/C nude ao longo do tempo por um período total de 14 dias. Devido ao fato da meia-vida da galectina-3 marcada com ${ }^{99 m} \mathrm{Tc}$ não nos permitir estudos prolongados (dias), a galectina-3 recombinante humana foi marcada com o fluoróforo VivoTag 680XL (Gal-3-680XL) e posteriormente injetada em camundongos Balb/C nude previamente inoculados com as células de glioblastoma humano U87 (figura 25) ou as células gástricas humanas MKN45 (figura 26). Através do aparelho IVIS spectrum, pudemos observar inicialmente que a Gal-3-680XL é encontrada maioritariamente nos rins dos camundongos inoculados com as células U87, não ligando no tumor (figura 25). Entretanto, nos camundongos inoculados com as células MKN45, a gal-3-680XL é encontrada por todo o animal às 48h e 96h (figura $26 \mathrm{~A}$ ) e mais aparentemente nos rins e cauda do animal ao final de 14 dias. Após retirada dos órgãos principais dos camundongos, incluindo o tumor (figura 26 B) foi possível verificar que a Gal-3-680XL é encontrada principalmente nos rins, intestino e fracamente no tumor às $48 \mathrm{~h}$ e $96 \mathrm{~h}$. Ao final de 14 dias, apenas foi possível observar a presença de galectina-3 nos rins, sugerindo que esta lectina é amplamente retida nos rins ao longo do tempo.

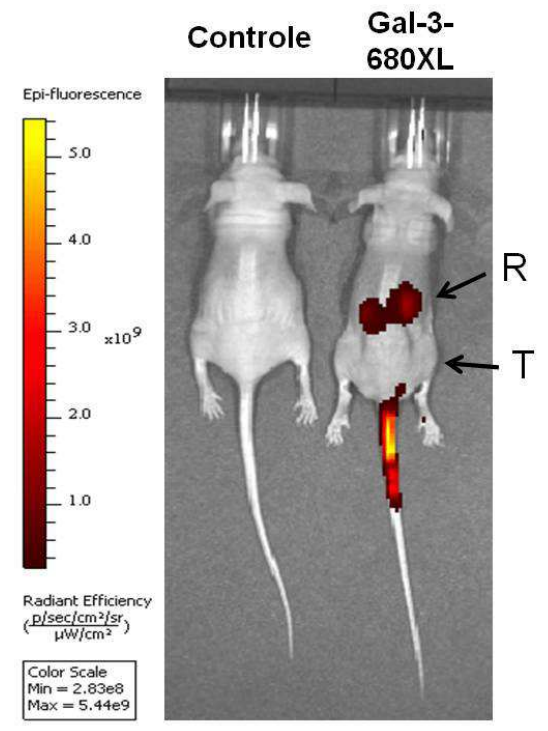

Figura 25. Imagem por fluorescência da Galectina-3 nativa administrada I.V. Galectina-3 humana foi conjugado com kit de marcação de proteínas VivoTag 680XL (Gal-3-680XL). Em seguida, foi injetada em camundongos Balb/c nude portadores de tumores derivado das células U87. Imagem por fluorescência in vivo foi analisada 
utilizando equipamento IVIS Spectrum (Perkin Elmer) ao fim de 72h, R - Rim, T Tumor.
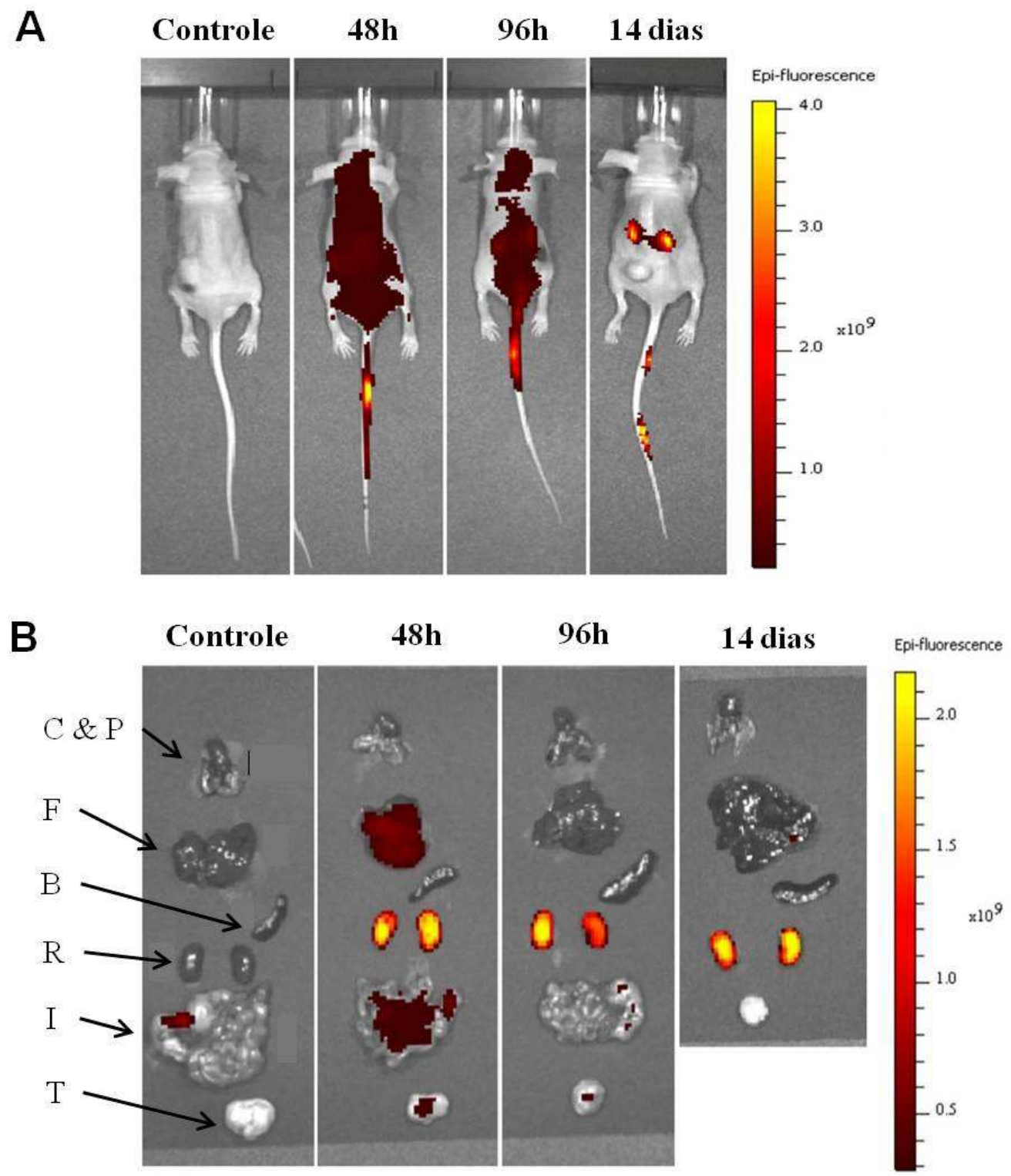

Figura 26. Imagem por fluorescência da Galectina-3 nativa administrada I.V. Galectina-3 humana foi conjugado com kit de marcação de proteínas VivoTag 680XL (Gal-3-680XL). Em seguida, foi injetada em camundongos Balb/c nude portadores de tumores derivado das células MKN45. (A) Imagem por fluorescência in vivo foi analisada utilizando equipamento IVIS Spectrum (Perkin Elmer) ao fim de 48h, $96 \mathrm{~h}$ e 14 dias no animal inteiro. (B) Imagem por fluorescência dos órgãos individuais C\&P Coração e Pulmão, F - Fígado, B - Baço, R - Rim, I - Intestino, T - Tumor. 


\section{5) Discussão}

Ao longo deste trabalho foi possível demonstrar que galectina-3 atua como molécula antiproliferativa quando administrada em conjunto com o quimioterápico temozolamida tanto in vitro como in vivo no modelo de glioblastoma humano (células U87). Além do mais, foi possível estudar e obervar a biodistribuição de galectina-3 in vivo tanto por meio SPECT-CT como utlizando o aparelho IVIS-SPECTRUM. Foi possivel observar pela primeira vez que galectina-3 se liga preferencilmente aos rins dos camundongos Balb/c nude e portanto, sua ação antiproliferativa tumoral poderá não ser uma consequeência da sua ação direta no tumor.

A galectina-3 participa de uma ampla gama de atividades em células tumorais, tais como angiogênese, adesão celular, apoptose, migração celular e metástase, desempenhando assim um papel importante no câncer. Tem sido observado que esta proteína aumenta a motilidade das células endoteliais in vitro, e adicionalmente, auxilia a formação de novos vasos capilares in vivo em ratos. Este efeito de promoção da angiogênese envolve a interação da galectina-3 com glicanos expressos em moléculas da superfície das células endoteliais tais como as integrinas ${ }^{[21]}$. Além do mais, a superexpressão de galectina-3 associada ao tumor aumenta a adesão de células tumorais à matriz extracelular (ECM) promovendo a migração das células tumorais e posterior liberação de células do tumor a partir dos locais de tumores primários (metastização). Tal efeito de galectina-3 é atribuído à sua interação com uma variedade de glicoproteínas da ECM tais como fibronectinas, colágeno IV, elastina e laminina ${ }^{[21]}$.

Investigações recentes têm revelado que a galectina-3 circulante pode desempenhar um papel muito importante na sobrevivência de células tumorais na circulação sanguínea e no processo de metástase. Em síntese, esta proteína está envolvida tanto na agregação homotípica (possibilitando a formação de micro êmbolos tumorais) quanto na heterotípica, interagindo com células de superfícies endoteliais e favorecendo a invasão tecidual ${ }^{[23]}$.

Visto a importância do papel da galectina-3 em modular diversos processos no câncer, é razoável imaginar a galectina-3 como um provável alvo molecular para terapia, e de fato muitos esforços tem sido investidos nesta linha. A literatura tem relatado sucesso terapêutico em testes in vitro, por exemplo, o tratamento de linhagem de melanoma B16 com um anticorpo monoclonal contra lectinas de superfície de células tumorais, inibiu fortemente a metástase pulmonar experimental de melanomas ${ }^{[47]}$. Em 
outro exemplo, Radosavljevic e colaboradores utilizaram camundongos nocautes para galectina-3 (Lgals-3 ${ }^{-/}$) em modelo de melanoma maligno, e demonstraram que a ausência da expressão de galectina-3 dificultava o estabelecimento de metástase no pulmão. Tal efeito foi atribuído tanto à menor adesão de células tumorais ao ECM quanto à modulação do sistema imune. Os camundongos (Lgals- $3^{-/}$) apresentavam níveis séricos elevados de IFN- $\gamma$ e IL-17, e uma diminuição na percentagem e número total de células CD4 T reguladoras em comparação com grupo controle. Observaram que os efeitos protetores de galectina-3 quanto à disseminação metastática de melanoma era dependente de células NK. Assim, a inibição específica de galectina-3 poderia impedir a metástase do melanoma, diminuindo a adesão de células de tumor e de um reforço de NK mediada por células de resposta imune anti-tumoral ${ }^{[47]}$.

Logo, a inibição da galectina-3 na superfície celular poderia acarretar em uma ferramenta interessante como terapia antitumoral. Este provável mecanismo levou por exemplo Mirandola e colaboradores a testar uma forma truncada de galectina-3, na qual falta a porção N-terminal reguladora da molécula. Como já comentado, esse domínio Nterminal é de fundamental importância para que ocorra a formação de oligômeros e consequentemente permita mediar os processos de adesão célula-célula e célula-matriz. Os autores postularam que esta forma truncada funcionaria como um inibidor negativo dominante da galectina-3 nativa, prejudicando a agregação homotípica e heterotípica das células tumorais. Os pesquisadores demonstraram que o tratamento com galectina-3 truncada diminuiu o crescimento tumoral, e quando associado a quimioterápico a redução tumoral era ainda mais significativa, chegando a uma redução de $94 \%{ }^{[42]}$. Esta observação animadora incentivou outros pesquisadores a investir esforços em propostas semelhantes, como por exemplo a utilização de inibidores solúveis que bloqueassem a ligação a $\beta$-galactosideos (porção de reconhecimento a carboidratos) para coibir a adesão.

No entanto, em nenhum dos trabalhos acima mencionados, foi demonstrado e identificado o local de ação da galectina-3 truncada in vivo. Dessa forma, embora o efeito inibidor de galectina-3 truncada seja evidente, não podemos considerar a inibição da adesão celular entre as células tumorais como o único mecanismo responsável pelo efeito terapêutico de galectina-3 truncada. Além do mais, foi verificado que tanto a galectina-3 nativa e truncada em alguns casos produziram efeitos oposto (pró- ou antiapotóticos) em diferentes tipos de células ou em diferentes condições. 
De fato, foi previamente demonstrado que galectina-3 extracelular, ao contrário da intracelular, é pró-apoptótica e é capaz de induzir a apoptose de células $\mathrm{T}$ humanas ${ }^{[48]}$. Além do mais, foi verificado que a galectina-3 extracelular foi capaz de promover a apoptose das células SW48 (colonócitos). A super-expressão da enzima ST6Gal-I nessas células (que adiciona ácido siálico terminal a N-glicanos e portanto, mascara o reconhecimento de $\mathrm{N}$-glicanos pela galectina-3) foi capaz de proteger as células contra a morte celular induzida por galectina- $3^{[49]}$.

Por conseguinte nos propusemos a avaliar o efeito da galectina- 3 nativa e sua forma truncada associadas ou não ao quimioterápico de referência (TMZ) em linhagem de gliobastoma U87. Dessa forma, poderíamos comparar a eficácia do tratamento com galectina-3 truncada à sua forma nativa, visto que até o momento os autores ${ }^{[41,42]}$ não haviam utilizado a galectina-3 nativa como um possível controle negativo.

Nossos resultados revelaram que apenas a galectina-3 nativa associada à ação da temozolamida apresentou atividade terapêutica promissora, essencialmente por inibir a proliferação celular tumoral in vitro e in vivo das células de glioblastoma humano, U87. Esses dados estão de acordo com o efeito pró-apoptótico de galectina-3 extracelular previamente descrito e sugerem que o efeito antitumoral da galectina-3 truncada ou nativa pode ter consequências variadas dependendo da linhagem de célula tumoral utilizada $^{[41,42]}$.

Interessantemente, apesar de ter sido observado um efeito pró-apoptótico de galectina-3 extracelular em associação com temozolamida in vivo, o efeito da galectina3 na proliferação tumoral aparenta não ser uma consequência da ação direta da galectina-3 no tumor. Ou seja, neste trabalho não nos foi possível observar uma colocalização de galectina-3 com o tumor nos modelos in vivo utilizados. Dessa forma é possível que o efeito pró-tumoral induzido por galectina-3 tenha sido consequência da interação de galectina-3 com outras células do organismo, ou seja, tenha sido um efeito indireto.

\section{1) Considerações finais (ensaios futuros)}

Os resultados obtidos evidenciam o papel pró-apoptótico de galectina-3 quando adicionada exógenamente em conjunto com o quimioterápico temozolamida. No entanto, não foram esclarecidos os mecanismos pelos quais galectina-3 levou a uma redução do crescimento tumoral, ou se de alguma forma influenciou a ação da 
temozolamida. Dessa forma, ensaios que avaliem as vias pró-apoptóticas das células tumorais após a adição de galectina-3 serão de grande importância para clarificar esse aspecto. 


\section{6) Conclusões}

Com os resultados obtidos, podemos inferir os seguintes pontos a respeito do efeito terapêutico de galectina-3 em glioblastoma:

1- A forma truncada de galectina-3 (gal-3c) não apresentou um resultado promissor nos testes in vitro realizados com a linhagem de glioblastoma humana U87.

2- A Galectina-3 nativa apresentou um efeito antiproliferativo na linhagem de gliobastoma U87 in vitro e in vivo quando associada com a temozolamida.

3- A galectina-3 pode ser um promissor agente terapêutico coadjuvante em combinação com temozolamida in vivo.

4- Não estava presente no tumor nos ensaios de biodistribuição tanto por SPECT como por fluorescência. 


\section{7) Referência bibliográfica (ainda desatualizado)}

[1] - Qin C, Zhu S, Tian J. New Optical Molecular Imaging Systems. Current Pharmaceutical Biotechnology. 2010; 11:620-627.

[2] - Weissleder R, Pittet MJ. Imaging in the era of molecular oncology. Nature. 2008; 452: 580-590.

[3] - Kim HL. Optical imaging in oncology. Urologic Oncology: Seminars and Original Investigations. 2009; 27: 298-300.

[4] - Herschman HR. Molecular Imaging: Looking at Problems, Seeing Solutions. Science. 2003; 302: 605-608.

[5] - Pysz MA, Gambhir SS, Willmann JK. Molecular Imaging: Current Status and Emerging Strategies. Clin Radiol. 2010; 65: 500-516.

[6] - Jacobson O, Chen X. Interrogating Tumor Metabolism and Tumor Microenvironments Using Molecular Positron Emission Tomography Imaging. Theranostic Approaches to Improve Therapeutics. Pharmacol Rev. 2013; 65: 12141256.

[7] - Robilotta CC. A tomografia por emissão de pósitrons: uma nova modalidade na medicina nuclear brasileira. Rev Panam Salud Publica. 2006; 20 (2/3):134-42.

[8] - Hutchins GD, Miller MA, Soon VC. Timothy Receveur. Small Animal PET Imaging. ILAR J. 2008; 49 (1): 54-65.

[9] - Hicks RJ, Hofman MS. Is there still a role for SPECT-CT in oncology in the PET-CT era? Nat. Rev. Clin. Oncol. 2012; 9: 712-720.

[10] - Aoki SM. Uma Proposta para Avaliação do Desempenho de Câmaras PET/SPECT [Dissertação]. São Paulo: Instituto de Física, Universidade de São Paulo; 2002.

[11] - Projeto FRIDA 2005/2006. Desenvolvimento de Plugin Java para Reconstrução e $\begin{array}{lllll}\text { Visualização em } & \text { Medicina } & \text { Nuclear } & \text { disponível }\end{array}$ http://www.pucrs.br/fisica/pesquisas/nimed/nucnovo/arquivos/RevisaoLiteraturaExtendi da.pdf

[12] - Essen M, Sundin A, Krenning EP, Kwekkeboom DJ. Neuroendocrine tumours: the role of imaging for diagnosis and therapy. Nat. Rev. Endocrinol. 2014; 10: 102-114. [13] - Rice BW, Cable MD, Nelson MB. In vivo imaging of light-emitting probes. Journal of Biomedical Optics. 2001; 6(4): 432-440. 
[14] - Hickson J. In vivo optical imaging: Preclinical applications and considerations. Urologic Oncology: Seminars and Original Investigations . 2009; 27: 295-297.

[15] - Keereweer S, Van Driel PBAA, Snoeks TJA, Kerrebijn JDF, Baatenburg de Jong RJ, Vahrmeijer AL, Sterenborg HJCM, Löwik CWGM. Optical Image-Guided Cancer Surgery: Challenges and Limitations. Clin Cancer Res 2013;19:3745-3754.

[16] - Bu L, Ma X, Tu Y, Shen B, Cheng Z. Optical Image-Guided Cancer Therapy. Current Pharmaceutical Biotechnology. 2013; 14: 723-732.

[17] - Dumic J, Dabelic S, Flögel M. Galectin-3: an open-ended story. Biochim Biophys Acta. 2006; 1760: 616-635.

[18] - Hughes RC. Galectins as modulators of cell adhesion. Biochimie. 2001; 83: 667676.

[19] - Elola MT, Wolfenstein-Todel C, Troncoso MF, Vasta GR, Rabinovich GA. Galectins: matricellular glycan-binding proteins linking cell adhesion, migration, and survival. Cell Molecular Life Science. 2007; 64: 1679-1700.

[20] - Liu FT, Rabinovich GA. Galectins as modulators of tumour progression. Nature Review Cancer. 2005; 5: 29-41.

[21] - Newlaczyl AN, Yu, L. Galectin-3 - A jack-of-all-trades in cancer. Cancer Letters. 2011; 313: 123-128.

[22] - Yang RY, Rabinovich GA, Liu FT. Galectins: structure, function and therapeutic potential. Expert. Rev. Mol. Med. 2008; 10: e17.

[23] - Barrow H, Rhodes JM, Yu L. The role of galectins in colorectal cancer progression. Int. J. Cancer. 2011;129; 1-8

[24] - Zhao Q, Barclay M, Hilkens J, Guo X, Barrow H, Rhodes JM, Yu L. Interaction between circulating galectin-3 and cancer-associated MUC1 enhances tumour cell homotypic aggregation and prevents anoikis. Molecular Cancer. 2010; 9 (154).

[25] - Brûle F, Califice S, Castronovo V. Expression of galectins in cancer: A critical review. Glycoconjugate Journal. 2002; 19: 537-542.

[26] - Inohara H, Honjo Y, Yoshii T, Akahani S, Yoshida J, Hattori K, Okamoto S, Sawada T, Raz A, Kubo T. Expression of Galectin-3 in Fine-Needle Aspirates as a Diagnostic Marker Differentiating Benign from Malignant Thyroid Neoplasms. Cancer. 1999; 85 (11): 2475-2484. 
[27] - Schoppner HL, Raz A, Ho SB, Bresalier RS. Expression of an Endogenous Galactose- Binding Lectin Correlates with Neoplastic Progression in the Colon. Cancer. 1995; 75: 2818-2826.

[28] - Louis DN, Ohgaki H, Wiestler OD, Cavenee WK, Burger PC, Jouvet A, Scheithauer BW, Kleihues P. The 2007 WHO classification of tumours of the central nervous system. Acta Neuropathology. 2007;114:97-109.

[29] - Najafi M, Soltanian-Zadeh H, Jafari-Khouzani K, Scarpace L, Mikkelsen T. Prediction of Glioblastoma Multiform Response to Bevacizumab Treatment Using Multi-Parametric MRI. PLoS One. 2012; 7: e29945.

[30] - Le Mercier M, Fortin S, Mathieu V, Kiss R, Lefranc F. Galectins and Gliomas. Brain Pathology. 2010; 20:17-27.

[31] - Giese A, Bjerkvig R, Berens ME, Westphal M. Cost of migration: invasion of malignant gliomas and implications for treatment. J Clin Oncol. 2003; 21:1624-1636.

[32] - Hoelzinger DB, Mariani L, Weis J, Woyke T, Berens TJ, McDonough WS, Sloan A, Coons SW, Berens ME. Gene expression profile of glioblastoma multiforme invasive phenotype points to new therapeutic targets. Neoplasia. 2005; 7: 7-16.

[33] - Demuth T, Berens ME. Molecular mechanisms of glioma cell migration and invasion. J. Neurooncology. 2004; 70: 217-28.

[34] - Henriksson R, Asklund T, Poulsen HS. Impact of therapy on quality of life, neurocognitive function and their correlates in glioblastoma multiforme. $J$ Neurooncology. 2011; 104: 639-646.

[35] - Park SH, Min HS, Kim B, Myung J, Paek SH. Galectin-3: a useful biomarker for differential diagnosis of brain tumors. Neuropathology. 2008; 28 (5): 497-506.

[36] - Neder L, Marie SKN, Carlotti Jr, CG, Gabbai AA, Rosenberg S, Malheiros SMF, Proto-Siqueira R, Oba-Shinjo SM, Uno M, Aguiar PH, Miura F, Chammas R, Colli BO, Silva Jr WA, Zago MA. Galectin-3 as an Immunohistochemical Tool to Distinguish Pilocytic Astrocytomas from Diffuse Astrocytomas, and Glioblastomas from Anaplastic Oligodendrogliomas. Brain Pathlogy. 2004; 14: 399-405.

[37] - Binh NH, Satoh K, Kobayashi K, Takamatsu M, Hatano Y, Hirata A, Tomita H, Kuno T, Hara A. Galectin-3 in preneoplastic lesions of glioma. J Neurooncol. 2013; 111:123-132. 
[38] - Schultz MJ, Swindall AF, Wright JW, Sztul ES, Landen CN, Bellis SL. ST6GalI sialyltransferase confers cisplatin resistance in ovarian tumor cells. J Ovarian Res. $2013 ; 6(25)$.

[39] - Zhuo Y, Chammas R, Bellis SL. Sialylation of $\beta 1$ integrins blocks cell adhesion to galectin-3 and protects cells against galectin-3 induced apoptose. The journal of Biological Chemistry. 2008; 283: 22177-22185.

[40] - Kolatsi-Joannou M, Price KL, Winyard PJ, Long DA. Modified Citrus Pectin Reduces Galectin-3 Expression and Disease Severity in Experimental Acute Kidney Injury, PLoS One. 2011;6(4): e18683.

[41] - John CM, Leffler H, Kahl-Knutsson B, Svensson I, Jarvis GA. In Orthotopic Nude Mouse Model of Human Breast Cancer Truncated Galectin-3 Inhibits Tumor Growth and Metastasis. Clin Cancer Res. 2003; 9: 2374-2383.

[42] - Mirandola L, Yu Y, Chui K, Jenkins MR, Cobos E, John CM, Chiriva-Internati M. Galectin-3C Inhibits Tumor Growth and Increases the Anticancer Activity of Bortezomib in a Murine Model of Human Multiple Myeloma, PLoS One. 2011; 6(7) :e21811.

[43] - Newton-Northup JR, Dickerson MT, Ma L, Besch-Williford CL, Deutscher SL. Inhibition of metastatic tumor formation in vivo by a bacteriophage display-derived galectin-3 targeting peptide, Clin Exp Metastasis. 2013; 30: 119-132 [44] - Fermino ML, Polli CD, Toledo KA, Liu F, Hsu DK, Roque-Barreira MC, Da Silva GP, Bernardes ES, Halbwachs-Mecarelli L. LPS-Induced Galectin-3 Oligomerization Results in Enhancement of Neutrophil Activation. PLoS One. 2011; 6 (10): e26004.

[45] - Hsu DK, Zuberi RI, Liu FT. Biochemical and biophysical characterization of human recombinant IgE-binding protein, an S-type animal lectin. J Biol Chem. 1992; 267: 14167-14174.

[46] - Massa SM, Cooper DN, Leffler H, Barondes SH. L-29, an endogenous lectin, binds to glycoconjugate ligands with positive cooperativity. Biochemistry. 1993; 32: 260-267.

[47] - Radosavljevic G, Jovanovic I, Majstorovic I, Mitrovic M, Lisnic VJ, Arsenijevic N, Jonjic S, Lukic ML. Deletion of galectin-3 in the host attenuates metastasis of murine melanoma by modulating tumor adhesion and NK cell activity. Clin Exp Metastasis. 2011; 28(5):451-462. 
[48] - Fukumori T, Takenaka Y, Yoshii T, Kim HC, Hogan V, Inohara H, Kagawa S, Raz A. CD29 and CD7 me- diate galectin-3-induced type II T-cell apoptosis. Cancer Res 2003; 63: 8302-8311.

[49] - Zhuo Y, Chammas R, Bellis SL. Sialylation of beta1 integrins blocks cell adhesion to galectin-3 and protects cells against galectin-3-induced apoptosis. $J$ Biol Chem. 2008; 283(32):22177-85 